Florida International University FIU Digital Commons

11-13-2009

\title{
Physiological performance measures and tolerance limits of estuarine indicator species in South Florida
}

Pamela Marie Bachman

Florida International University

DOI: $10.25148 /$ etd.FI14050401

Follow this and additional works at: https://digitalcommons.fiu.edu/etd

Part of the Biology Commons

\section{Recommended Citation}

Bachman, Pamela Marie, "Physiological performance measures and tolerance limits of estuarine indicator species in South Florida" (2009). FIU Electronic Theses and Dissertations. 1361.

https://digitalcommons.fiu.edu/etd/1361 
FLORIDA INTERNATIONAL UNIVERSITY

Miami, Florida

\section{PHYSIOLOGICAL PERFORMANCE MEASURES AND TOLERANCE LIMITS OF ESTUARINE INDICATOR SPECIES IN SOUTH FLORIDA}

A dissertation submitted in partial fulfillment of the

requirements for the degree of

DOCTOR OF PHILOSOPHY

in

BIOLOGY

by

Pamela Marie Bachman

2009 
To: Dean Kenneth Furton

College of Arts and Sciences

This dissertation, written by Pamela Marie Bachman, and entitled Physiological Performance Measures and Tolerance Limits of Estuarine Indicator Species in South Florida, having been approved in respect to style and intellectual content, is referred to you for judgment.

We have read this dissertation and recommend that it be approved.

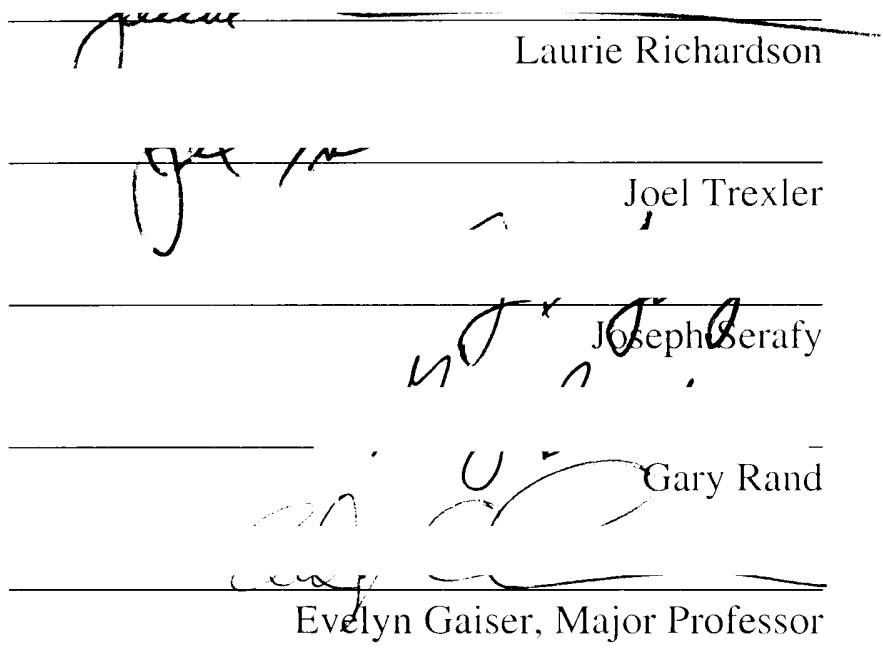

Date of Defense: November 13, 2009

The dissertation of Pamela Marie Bachman is approved.

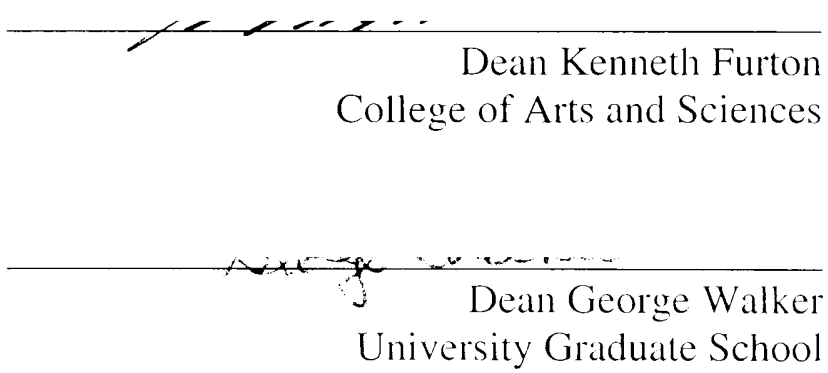

Florida International University, 2009 
(C) Copyright 2009 by Pamela Marie Bachman

All rights reserved. 


\section{ACKNOWLEDGMENTS}

This body of work was funded, in part, under Cooperative Agreement Numbers H5284020094 and H5284060010 from Everglades National Park, U.S. DOI. I would

like to thank Dr. William B. Perry of Everglades National Park for his kind support during this project. Special thanks go to my committee, especially Dr. Evelyn Gaiser, for their patience and guidance. Finally, I wish to thank Dr. Gary Rand for the years of support, project funding, use of laboratory facility, mentorship and inspiration. 


\title{
ABSTRACT OF THE DISSERTATION
}

\section{PHYSIOLOGICAL PERFORMANCE MEASURES AND TOLERANCE LIMITS OF \\ ESTUARINE INDICATOR SPECIES IN SOUTH FLORIDA}

by

\author{
Pamela Marie Bachman \\ Florida International University, 2009 \\ Miami, Florida \\ Professor Evelyn Gaiser, Major Professor
}

Current water management practices in South Florida have negatively impacted many species inhabiting Florida Bay. Variable and high salinity has been identified as a key stressor in these estuaries. The Comprehensive Everglades Restoration Plan (CERP) includes water redistribution projects that will restore natural freshwater flows to northeastern Florida Bay. My studies focused on the following central theme and hypotheses: Biological performance measures (i.e., growth, reproduction, survival), behavior (i.e., habitat preference and locomotor behavior) and diversity of estuarine fish will be controlled by changes in salinity and water quality that will occur as a result of the restoration of freshwater flow to the bay. A series of acute and subchronic physiological toxicity studies were conducted to determine the effects of salinity changes on the life stages (embryo/larval, juvenile, adult) and fecundity of four native estuarine fish (Cyprinodon variegatus, Floridichthys carpio, Poecilia latipinna, and Gambusia holbrooki). Fish were exposed to a range of salinity concentrations (freshwater to hypersaline) based on salinity profiles in the study areas. Growth (length, weight) and survival were measured. Salinity trials included both rapid and gradual change events. 
Results show negative effects of acute, abrupt salinity changes on fish survival, development and reproductive success as a result of salinity stress. Other studies targeted reproduction and critical embryo-larval/neonate development as key areas for detecting long-term population effects of salinity change in Florida Bay. Adults of $C$. variegatus and P. latipinna were also examined for behavioral responses to pulsed salinity changes. These responses include changes in swimming performance, locomotor behavior and zone preference. Finally, an ecological risk assessment was conducted for adverse salinity conditions in northeastern Florida Bay. Using the U.S. EPA's framework, the risk to estuarine fish species diversity was assessed against regional salinity profiles from a 17-year database. Based on the risk assessment, target salinity profiles for these areas are recommended for managers. 


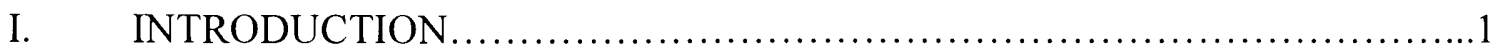

Central Theme of Dissertation........................................... 17

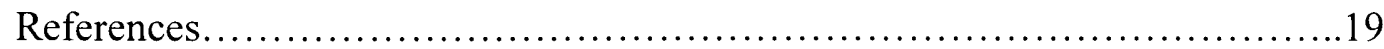

II. EFFECTS OF SALINITY ON NATIVE ESTUARINE FISH SPECIES IN SOUTH FLORIDA: TOXICOLOGY STUDIES ...........................28

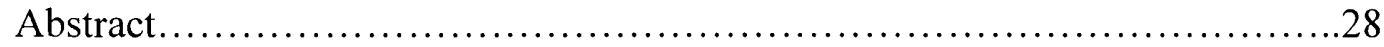

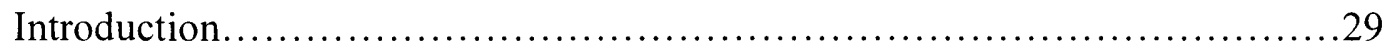

Materials and Methods........................................................

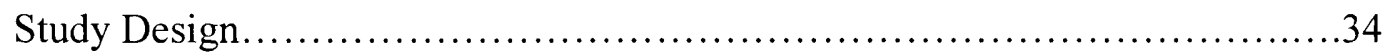

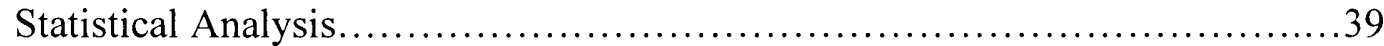

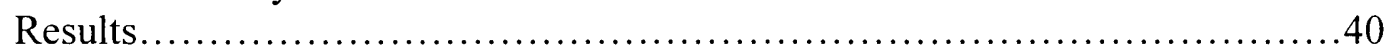

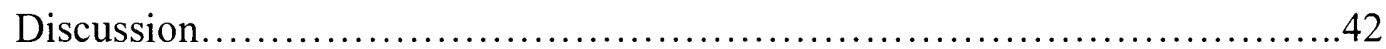

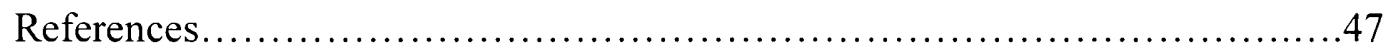

III. BEHAVIORAL EFFECTS OF SALINITY CHANGE ON CYPRINODON VARIEGATUS AND POECELIA LATIPINNA ...............................64

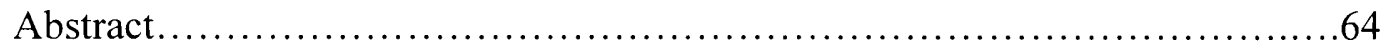

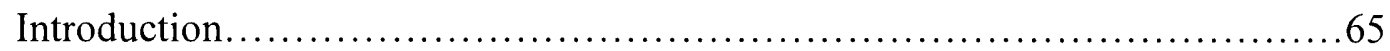

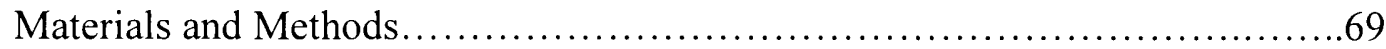

Statistical Analysis......................................................... 76

Results..........

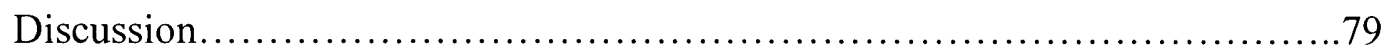

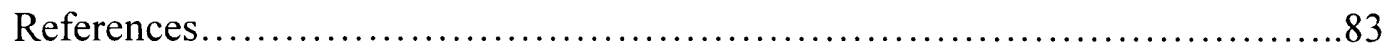

IV. AN ECOLOGICAL RISK ASSESSMENTOF SALINITY IN NORTHEAST

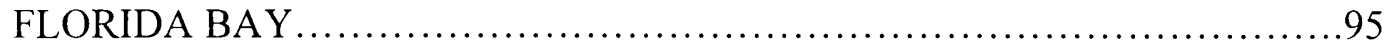

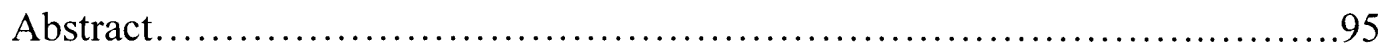

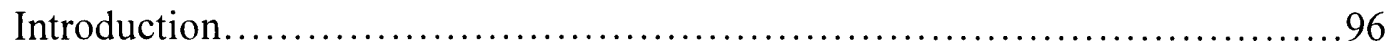

An Ecological Risk Assessment of Salinity in Northeast Florida Bay using the U.S. EPA Framework and PRA Approach................................106

Problem Formulation....................................................107

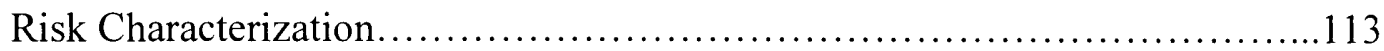

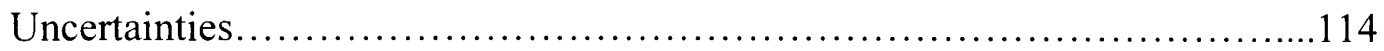

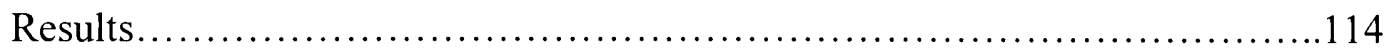

Discussion and Recommendations.....................................116

References.......................................................... 122

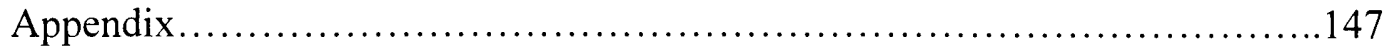

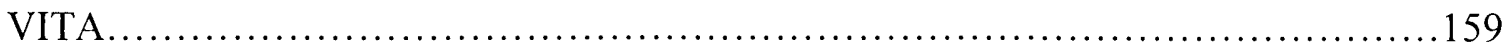




\section{LIST OF TABLES}

TABLE

PAGE

1. Cyprinodon variegatus Embryo-larval Salinity Study..........................55

2. Poecilia latipinna Chronic Neonate-fry Salinity Study. ..........................55

3. Results of Embryo-larval studies with native (a) and non-native stock (b) $\ldots \ldots \ldots \ldots . .56$

4. Mean weights $(\mathrm{mg})$ of Cyprinodon variegatus larvae produced at different salinity

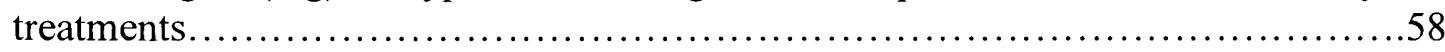

5. Survival of larvae produced at different salinity treatments......................60

6. Mean weight and number of eggs produced at different salinities...............62

7. Standard length and wet weights of fish used in behavioral toxicity studies..........89

8. Summary of BACI analysis data for Poecilia latipinna .........................92

9. Summary of BACI analysis data for Cyprinodon variegatus........................93

10. Salinity guild designation based on Venice classification for use in JPCs..........138

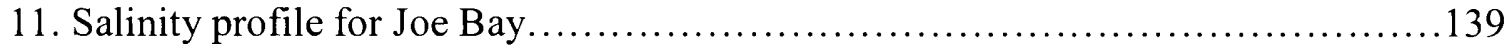

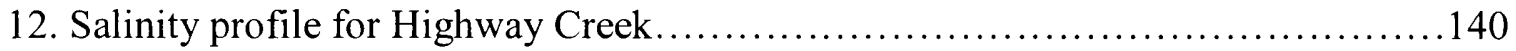

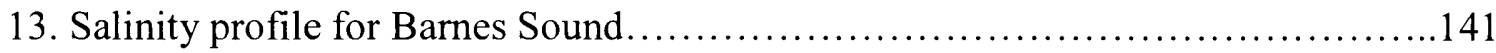

14. Salinity profile for Taylor River......................................... 142

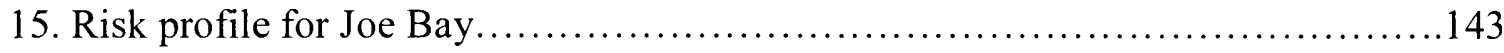

16. Risk profile for Highway Creek........................................... 144

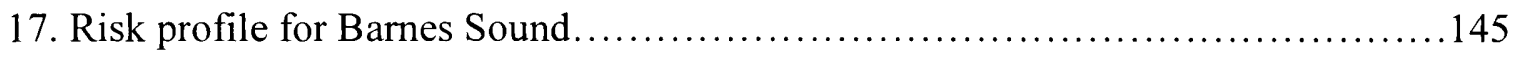

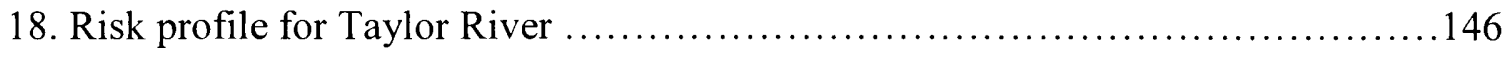

19. Appendix A: Species used in Species Sensitivity Distribution...................147

20. Appendix B: Diversity calculation by HY and Sampling Site...................149 


\section{LIST OF FIGURES}

FIGURE

PAGE

1. Example of spatial and temporal salinity variability in two areas of Northeastern Florida Bay... 26

2. Zones of Resistance and Compatibility (after Vernberg and Vernberg, 1976)........27

3. South Florida and Florida Bay (from USGS).

4. Flowchart for statistical analysis of fish survival data (U.S. EPA, 2002)............50

5. Flowchart of statistical analysis for fish growth data (U.S. EPA, 2002)............51

6. Static Test Results: Percent mortality at $0 \mathrm{ppt}$ Treatment for each species...........52

7. Northeast Florida Bay salinity ranges for fish species from this project..............53

8. Mean weights $(\mathrm{mg})$ of Cyprinodon variegatus larvae produced in different salinity treatments.

9. Survival of larvae produced at different salinity treatments

10. Mean cumulative number of eggs produced at different salinity treatments 61

11. Mean egg weight $(\mathrm{mg})$ produced at different salinity treatments... 63

12. Flow chart of behavioral responses to environmental perturbation and possible consequences.

13. Behavioral analysis system 86

14. (L) Three-dimensional view of behavior tank with water delivery tubes exposed.

(R) Top view of with water deliver tubes and manifold exposed

15. Lateral views of delivery manifold (top) and flow through tank with sloping false bottom (below).

16. Location of salinity change vector in behavior tank

17. Data profiles for different approaches for impact assessment.

18. Statistically significant locomotor endpoints for P. latipinna $(\mathrm{p}<0.05)$. 94 
19. The U.S. EPA's (1992) frame work for Ecological Risk Assessment (ERA). 127

20. Linearized probability distributions of exposure and response (effect) data.... .128

21. Derivation of joint probability curve (JPC) from exposure and response probability functions.

22. Interpretation of JPC in decision making. 130

23. Florida Bay map illustrating embayments and target salinity zones from the Florida bay/Florida Keys Feasibility Study.

24. Audubon Sampling sites

25. Species Sensitivity Distribution (SSD) for mean salinity affinity for demersal fishes in northeast Florida Bay...

26. JPC for Joe Bay. 134

27. JPC for Highway Creek.

28. JPC for Barnes Sound.

29. JPC for Taylor River. 137 


\section{Chapter I}

\section{INTRODUCTION}

The southern Florida peninsula encompasses approximately $28,000 \mathrm{~km}^{2}$ and includes a diverse system of interconnected subtropical habitats that function as a myriad of wetlands, uplands and coastal and marine areas. Comprised of 16 counties, this area is under the jurisdiction of the South Florida Water Management District (SFWMD) and the United Stats Department of the Interior (U.S. DOI. It extends from Orlando to the Florida Keys and is dominated by the watersheds of the Kissimmee River southward through Lake Okeechobee and the Everglades into highly productive estuaries and nearshore coastal waters, including Biscayne and Florida Bays.

South Florida has a low topographic gradient, is surrounded by thousands of miles of coastline and receives approximately $101-165 \mathrm{~cm}$ of rainfall annually $(60 \%$ within the wet season), making it vulnerable to flooding. Water quality and quantity issues in South Florida ecosystems have resulted from human changes to the hydrologic system which began in the late 1800 s, with dredging that channelized the Caloosahatchee River and connected it to Lake Okeechobee. Population growth began to escalate in the early 1900s and changes in the hydrologic structures of South Florida culminated with U.S. Congressional authorization of the Central and Southern Florida (C \& SF) Flood Control Project in 1948, which focused on flood control, drainage and water supply. The C \& SF Project consisted of 1400 miles of primary canals and more than 100 water control projects. The C\& SF Project, in trying to provide for the water needs of South Florida, led to hydrologic fragmentation of the Greater Everglades and affected the quantity and 
natural timing of freshwater deliveries to and through the surrounding areas. It has thus created land-use changes that have decreased the land available for water storage and recharge. For the next 50 years following implementation of the C\&SF project, population growth, urbanization and agricultural practices significantly exacerbated the degradation and loss of natural ecosystems in South Florida.

Less than half of the original wetland acreage that functioned as natural filters and water retention areas (WTAs) was lost or adversely impacted due to development and drainage changes. Presently, surface water discharges from canals into Florida and Biscayne Bays are heavier during wet periods and lighter during dry periods, producing higher salinity fluctuations in the bays and adversely affecting habitats. Impact on groundwater storage capacity is particularly significant since municipal water ( $\sim 95 \%)$ and agricultural water $(\sim 5 \%)$ supplies in South Florida come from aquifers.

Water quality was also degraded in some areas by phosphorus, pesticides and metals from agriculture and urban runoff (Science Subgroup, 1996). Evidence that changes in surface, groundwater and water quality have adversely affected plant and animal species and habitats includes:

*wading bird populations have declined ( $90 \%)$

*69 species are listed on the federal endangered and threatened list by U.S. Fish and Wildlife Service

${ }^{*}$ spread of invasive, non-indigenous, exotic plant and animal species

*declines in commercial and recreational fisheries in Biscayne and Florida Bays *decrease in the number of Everglades tree islands 
In the last 30 years, the Florida legislature and U.S. Congress produced legislation to manage growth and protect the natural environment of South Florida, including the Everglades, through state, federal and tribal programs. This began in 1972 with Florida's Water Development Act to establish water policy and the Land Conservation Act that authorized the issuance of bonds to purchase land. In 1996, U.S. Congress, under the Water Resources Development Act, formally established the South Florida Ecosystem Restoration Task Force to coordinate restoration efforts and authorized a review study of the C\& SF Project known as the Restudy. The goal of the Restudy was to modify the C\& SF project to restore the natural hydropattern and maintain flood control and to improve urban and agricultural water supplies. The U.S. Department of the Interior in 1996 also prepared a report entitled "A Comprehensive Plan for the Restoration of the Everglades" and in 2000, the U.S. Congress authorized the Comprehensive Everglades Restoration Plan (CERP) as part of the Water Resources Development Act which will be implemented at the cost of approximately 8 billion dollars over 40 years. The goal of the CERP is to modify the C\& SF project to restore and preserve the hydrology of the predrainage ecosystem to a more natural state, to protect the quality of the remaining habitats, to promote the return of populations of plants and animals and to foster human development compatible with sustaining a healthy ecosystem while providing for flood protection and water supply. CERP is led by the U.S. Army Corps of Engineers (USACE) and SFWMD and it is the framework for ecosystem restoration activities in South Florida since it focuses on the quantity, quality, timing and deliveries of freshwater supplying the system. 
Much of the South Florida restoration effort originally concentrated on water quantity versus water quality (Scott et al., 2002). However, it is evident from chemical monitoring programs in South Florida that organic and inorganic contaminants are present at concentrations in surface waters and sediment that may present potential adverse effects and risks to organisms. For example, since the mid-1980s, the SFWMD has been monitoring pesticides in South Florida surface waters and sediment, and several compounds including DDT, DDE, DDD, ametryn, atrazine, dicofol, diquat and endosulfan sulfate were frequently detected (Miles and Pfeuffer, 1997). Detectable residues of endosulfan were consistently present in surface water of one canal location (C-111), adjacent to Everglades National Park and occasionally exceeded Florida Department of Environmental Protection (FDEP) and U.S. Environmental Protection Agency (U.S.EPA) water quality criteria. Surface water sampling by the National Oceanic and Atmospheric Administration (NOAA) confirmed these findings (Scott et al., 1994). NOAA also conducted monitoring studies from 1993-1997 and indicated the presence of endosulfan, atrazine, chlorpyrifos and chlorothalonil in surface waters of canals adjacent to agricultural areas that drain into the C-111 and in northeast Florida Bay (Scott et al., 2002). Waters from canals contained detectable concentrations of endosulfan that sporadically exceeded the U.S. EPA freshwater quality criterion. Florida Bay waters also occasionally exceeded the U.S.EPA saltwater quality criterion for endosulfan. In addition, results of sediment toxicity tests indicated that sediment samples from a freshwater canal (C-111) and northeastern Florida Bay were toxic to copepods (Amphiascus tenuiremis) and juvenile clams (Mercenaria mercenaria), as a result of chronic exposures. The U.S. EPA in 1995 also detected endosulfan, other organochlorine 
insecticides, PCBs and PAHs at several sediment sites on the C-111 system, and parts of northeast Florida Bay (Goodman et al. 1999). NOAA conducted a study from 1998 to 2000 and found endosulfan, chlorpyrifos, metolachlor and atrazine concentrations were highest in canal sites in the Everglades panhandle, south of the C-111, but concentrations decreased toward northeast Florida Bay (Fulton et al., 2004). Concentrations of endosulfan exceeded U.S.EPA freshwater and saltwater criterion. NOAA also found that grass shrimp (Palaemonetes intermedius) had significantly reduced levels of the enzyme acetylcholinesterase when exposed to canal waters (Military and North Canals) that empty into Biscayne Bay (Key et al., 2003). A large-scale sediment quality program conducted by NOAA in Biscayne Bay (North to South Biscayne Bay) from 1995-1996 found that: high molecular weight PAHs exceeded guideline concentrations more than low molecular weight PAHs, PCBs exceeded guideline concentrations but spatial scales of contamination were small, and copper, lead, mercury and zinc most frequently exceeded guideline concentrations and concentrations of cadmium, copper, lead and zinc were high relative to background levels (Long et al., 2002). Furthermore, the highest chemical concentrations were found in the Miami River which empties into North Biscayne Bay. In the most recent monitoring study by the U.S. Department of Agriculture atrazine, endosulfan, chlorpyrifos, metolachlor, and chlorothalonil were the most frequently detected pesticides in water in South Florida canals and Biscayne Bay (Harman-Fetcho et al., 2005).

The U.S. General Accounting Office (U.S.GAO) prepared a report for the U.S. Department of the Interior, on gaps that exist in scientific information on the restoration of South Florida and indicated the need for studies on "more system-wide work on 
screening for contaminants" and the "risks faced by organisms living in areas with contaminants" and, "if not addressed soon, will hinder the success of restoration" (U.S.GAO, 2003).

As highlighted above, several toxicological and ecological risk assessment studies have been conducted over recent years to assess the effects of anthropogenic contamination in South Florida. However, patterns of naturally occurring abiotic factors such as salinity, when disrupted, can also be viewed as a contaminant or stressor to the native biota. Freshwater inflows into coastal areas and the resultant changing salinities are a major issue in the CERP and can be examined from an environmental toxicology viewpoint.

Water management practices for the Everglades have resulted in changes in salinity patterns that exceed the normal variability of the Florida Bay system, particularly in northeast Florida Bay (Marshall et al., 2009). These management practices (as briefly discussed above) have resulted in altered hydropatterns, reduced hydroperiods, as well as a general increase in salinities in the Bay (Marshall et al., 2009). The changes in salinity in the Bay have been linked to declines native forage fish species and the higher trophic levels that depend upon them (Lorenz and Serafy, 2006). Current salinity patterns in the bay can range from hyper- to hypo-saline and vary spatially and temporally (Nuttle et al., 2000). Figure 1.1 (Hittle and Patino, 2000) gives an example on the daily salinity variability within a two-year period for two areas of northeastern Florida Bay. 
Hence, salinity in Florida Bay, due to increased in both the variability and average value, can be views in the context of a toxicological stressor. Herein follows an overview of salinity as a stressor.

Estuaries and salinity

Estuaries are dynamic systems characterized by rapidly changing physio-chemical environments. The energetic demands on organisms are great, and many species are excluded from these habitats as a result (Day Jr. et al. 1989).

Vernberg and Vernberg (1976) described the physiological and behavioral effects of estuarine environments on animals. They postulated that when exposed to a stressful environment such as an estuary, there are three primary responses from the organism: 1) avoidance of the stressor; 2) adaptation or adjustment to the stressor, and hence survival; and 3) death. Across the environmental gradient of an abiotic factor, an organism will encounter a range that is conducive to life (Zone of Compatibility) as well as conditions which are detrimental (Zones of Resistence) (Vernberg and Vernberg, 1976). This dynamic is illustrated in Figure 1.2.

The most difficult stressor for estuarine fish is salinity and the physiological need to osmoregulate (Day Jr. et al, 1989). In order to maintain internal osmotic concentrations, estuarine fish have physiological and behavioral adaptations to minimize osmotic stress. These adaptations include, but are not limited to: scales/skin that are relatively impermeable; a mucous coating; control of drinking rate and/or excretion of water in urine; and avoidance of adverse conditions (Day Jr., et al 1989). 
Though distribution of estuarine organisms is controlled by no single factor, salinity plays a major deterministic role. Other factors that influence distribution are temperature, oxygen, substrate and food availability (Vernberg and Vernberg, 1972).

Salinity as a stressor

A stressor is any condition or situation that causes a biological system to mobilize its resources and increase its energy expenditure (Lugo, 1978). Stress is the response of the system to the stressor via increase in energy expenditure. Energy is "stored" as either glycogen or lipids with the fish. It is documented that lipid constituents within various organs (eye, gill, liver, digestive tract and gonads) and muscles are influenced by environmental salinity changes (Daikoku et al., 1982). As changes in survival, growth, and development may occur via an energetic route, salinity thus becomes is an important limiting and modifying factor in the physiology of estuarine fish.

Salinity and osmotic pressure of fluids are interrelated, since reduced salinity typically results in reduced osmotic pressure. Disruption of the normal pattern of hyper/hypoosmoregulation by salinity changes may affect tolerances to metals and organic contaminants. Thermal tolerance may also be modified by changes in salinity. For marine organisms, the upper lethal temperature decreases as salinity decreases (Kinne, 1964). Larval fish move into estuaries where they mature as post-larval juveniles to adults before they migrate to marine environments to spawn. Daily and seasonal fluctuations in salinity and temperature are characteristic of estuaries and although postlarval fish are tolerant to a wide range of water quality exposure regimes during these developmental stages, their survival, growth and development can be adversely affected by rapid fluctuations caused by altered flow patterns. 
Survival

Some species can slowly acclimate to high salinity and some intertidal organisms can and do live in low salinity waters. But often these intertidal species cannot reproduce there and their repopulation depends on invasion of larvae or adult migratory populations from higher salinity waters. For example, the amphipod Corophium volutator was found in salinities as low as $2 \mathrm{ppt}$, but breeding occurred in salinities greater than $7.5 \mathrm{ppt}$ (McLusky, 1968). Temperature and salinity can act jointly affect the survival of estuarine organisms. Survival time of the polychaete worm, Clymenella torquata at $37^{\circ} \mathrm{C}$ is markedly less at low salinities (Kenny, 1969). However, at low temperatures, the worms can tolerate low salinities for prolonged periods of time (Kenny, 1969). Though tolerant of a wide range of salinities (0-164 ppt) when gradually acclimated, Cyprinodon variegatus (Sheepshead minnow) has shown a high degree of mortality when exposed to rapid changes in salinity (Serafy, 1997; Nordlie, 2006). Hence, the rate of salinity change that an organism experiences is a likely factor in its ability to tolerate variable salinity environments (Nordlie, 2006).

Reproduction and Development

There is also evidence that salinity tolerances of progeny may depend upon the salinity to which the parent stock is adapted. Offspring of low salinity adapted parent stocks tolerate transfer to freshwater better than offspring from parent stocks grown at high salinities (Kinne, 1953). Salinity differentially influences various stages of the reproductive process. Fertilization, for example may occur over a wider range of salinities than subsequent larval growth and development. Fertilization, in Mytilus edulis occurred in salinities from $15-40 \mathrm{ppt}$, but successful development to the trochophore 
stage occurred only in salinities of 30-40 ppt (Bayne, 1965). In addition, larval development of some estuarine intertidal crabs is limited to the lower salinities of estuarine waters. For example, the wharf crab, Sesarma cinereum, has four zoeal stages and a megalops stage before it undergoes development to the crab stage, and it is the fourth zoeal stage which is most sensitive. Maximum survival and molting of this stage to megalops occurs in salinities of $26.7 \mathrm{ppt}$, and if higher salinities exist the crabs may die (Costlow et al., 1960). In the lingcod (Ophiodon elongatus), salinity and temperature have been shown to jointly influence egg hatchability and development and the incidence of deformities (Cook et al., 2005). In the flagfish, Jordanella floridae, increases in temperature were shown to increase egg development, while egg hatchability increased with increasing salinity (St. Mary et al., 2004). Gestation time and growth rate of neonates of the livebearer, Poecelia latipinna, were shown to be affected by changes in salinity (Kumaraguru et al., 2005). Trexler and Travis (1990) showed that low salinity negatively affected the size and maturation of female $P$. latipinna, fed at a constant food level, when compared to females raised at higher salinities.

In addition to differences among species, previous studies have demonstrated that salinity tolerance is size- and age-dependent for penaeid shrimp (Alvarez et al. 2004). Size is critical in determining postlarval survival to salinity stress (Alvarez et al., 2004). Tsuzuki and Cavalli (2000) found that developmental stage also influenced tolerance to salinity fluctuations. Their studies concluded that larger and older postlarvae tend to be better able to cope with salinity changes likely due to their more developed osmoregulatory capacity. In teleosts, prelarvae are able to osmoregulate via the 
integument and shift to use of the gills during the larval stage, hence their ability to osmoregulate also increases with age (Varsamos et al., 2005).

Metabolism

Since changing salinity is a characteristic of estuaries, estuarine animals exhibit a wide diversity of metabolic responses to variable salinities (Kinne, 1967). Laboratory studies with aquatic organisms have shown that standard metabolic rates and osmoregulatory capabilities are affected by salinity (Plaut 1999, Nordlie 1985). Wuenschel et al. (2005) reported that $\mathrm{O}_{2}$ consumption in juvenile gray snapper was higher at higher salinities. The authors further extrapolated that higher metabolic costs, at higher salinities, could affect overall juvenile production. Haney et al. (1999) showed that even the widely salinity tolerant sheepshead minnow (Cyprinodon variegatus) exhibited depressions in its resting metabolic rate (RMR) at freshwater and hypersaline ( $>40 \mathrm{ppt}$ ) conditions resulting in overall lower metabolism and reduced energy expenditure. Fluctuating salinity as well as less-than-optimal salinity levels have been reported to have direct effects on the metabolic response, distribution, growth and survival in penaeid shrimp (Browder et al. 1999, Ramirez-Rodriguez et al. 2003, Tsuzuki et al. 2003, Allan et al. 2006); even so, the physiological responses of shrimp to fluctuating salinities are not fully understood.

Growth

Increases in temperature resulted in increased linear and specific growth rate as well as overall growth efficiency in juvenile gray snapper, Lutjanus griseus (Wuenschel et al., 2004) However, an increase in salinity was found to negatively affect the growth efficiency of this same species (Wuenschel et al., 2004). Hypersaline events in Florida 
have also been linked to growth reductions in juvenile American crocodiles (Crocodylus acutus) (Richards et al., 2004). Juvenile cobias (Rachycentron canadum) have shown negative growth effects in relation to lowered salinity (Denson et al., 2003). Hurtado et al. (2006) found significant differences in growth for the penaeid Litopenaeus vannamei at high and low osmotic pressure.

Body Fluid Homeostasis

The absence of mortality does not necessarily mean the absence of adverse effects. Fluctuating salinity has been shown to cause a disruption in the osmotic balance in juvenile shrimp (Chen et al. 1996). These salinity fluctuations result in compensation by the organism in an attempt to readjust the osmotic balance, which causes a considerable expenditure of energy possibly leading to growth and reproductive effects (Chen et al. 1996). Plasma osmotic concentration in teleost fish has been shown to increase with increases in salinity (Jordan et al., 1993). Sulikowski and Maginniss (2001) also documented salinity induced changes in the blood fluid homeostasis of stingrays. Hyposaline conditions were shown to reduce both plasma osmolality and hematocrit count in juvenile cobia (Denson et al., 2003). Erythrocyte count in fish has also been shown to be influenced by changes in salinity (Nespolo and Rosemann, 2002). As erythrocytes are linked with $\mathrm{O}_{2}$ transport efficiency, changes in their volume can thus influence overall metabolic performance of the organism (Nespolo and Rosemann, 2002). Endocrinology

The hormone prolactin (PRL) has been linked to freshwater adaptation in euryhaline fish, by preventing the uptake of water and increasing ion retention (Manzon, 2002). Prolactin is a versatile hormone also linked to growth, reproduction, behavior, 
metabolism and immunoregulation in vertebrates (Manzon, 2002). PRL levels have been shown to be greatly influenced by salinity in estuarine fish, with levels increasing with freshwater adaptation(Manzon, 2002).

Behavior

The behavior of aquatic organisms can be affected by low concentrations of a chemical stressor that at higher concentrations can influence physiology and biochemistry (Rand, 1984). Hence, an organism's behavior may prove to be a more sensitive indicator of stress. Both food intake and food selection were shown to be influenced by salinity in the European sea bass (Dicentrarchus labrax) (Rubio et al., 2005). The authors found that changes in salinity altered the preference for proteins and carbohydrates in sea bass subjected to salinity changes.

Distribution

Salinity also limits the distribution of estuarine animals. The number of species present or species diversity in an estuary decreases with a decrease in salinity (Wells, 1961) but it should be noted that other abiotic factors (e.g., temperature, oxygen, contaminants) may also vary with salinity changes. Salinity fluctuations have been shown to be the key drivers in influencing fish abundance and distribution in estuaries (Whitfield, 1996; Paperno et al., 2004). A decrease in the growth of plants and diversity of animal communities has been noted in Biscayne Bay as a result of canal-driven freshwater inflow (Brook, 1982; Serafy et al., 1997; Lorenz et al., 1997). There is a general pattern of low densities of juveniles (Berkeley and Campos, 1984) that may reflect poor growth and/or survival of early life stages at low salinities $(<20 \mathrm{ppt})$. South Florida Regional Considerations 
Along with animal distribution, salinity can also be a limiting factor in the distribution of plants. Marsh plants were shown to respond to salinity gradients in several Florida tidal rivers, though it should be noted that salinity was not the sole contributing factor to distribution and abundance (Clewell et al. 2002). Other authors (Clewell et al., 1999; Mattson 2002, and Alexander and Dunton 2006) have linked salinity and changes in the salinity regime of a given area as a driver of plant communities.

Chesnes (2002) studied the effects of pulsed salinity changes (14-28 ppt) on several species of Florida seagrasses. The response to salinity stress was species specific, with turtle grass (Thalassia testudinum) showing the most sensitivity and widgeongrass (Ruppia maritima) showing the least. The author concluded that in areas subject to fluctuating salinity like northern Florida Bay, salinity is a primary driver for the abundance and distribution of submerged macrophytes. Additionally, La Peyre and Rowe (2003) found that growth of widgeongrass was better in constant salinity conditions vs. pulsed conditions. Both pulsed and gradual salinity changes (to hypersaline conditions) were examined Koch and Durako (2005) and Koch et al.(2007) in multiple species of seagrass. In both papers it was shown that while rapid changes in salinity produced negative effects, gradual changes which allowed a period of osmotic adjustment resulted in acclimation and survival.

The American crocodile (Crocodylus acutus), a resident of Florida Bay, is also sensitive to salinity. Mazzotti and Dunson (1989) showed that juvenile C. acutus lacked a functioning salt secreting gland and cannot survive in salinities above $20 \mathrm{ppt}$ for extended periods without drinking freshwater (rainwater). Earlier work by Dunson 
(1970) examined the effects of marine conditions ( $35 \mathrm{ppt}$ ) on crocodile hatchlings and concluded that such exposures caused a loss of body mass ( $1 \%$ per day) and were not conducive to survival. However, a population of crocodiles in South Florida exposed to fluctuating salinitity regimes was shown to be able to survive higher salinities because of periodic exposure to lower salinities. Ingestion of fresh or hyposaline water during these low salinity periods allowed for sufficient osmoregulation by the crocodiles (Mazzotti et. al. 1986).

Rapid changes in salinity and effects on mortality were studied by Serafy et al (1997) for 10 species of estuarine fish native to South Florida. In these studies fish, acclimated to $32 \mathrm{ppt}$, were directly transferred to freshwater and returned to $32 \mathrm{ppt}$ within a two hour timeframe representing real-time salinity changes that occur in Biscayne Bay due to water management practices (e.g. opening of a flood gate). Results showed that the degree of mortality was species specific, with certain resident species experiencing 100\% mortality (e.g. Cyprinodon variegatus) while others were unaffected (e.g. Lutjanus griseus).

Because of their dynamic nature, estuaries are subject to daily changes in both salinity and temperature corresponding to the timing and quantity of freshwater and saltwater delivery. However, the quality of the freshwater delivery also becomes an important consideration in areas with upstream contamination (Eddy, 2005). An additional consideration in bay health is the presence and availability of contaminants. Salinity and/or temperature induced stress changes in organismal physiology may also alter the availability of a contaminant by effecting changes at the site of uptake or in it's metabolic activities. 
Components of the Comprehensive Everglades Restoration Plan (CERP) especially storage, seepage control, redirection of canal flows to overland water and wastewater reuse plants will be used to restore more natural freshwater flows to Florida Bay. However, marine and estuarine communities may be affected by abrupt salinity changes, long-range salinity shifts and a decline in water quality from contaminants resulting from land use changes, human activities and water reuse.

Toxicity of metals is inversely related to salinity in that decreases in salinity produce increases in sensitivity of fish (Voyer et al., 1979; 1982). In addition, organic contaminants are more soluble and bioavailable in fresh waters and are less soluble in salt waters (Hamelink et al., 1994). Studies have demonstrated the presence of contaminants (metals and organics like pesticides, PCBs, PAHs) in the waters and sediments of Florida Bay and adjoining canals, rivers, and streams (Fulton et al., 2004). According to Pait et al., (1992) Dade County ranks second in the nation for hazards associated with pesticide applications in coastal areas. Long et al. (2000) and Carriger et al. (2006) have also shown sediment toxicity in peripheral canals and tributaries of the bay. Other than these studies little toxicological work has been performed for the bay and its freshwater sources. Furthermore, depressions in the $\mathrm{pH}$ of saltwater that result from its dilution with freshwater in estuaries may increase either salinity-induced stress and/or the bioavailability of heavy metals and other organic contaminants in the bay (Hamelink et al., 1994). Ammonia toxicity in estuaries has also been associated with lowered $\mathrm{pH}$ as a result of freshwater influx (Eddy 2005). Data on the interaction of salinity and/or temperature and contaminants is limited (Hall Jr. and Anderson, 1995). 
Central Theme of Dissertation

Timing, volume, delivery and quality of freshwater to Florida Bay can affect the structure and functional aspects of the diverse fish communities in the bay. Therefore, the biological performance measures of estuarine fish will be controlled by changes in salinity, temperature and water quality that will occur as a result of the restoration of freshwater flow to the bay.

With respect to the CERP, freshwater redistribution that ensures a salinity gradient that will support mangrove and estuarine communities is required to restore and maintain these critical South Florida ecosystems (Davis et al., 2005). Data gaps on the effects of water redistribution on bay communities (or lack of redistribution) must be addressed to maximize the restoration of Florida Bay and associated natural systems in this watershed. As altered salinity patterns in the Bay have been linked to declines in the abundance of both dermersal fish and the higher trophic level species that depend upon them, examination of the effects of salinity changes on native fish species can help resource managers understand the potential risks and reduce uncertainties concerning biological impacts of the CERP.

This dissertation will focus on the following two central hypotheses.

Hypothesis 1: Salinity is a significant limiting/modifying factor for optimum growth, development, survival and distribution of indigenous fish.

Hypothesis 2: Changes (decreases and increases) either abrupt or long-term in salinity of saltwater will exert adverse effects on growth, development, survival and distribution of acclimated indigenous fish. 
I proposed to test these hypotheses to fill data gaps that must be addressed to maximize restoration of Florida Bay and associated natural systems in this watershed. This will allow us to understand potential risks and reducing uncertainties concerning biological impacts of proposed CERP activities.

I addressed these hypotheses through the use and quantification of performance measures (e.g., survival, growth, development, behavior) in indigenous fish species as the measurement endpoints to assess responses to the stressor (salinity). Each chapter was written with the goal of providing information and tools that can be used by regulatory agencies for management of South Florida systems in regards to the CERP.

Chapter II explores the biological effects of salinity change on four native, estuarine fish species. The endpoints selected were determined by the U.S. EPA as regulatory endpoints perceived by Congress to be of sufficient societal or economic importance to be protected by legislation. Chapter III moves beyond the physiological effects and focuses on the behavioral changes associated with variable salinity, particularly attraction and avoidance. For Chapter IV, I conducted a probabilistic ecological risk assessment to estimate the risk of real-time salinity profiles to the presence and diversity of estuarine fish. This risk assessment was conducted for four embayments of northeastern Florida Bay that are of critical importance as feeding grounds for higher trophic level species. The approach and endpoints are presently being used in assessing potential ecological risks of chemicals under TSCA and FIFRA by the U.S.EPA. 


\section{References}

Alexander, H. D. and K. H. Dunton. (2006). Treated wastewater effluent as an alternative freshwater source in a hypersaline salt marsh: Impacts on salinity, inorganic nitrogen, and emergent vegetation. Journal of Coastal Research 22(2):377-392.

Allan, EL et al. (2006) Effects of temperature and salinity on the standard metabolic rate (SMR) of the caridean shrimp. J. Exper. Mar. Bio. Ecol. 337:103-108.

Alvarez, A.L et al. (2004) Salinty stress test as a predictor of survival during growout in pacific white shrimp (Litopenaeus vannamei). Aquaculture. 237: 237- 249.

Bayne, BL (1965) The gregarious behavior of the larvae of Ostrea edulis (L.). Ophelia 2: $1-47$

Berkeley, SA and WL Campos (1984) Fisheries assessment of Biscayne Bay. Final report to Dade County Department of Environmental Research Management. 212 pp.

Brook, IM (1982) The effect of canal discharge on the stability of two seagrass benthic communities in Biscayne National Park, Florida. Proceedings of the International Symposium on Coastal Lagoons, Bordeaux, France. Oceanol Acta 63-72

Browder, JA et al. (1999) Environmental influences on the potential recruitment of pink shrimp, Farfantepenaeus duorarum, from Florida Bay nursery grounds. Estuaries. 22(2B): 484-499.

Carriger JF et al (2006) Pesticides of potential ecological concern in sediment from South Florida canals: an ecological risk prioritization for aquatic arthropods. Soil Sed. Contam. 15: 21-45

Chen JC, et al. (1996) Survival, growth and intermolt period of juvenile Peneaus chinensis reared at different combinations of salinity and temperature. J. Exp. Mar. Bio. Ecol. 204: 169-178.

Chesnes, T. C. (2002). Responses of Subtropical Seagrasses to Fluctuations in Salinity within an Experimental Facility. Dissertation. University of Florida.

Clewell, A. F., R. S. Beaman, C. L. Coultas and M. E. Lasley. (1999). Suwannee River Tidal Marsh Vegetation and Its Response to External Variables and Endogenous Community Processes. Suwannee River Water Management District. A.F. Clewell, Inc., Quincy, FL. 
Clewell, A. F., M. S. Flannery, S. S. Janicki, R. D. Eisenwerth, and R. T. Montgomery. (2002). An Analysis of the Vegetation-Salinity Relationships in Seven Tidal Rivers on the Coast of West-Central Florida (Draft). Southwest Florida Water Management District, Brooksville, FL.

Cook MA et al. (2005) Effects of salinity and temperature during incubation on hatching and development of lingcod Ophiodon elongatus Girard, embryos. Aquaculture Res. 36: 1298-1303

Costlow JD et al. (1960) The effect of salinity and temperature on larval development of Sesarma cinereum (Bosc) reared in the laboratory. Biol. Bull. 118:183-202.

Daikoku, T et al.(1982) Lipid and fatty acid compositions and their changes in the different organs and tissues of guppy, Poecilia reticulata on sea water adaptation. Comp. Biochem. Physiol.73A: 167-174

Davis SM et al. (2005) A conceptual model of ecological interactions in the mangrove estuaries of the Florida Everglades. Wetlands 25(4): 832-842

Day Jr., JW et al. (1989) Estuarine ecology. John Wiley \& Sons, New York. 558 pp.

Denson MR et al. (2003) Effects of salinity on growth, survival, and selected hematological parameters of juvenile cobia Rachycentron canadum. J.World. Aqua. 34: 496-504

Dunson, W. A. (1970). Some aspects of electrolyte and water balance in three estuarine reptiles, the diamondback terrapin, American and "salt water" crocodiles. Comparative Biochemistry and Physiology 32:161-164.

Eddy, FB (2005) Ammonia in estuaries and effects on fish. J. Fish Biol. 67: 1495-1513

Fulton MH, Scott GI, DeLorenzo ME, Key PB, Bearden DW, Strozier ED, Madden CJ (2004) Surface water pesticide movement from the Dade County agricultural area to the Everglades and Florida Bay via the C-111 canal. Bull Environ Contam Toxicol 73: 527-534

Goodman LR, Lewis MA, Macauley JM, Smith R Jr, Moore JC (1999) Preliminary survey of chemical contaminants in water, sediment, and aquatic biota at selected sites in Northeastern Florida Bay and canal C-111. Gulf of Mexico Science 17:116

Hall Jr., LW and RD Anderson (1995) The influence of salinity on the toxicity of various classes of chemicals to aquatic biota. Crit. Rev. Toxicol. 25(4): 281-346 
Hamelink, JL et al. eds. (1994) Bioavailability: Physical, Chemical, and Biological Interactions. Special publication of SETAC. Lewis Publishers, Boca Raton, FL. 239 pp.

Haney DC et al. (1999) Influence of simulated tidal changes in ambient salinity on routine metabolic rate in Cyprinodon variegatus. Copeia 2:509-514

Harman-Fetcho JA, Hapeman CJ, McConnell LL, Potter TL, Rice CP, Sadeghi AM, Smith RD, Bialek K, Sefton KA, Schaffer BA, Curry R (2005) Pesticide occurrence in selected South Florida canals and Biscayne Bay during high agricultural activity. J Agr Food Chem 53:6040-6048

Hittle, CD and E. Patino. (2000) Magnitude and Distribution of Flows into Northeastern Florida Bay. U.S. Geological Survey Fact Sheet 030-00.

Hurtado, MA et al. (2006) Effect of hypo- and hyper-saline conditions on osmolarity and fatty acid composition of juvenile shrimp Litopenaeus vannamei fed low- and high-HUFA diets. Aqua. Res. 37: 1316-1326.

Jordan F et al. (1993) Plasma osmotic regulation and routine metabolism in the Eutis Pupfish, Cyprinodon variegatus hubbsi. Copeia 3:784-789

Kenny, R. (1969) The effects of temperature, salinity, and substrate on distribution of Clymenella torquata (Leidy) Polychorta. Ecol 50: 624-631.

Key PB, Fulton MH, Harman-Fetcho JA, McConnell LL. (2003). Acetylcholinesterase activity in grass shrimp and aqueous pesticide levels from South Florida drainage canals. Arch. Environ. Contam. Toxicol. 45(3): 371-7.

Kinne, O. (1953) Zur Biologie and physiologie von Gammurus duebeni Lillj. Z. Wiss. Zool.157: 427-491.

Kinne, O. (1964) The effects of temperature and salinity on marine and brackish water animals. II. Salinity and temperature salinity combinations. Oceanogr. Mar. Biol. Ann. Rev. 2: 281-339.

Kinne, O. (1967) Physiology of estuarine organisms with special reference to salinity and temperature. In Estuaries. GH Lauff, ed. AAAS Publ.No. 83, Washington DCpp. 525-540.

Koch, M. S. and M. J. Durako. (2005). High Salinity and Multiple Stressor Effects on Seagrass Communities of Florida Bay. Task 13 Final Report, South Florida Water Management District Contract No. 12430. 
Koch, M.S., S. A. Schopmeyer, C. Kyhn-Hansen, C.J. Madden and J.S. Peters. (2007). Tropical seagrass species tolerance to hypersalinity stress. Aquatic Botany $86: 16-$ 24.

Kumaraguru KP et al. (2005) Effect of salinity on gestation period, fry production, and growth performance of the sailfin molly (Poecelia latipinna Leseur) in captivity. Israeli J. Aqua. - Bamidgeh 57(3): 191-196

La Peyre, M. K. and S. Rowe. (2003). Effects of salinity changes on growth of Ruppia maritima L. Aquatic Botany 77:235-241.

Long, ER et al. (2000) Magnitude and extent of chemical contamination and toxicity in sediments in Biscayne Bay and vicinity. NOAA Technical memorandum. National Oceanic and Atmospheric Administration, Silver Springs, Maryland.

Long ER, Hameedi MJ, Sloane GM, Read LB (2002) Chemical contamination, toxicity, and benthic community indices in sediments of the Lower Miami River and adjoining portions of Biscayne Bay, Florida. Estuaries 25:622-637

Lorenz, JJ et al. (1997) The effects of hydrology on resident fishes of the Everglades mangrove zone. Final report to the South Florida Research Center, Everglades National Park, Homestead Florida. 193 pp.

Lorenz JJ, Serafy JE (2006) Subtropical wetland fish assemblages and changing salinity regimes: Implications for everglades restoration. Hydrobiologia 561: 401-422.

Lugo, AE. (1978) Stress and Ecosystems. In Energy and Environmental Stress in Aquatic Systems. JH Thorp and JW Gibbons, eds. Tech. Inf. Cent. U.S. Dept. of Energy, Washington DC, pp.62-101.

Manzon, LA. (2002) The role of prolactin in fish osmoregulation: a review. Gen. Comp. Endo. 125: 291-310

Marshall, FE III, Wingard, GL, Pitts P. (2009) A simulation of historic hydrology and salinity in Everglades National Park: Coupling paleoecologic assemblage data with regression models. Estuaries and Coast 32:37-53.

Mattson, R. A. (2002). A resource-based framework for establishing freshwater inflow requirements for the Suwannee River estuary. Estuaries 25(68):1333-1342.

Mazzotti, F. J., B. Bohnsack, M. P. McMahon, and J. R. Wilcox. (1986). Field and laboratory observations on the effects of high temperature and salinity on hatchling Crocodylus acutus. Herpetologica 42(2):191-196. 
Mazzotti, F. J. and W. A. Dunson. (1989). Osmoregulation in crocodilians. American Zoologist 29(3):903-920.

McLusky, DS. (1968) Some effects of salinity on the distribution and abundance of Corophium volutator in the Ythan estuary. J. Mar. Biol. 48: 443-454

Miles CJ, Pfeuffer RJ (1997) Pesticides in canals of south Florida. Arch Environ Contam Toxicol 32:337-345

Nespolo, RF and M. Rosenmann (2002) Intraspecific allometry of haemetological parameters in Basilichthys australis J. Fish Biol. 60:1358-1362

Nordlie, FG. (1985) Osmotic regulation in the sheepshead minnow Cyprinodon variegatus. J. Fish. Biol. 26:161-170.

Nordlie, FG. (2006) Physiochemical environments and tolerances of cyprinodontoid fishes found in estuaries and salt marshes of eastern North America. Rev. Fish Biol. Fisheries. 16: 51-106.

Nuttle, WK, Fourqurean, JW, Cosby, BJ, Zieman, JC, Robblee, MB. (2000) Influence of net freshwater supply on Salinity in Florida Bay. Water Resources Research. 36(7) 1805- 1822.

Pait, AS et al. (1992) Agricultural pesticide use in coastal areas: a national summary. NOAA, Rockville, Maryland.

Paperno R and RB Brodie (2004) Effects of environmental variables upon the spatial and temporal structure of a fish community in a small, freshwater tributary of the Indian River Lagoon, Florida. Est. Coast. Shelf Sci. 61: 229-241

Plaut, I. (1999) Effects of salinity on survival, osmoregulation, and oxygen consumption in intertidal blenny, Parablennius sanguinolentus. Copeia. 3: 775-779.

Ramirez-Rodriguez, M. et al. (2003) Recruitment patterns of the pink shrimp Farfantepenaeus duorarum in the southern Gulf of Mexico. Fish. Res. 65 (1-3): 81-88.

Rand, GM (1984) The use of behavioral measurments to assess toxicant-induced stress in marine organisms. In Ecotoxicological testing for the marine environment. G. Persoone, E. Jaspers and C. Claus (Eds.) State Univ. Ghent and Inst. Mar. Scient. Res., Bredene, Belgium. Vol.2 588 p. 
Richards PM et al. (2004) Evaluating the effects of salinity on a simulated American crocodile (Crocodylus acutus) population with applications to conservation and Everglades restoration. Ecol. Model. 180: 371-394

Rubio VC et al. (2005) Effects of salinity on food intake and macronutrient selection in European sea bass. Phys. \& Behav. 85: 333-339

Science Subgroup. 1996. South Florida Ecosystem Restoration: Scientific Information Needs. Report to the Working Group of the South Florida Ecosystem Restoration Task Force. Miami, FL.

Scott GI, Fulton MH, Daugomah J, Strozier ED, Key PB, Pennington PL, Thompson BC, Wirth EF, Thayer G (1994) Monitoring of Pesticides in Surface Waters of Florida Bay and Adjacent Agricultural Watersheds: Implications for Future Management of Freshwater Inputs to Florida Bay. U.S. National Marine Fisheries Service, Charleston, SC

Scott GI, Fulton MH, Wirth EF, Chandler GT, Key PB, Daugomah JW, Bearden D, Chung KW, Strozier ED, DeLorenzo M, Sivertsen S, Dias A, Sanders M, Macauley JM, Goodman LR, LaCroix MW, Thayer GW, Kucklick J (2002) Toxicological studies in tropical ecosystems: an ecotoxicological risk assessment of pesticide runoff in South Florida estuarine ecosystems. J Agr Food Chem 50:4400-4408.

Serafy, JE et al. (1997) Effects of freshwater canal discharge on fish assemblages in a subtropical bay: field and laboratory observations. Mar. Ecol. Progress Series 160: $161-172$.

St. Mary CM et al. (2004) Environmental effects on egg development and hatching success in Jordanella floridae, a species with parental care. J. Fish Biol. 65: 760768.

Sulikowski JA and LA Maginniss (2001) Effects of environmental dilution on body fluid regulation in the yellow stingray, Urolophus jamaicensis. Comp. Biochem. Phys. Part A 128: 223-232

Trexler, JC and J Travis (1990). Phenotypic plasticity in the sailfin molly, Poecelia latipinna (Pisces:Poeciliidae). I . Field Experiments. Evol. 44:143-156.

Tsuzuki, MY and RO Cavalli. (2000) The effects of temperature, age, and acclimation to salinity on the survival of Farfantepenaeus paulensis Postlarvae. J. World Aqua. Soc. 31(3): 459-468.

Tsuzuki, MY et al. (2003) Effect of salinity on survival, growth, and oxygen consumption of the pink shrimp Farfantepenaeus paulensis (Perez-Farfante 1967). J. Shell. Res. 22(2): 555-559. 
U.S. GAO (U.S. General Accounting Office). (2003). South Florida Ecosystem

Restoration: Task Force Needs to Improve Science Coordination to Increase

Likelihood of Success. Report to Subcommittee on Interior and Related Agencies, Committee on Appropriations, House of Representatives. GAO-03-345.

Varsamos S et al. (2005) Ontogeny of osmoregulation in postembryonic fish: a review. Comp. Biochem. Phys. Part A 141: 401-429

Vernberg WB and F.J. Vernberg. (1972) Environmental physiology of marine animals. Springer-Verlag, New York. 346 pp.

Vernberg WB and F.J. Vernberg. (1976) Physiological adaptations of estuarine animals. Oceanus, 19 (5):48-54.

Voyer, RA et al. (1979) Hatching success and larval mortality in an estuarine teleost, Menidia menidia (Linnaeus), exposed to cadmium in constant and fluctuating salinity regimes. Bull. Environ. Contam. Toxicol. 23: 475-481.

Voyer, RA et al. (1982) Visibility of embryos of the winter flounder, Pseudopleuronectes americanus exposed to mixtures of cadmium and silver in combination with selected fixed salinities. Aquat. Toxicol. 2: 223-233

Wells, HW. (1961). The fauna of oyster beds, with special reference to the salinity factor. Ecol. Monogr. 31:239-266.

Whitfield AK (1996) A review of factors influencing fish utilization of South African estuaries. Trans. Roy. Soc. S. Afr. 51: 115-137

Wuenschel MJ et al (2004) Effect of temperature and salinity on the energetics of juvenile gray snapper (Lutjanus griseus): implications for nursery habitat value. J. exp. Mar. Biol. Ecol. 312: 33-347

Wuenschel MJ et al (2005) Metabolic response of juvenile gray snapper (Lutjanus griseus) to temperature and salinity: physiological cost of different environments. J. Exp. Mar. Biol. Ecol. 321:145-154 


\section{Daily Salinity at Joe Bay Creeks and Trout Creek. \\ 1999-2001}

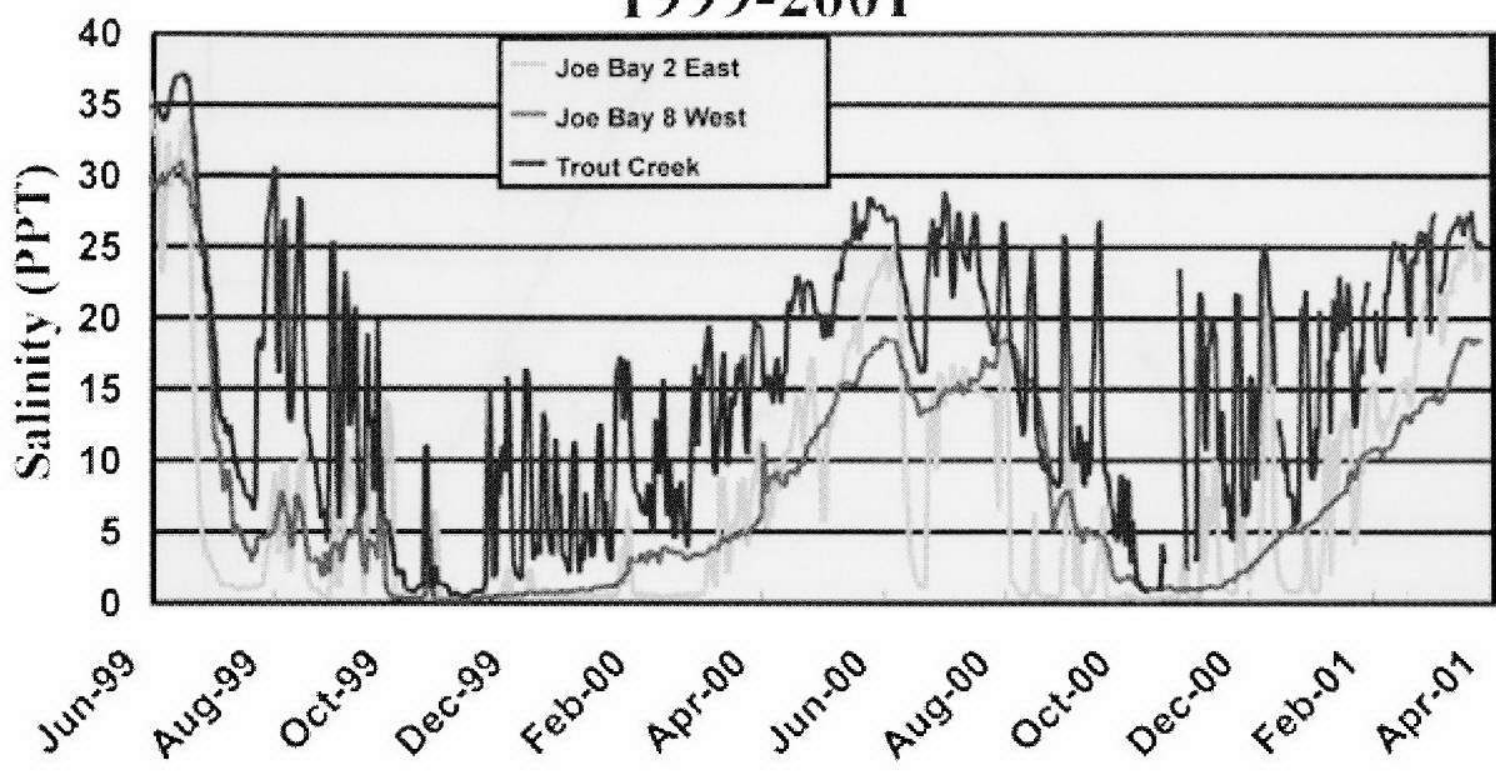

Figure 1.1. Example of spatial and temporal salinity variability in two areas of northeastern Florida Bay, Joe Bay and Trout Creek from 1999-2001. (Data and figure from Hittle and Patino, 2000) 


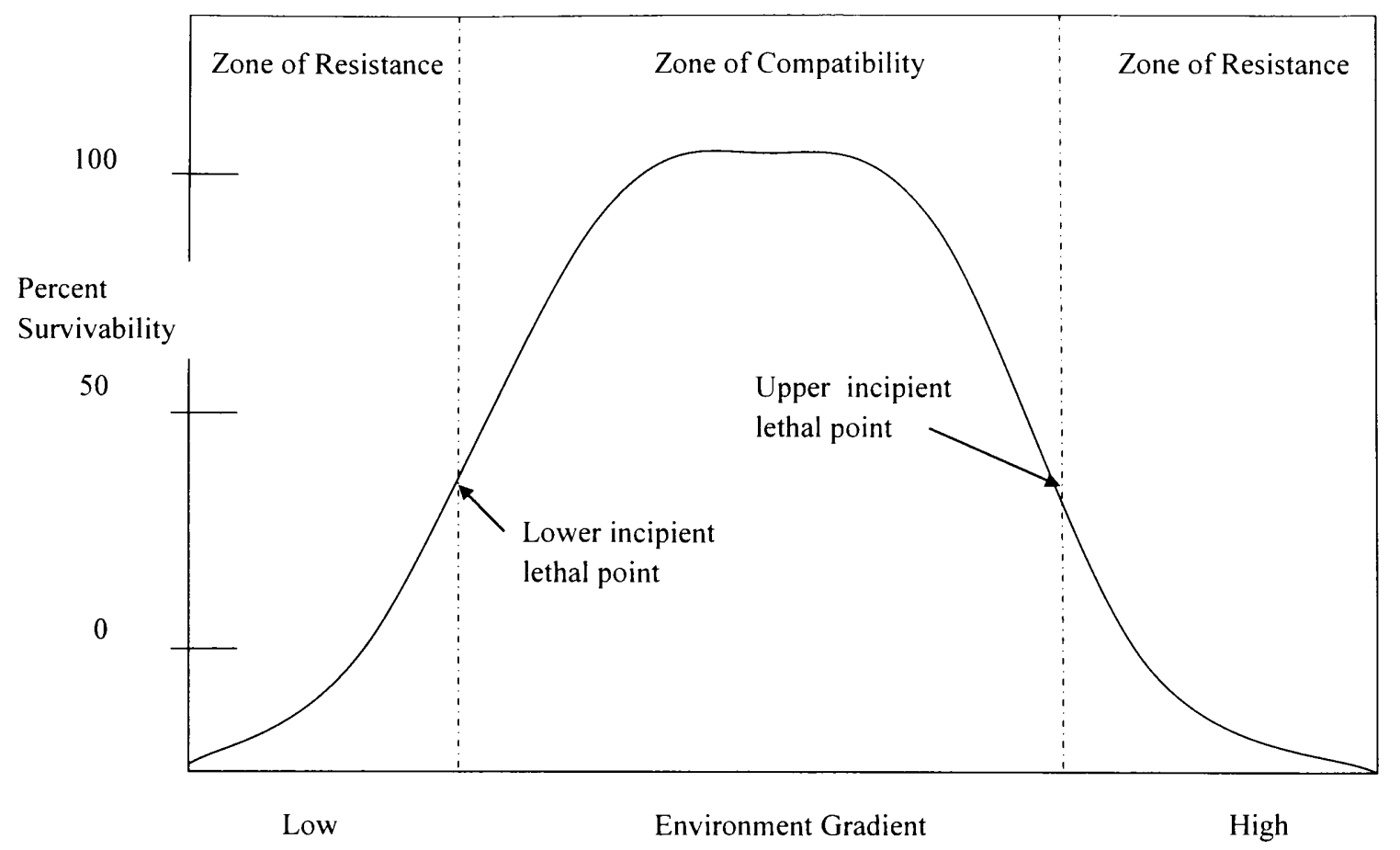

Figure 1.2. Zones of Resistance and Compatibility (after Vernberg and Vernberg, 1976). 


\section{Chapter II}

\section{EFFECTS OF SALINITY ON NATIVE ESTUARINE FISH SPECIES IN SOUTH}

FLORIDA: TOXICOLOGY STUDIES

Abstract

Variable and high salinities have been identified as key stressors in Florida Bay. The Comprehensive Everglades Restoration Plan (CERP) includes water redistribution projects that are intended to restore natural freshwater flows to northeastern Florida Bay. The present salinity regimes in the area, which span from hypo- to hypersaline, will be altered as a result of these actions. My research examined biological performance measures (i.e., growth and survival) of estuarine fish under varying salinity regimes that will occur as a result of the restoration of freshwater flow to the bay. A series of acute and subchronic studies were conducted to determine the effects of salinity changes on various life stages (embryo/larval, juvenile, adult) of four native estuarine fish (Cyprinodon variegatus, Floridichthys carpio, Poecilia latipinna, and Gambusia holbrooki). Fish were exposed to a range of salinity concentrations (freshwater to hypersaline) based on current salinity profiles in the study areas. Growth (length, weight), and survival were measured. Salinity exposures included both rapid and gradual change events. Results show adverse effects of acute, abrupt salinity changes on fish survival and development because of salinity stress. 
Introduction

Estuaries and coastal ecosystems experience a range of stresses, both natural and anthropogenic. Two of the most important factors affecting the overall functionality of an estuary are the timing and quality of the freshwater inflow, which subsequently affect the salinity regimes of the area (Montagna et al., 2002). Salinity is considered to be one of the primary environmental factors affecting the growth and survival of aquatic organisms because it can influence both physiological and ecological processes (Chen et al. 1996, Tsuzuki et al. 2003, Varsamos et al., 2005, Nordlie, 2006).

Florida Bay (referred to as the Bay) is a large, shallow (average depth 6-9 feet), subtropical estuary on the southern coast of Florida that, along with the Gulf of Mexico, receives water from the Everglades system (Lodge, 2005). The Bay (and its natural tributaries) is within the boundaries of Everglades National Park (Figure 2.1).

Salinity, circulation and water quality in the Bay depend primarily on freshwater inflow, wind-driven circulation and ocean exchange. Florida Bay provides critical habitat for the American crocodile and West Indian manatee and also supports a diverse natural assemblage of seagrass, hardbottom, and coastal mangrove communities despite hydrological alterations from urban development and the Central and South Florida (C\&SF) Flood Control project. The Bay also acts as a nursery for the larvae and juveniles of many critical species, including piscivorous fish and numerous wading bird species (Lorenz and Serafy, 2006).

Analysis of monitoring station data from areas of northeastern Florida Bay shows variable and hypo- to hypersaline events on both short (daily) and long (yearly) 
temporal scales (DBHYRDO Database, SFWMD). Salinities in these areas can range from freshwater conditions to over $40 \mathrm{ppt}$ (DBHYDRO Database, SFWMD).

A key component of the Bay is the large population of demersal fish that support Higher Trophic Levels (HTL) species. Declines in the abundance of HTL species (such as Roseate Spoonbill) that rely upon these forage fish have been linked to food stress (Ley et. al, 1994, Lorenz \& Serafy, 2006). There is evidence to suggest that the altered salinity patterns in the Bay are, in part, responsible for the decline in overall abundance of forage fish (Lorenz and Serafy, 2006).

Timing, volume, delivery and quality of freshwater to Florida Bay can affect the structure and functional aspects of the diverse fish communities in the bay. Therefore, the biological performance measures (survival, growth, development) of estuarine fish will be controlled by changes in salinity, temperature and water quality that will occur as a result of the restoration of freshwater flow to the Bay.

Field studies in northeastern Florida Bay have reported changes in demersal fish populations and abundance due to changes in salinity patterns (Lorenz and Serafy, 2006). Adults and juveniles of Bay fish species have been shown to exhibit different tolerances to salinity changes, with juveniles being less sensitive than adults (Christensen et al., 1997). Within a fish species, the geographic location and history of salinity exposure can influence the local population's tolerance for salinity change (Holt and Holt, 2003).

Currently, there is little laboratory research available that examines the optimal salinities or tolerance ranges for key forage fish species native to Florida Bay, especially on early life stages. (Nordlie, 2006). The following studies were conducted to determine 
if salinity is a significant limiting/modifying factor for optimum growth, development and survival of native fish.

Materials and Methods

Organisms and Water Quality

Four species of native estuarine fish collected from northeastern Florida Bay were used in these studies. They are as follows: Sailfin Molly (Poecilia latipinna); GoldSpotted Killifish (Floridichthys carpio); Sheepshead Minnow (Cyprinodon variegatus); and Eastern Mosquitofish (Gambusia holbrooki). The species chosen comprise the bulk of demersal fish biomass found in these areas (Lorenz and Serafy, 2006). These species represent a broad range of salinity tolerances and life history strategies. Two species (Cyprinodon variegatus and Floridichthys carpio) are egg-layers and the other two species (Poecilia latipinna and Gambusia holbrooki) are live-bearers.

To establish cultures, fish were collected from Little Blackwater Sound, in northeastern Florida Bay using a 1/4" mesh seine net. Capture and transport techniques were developed to minimize pain and distress to fish and handling was minimized. Fish were transported in aerated water from the collection site water in a cooler. The maximum time from capture to arrival at the laboratory did not exceed three hours for all sampling trips. Sampling trips were conducted to supply individuals to establish in-house breeding cultures at the Florida International University Ecotoxicology \& Risk Assessment Laboratory.

Upon arrival at the laboratory, fish were acclimated to culture water and temperature conditions ( $15 \mathrm{ppt}$ and $22^{\circ} \mathrm{C}$, respectively). Fish were separated by species and visually inspected for parasites and outward signs of infection. Two types of 
prophylactic treatments, a paracide (formalin) and an antibiotic (nitrofurazone) were administered to all wild-caught fish entering the laboratory to prevent contamination of clean stocks. For ecto-parasite treatment, fish were dipped for 30 minutes in a $250 \mathrm{mg} / \mathrm{L}$ formalin solution with aeration and then placed back in clean water. Twenty-four hours after parasite treatment, a dose of $20 \mathrm{mg}$ nitrofurazone per liter of tank water was administered for a period of 3 days as an antibiotic measure. Hospital tanks for the fish had no filtration (to prevent loss of antibiotic) and were held with constant aeration, temperature and light regime for the duration of the prophylactic treatment. A $100 \%$ water renewal and fresh batch of antibiotic were prepared for each 24 hours of treatment.

All fish were maintained on a recirculating water system at the appropriate salinity. Each recirculating system consisted of a particle (sand) filter, biological filter and UV sterilizer. Tanks ranged in size from 10 gallon glass aquaria to 300 gallon fiberglass tanks. Each tank was provided continous aeration and controlled temperature $\left(22^{\circ} \mathrm{C}\right)$. Indoor tanks had a controlled lighting regime of 16 hours daylight to 8 hours darkness.

All fish were cultured at the optimum conditions for health and welfare, and to minimize distress. Water quality was monitored regularly, with temperature and salinity monitored daily while dissolved oxygen (D.O.) and $\mathrm{pH}$ were measured on a weekly basis. The loading volume of fish per tank was based on organism and tank size, and structured in such a way as to not cause undue stress to fish.

Fish used in the studies were euthanized post-test using a concentrated solution of MS-222. Returning fish to the wild, or back into the laboratory broodstock culture was not a viable option. These fish may have been compromised by their exposure to the 
substances we were testing, and we did not wish to further compromise wild or breeding stocks by their re-introduction.

Our laboratory has developed Standard Operating Procedures for the culturing of the above mentioned animals. These procedures are based upon the following souces: Guidelines for Use of Fishes in Research (American Fisheries Society, 2004); U.S. EPA Good Laboratory Practice (GLP) Standards 160.90: Animal and other test system care; and U.S. EPA methods for fish culture as described in document EPA/600/4-90/027F August 1993. Fish collection, husbandry and testing were conducted in accordance with FIU IACUC Protocols 04-029 and 04-030.

Offspring $\left(\mathrm{F}_{1}\right)$ were produced through both natural and artificial means from the field-collected parental generation $\left(\mathrm{F}_{0}\right)$. Artificial reproduction of sheepshead minnows was conducted through use of Human Chorionic Gonadotropin (HCG) under the procedure outlined in U.S. EPA document 1005.0 (in EPA-821-R-02-014, 2002).

Laboratory Resources

All experimentation was carried out at Florida International University's Southeast Environmental Research Center Ecotoxicology Laboratory located on Biscayne Bay in North Miami, Florida, a NELAC certified facility.

The laboratory's location and computer-interface systems provided the capability to conduct toxicity exposures in natural full-strength seawater as well as freshwater. The laboratory contains a salinity control system to automatically produce a range of salinities for estuarine studies based upon study needs. 
The source of full-strength seawater ( $30 \mathrm{ppt}$ ) was a saltwater aquifer supplied by Biscayne Bay. Dilution of the 30 ppt source water for the laboratory was controlled by the automated salinity system. Hypersaline water (>30 ppt $-60 \mathrm{ppt})$ was formulated from the laboratory source saltwater combined with Instant Ocean Sea Salts (Aquarium Systems, Inc.).

Study Design

In salinity toxicity studies, water hardness and alkalinity of freshwater were measured and ranged from 60 to $100 \mathrm{mg} / 1$ (as $\mathrm{CaCO}_{3}$ ) and from 54 to $83 \mathrm{mg} / \mathrm{l}$, respectively. Salinity, conductivity, dissolved oxygen and temperature were monitored daily, while $\mathrm{pH}$ and total ammonia $(\mathrm{mg} / \mathrm{l})$ were monitored weekly.

For all studies, $\mathrm{pH}$ ranged from 7.20 to 8.68 and total ammonia never exceeded $0.7 \mathrm{mg} / 1$. A temperature of $25^{\circ} \mathrm{C}\left(+/-1{ }^{\circ} \mathrm{C}\right)$ and a photoperiod $(16 \mathrm{~L}: 8 \mathrm{D})$ were maintained throughout the duration of the studies. The study areas were curtained off from the main laboratory to minimize any disturbance. Salinities were maintained at $+/-$ 1 ppt of the target value, and dissolved oxygen was maintained at greater that $80 \%$ saturation in all treatments. In long-term studies, fish were fed daily with Aquatox (Zeigler Bros. Inc.) flake food until satiation. Young fish (neonates and fry up to 2 weeks old) were fed less than 24-hour old brine shrimp nauplii (Artemia spp.. NABS, LLC). Uneaten food was siphoned from tanks daily.

Static renewal and flow-though water exposures were used for the toxicity studies to simulate salinity regime changes in Florida Bay. Static renewal was used to mimic abrupt salinity changes. Flow-through systems were used to conduct short-term (acute) 
and long-term (chronic) exposures with gradual salinity change to determine effects on survival, growth, and reproduction of fish. The flow-through system produces five different salinity concentrations and is controlled by Windows software.

Acute Toxicity of Salinity Changes to Adult Estuarine Fish Under Static Conditions

Each of the four fish species were exposed to abrupt salinity changes to evaluate the direct effects of salinity on survival. Adults of each species were acclimated under culture conditions for 14 days to a salinity of 30 ppt and exposed to an abrupt salinity change, via direct transfer, resulting in final salinities of $15,8,4,2$ and 0 ppt respectively. Control fish were maintained at 30 ppt. Observations were made for 10 days. Each salinity treatment contained two replicates with 10 fish per replicate in $10 \mathrm{~L}$ glass aquaria with aeration. The study was conducted under static-renewal conditions with $50 \%$ water exchange daily.

Acute Toxicity of Salinity Changes to Adult Estuarine Fish Under Flow-Through Conditions

Fish were exposed to gradual salinity changes and evaluated for effects on survival for 96 hours. To simulate a more natural and less-abrupt change in salinity, a flowthrough diluter system was used. The study was initiated with all tanks at the control salinity (30 ppt or $15 \mathrm{ppt}$ ) and employed the automated flow-through diluter to gradually change salinity to the target concentration over a 24 hour period. Two scenarios were conducted with baseline initial salinities from near-marine (30 ppt) and estuarine (15 ppt) conditions. 
Adults of each species were first acclimated for 14 days to a salinity of 30 or $15 \mathrm{ppt}$ (control scenario I \& II, respectively) and exposed to a gradual change in salinity resulting in final salinities of $30,15,8,4,2$ and 0 ppt. Control groups for each scenario were kept at their respective acclimated salinity, either 30 or 15 ppt. Each salinity treatment contained two replicates with 10 fish per replicate. Exposure tanks were 18liter glass aquaria provided with aeration.

Fish Early Life Stage (ELS) Toxicity Study

Fish ELS studies were conducted to determine the effects of salinity change on survival and growth of $C$. variegatus embryos/larvae and P. latipinna neonates. Procedures followed U.S. EPA toxicity methodology for fish ELS studies (U.S. EPA, 2002). Exposure of C. variegatus was initiated within $24 \mathrm{hr}$ after fertilization and exposure of $P$. latipinna was initiated with $<24 \mathrm{hr}$ old neonates that were all initially maintained in water with a salinity of $15 \mathrm{ppt}$. Embryos (C. variegates) or neonates ( $P$. latipinna) were distributed, five at a time, by stratified random assignment to each labeled chamber using a serological pipette until each chamber contained 40 embryos or neonates. There were 40 embryos or neonates per replicate with two replicates per salinity treatment concentration and six salinity concentrations $(30,15,8,4,2$ and $0 \mathrm{ppt})$ held under flow through conditions for 60 days after test initiation. The controls for both species were the treatment groups that were maintained consistently at a salinity of 15 ppt. Dead eggs and fry were removed daily and counted. When hatch was complete the number of live and dead organisms was recorded. Percentage hatch was calculated as the number of live, normal fry in each chamber/40 embryos. Fry were fed $24 \mathrm{hr}$ old brine shrimp nauplii, two times per day. After $14 \mathrm{~d}$, young fish were switched to a diet of 
Aquatox flake food. Fish were fed to satiation on both diets, and excess food was siphoned daily from tanks.

Daily observations were recorded for both species on fry mortality, behavior and appearance. At the end of the $60 \mathrm{~d}$ exposure periods, the fry from each chamber were anaesthetized with MS-222 and percentage survival, mean total length and wet weight were determined. Fry were measured individually to the nearest $\mathrm{mm}$ to calculate a mean and standard deviation for total length and fry were weighed to the nearest mg to calculate average wet weight.

Acute Studies- Hypersalinity

Studies were conducted with two different genetic strains of $C$. variegatus to identify response differences between native and commercially produced stock. Embryos of a non-Florida Bay population were purchased from a commercial supplier (Aquatic Biosystems, Ft. Collins, CO). As this stock was cultured at $25 \mathrm{ppt}$, the control salinity for this study was set at $25 \mathrm{ppt}$ instead of $15 \mathrm{ppt}$.

Cyprinodon variegatus embryos ( $<24 \mathrm{hrs})$ were exposed to salinities ranging from 0 $60 \mathrm{ppt}$ in $9 \mathrm{~d}$ studies to determine the response of acute exposure. The study duration, and age of the organisms were chosen to target life stages likely to be affected by salinity change. These studies were conducted following U.S. EPA methods (U.S. EPA, 2002) and contained the following salinity treatments $60,50,40,30,15,8,4,2$ and 0 ppt with four replicates per treatment and 15 organisms per replicate. Studies were conducted under static-renewal conditions in $600 \mathrm{ml}$ beakers. The control salinity for these studies 
was either $15 \mathrm{ppt}$ or $25 \mathrm{ppt}$, the salinity at which the parent stock were cultured and held in the laboratory.

Daily observations were recorded on hatching, behavior and appearance. When hatching was complete, the number of live and dead fry was recorded from each chamber, and percentage hatch was recorded. At the end of the $9 \mathrm{~d}$ exposure period, the fry from each chamber were anaesthetized with MS-222 and percentage survival, mean total length and wet weight were determined. Fry were measured individually to the nearest $\mathrm{mm}$ to calculate a mean and standard deviation for total length and fry were weighed to the nearest $\mathrm{mg}$ to calculate average wet weight.

Reproduction Studies

The breeding success of the sheepshead minnow was examined as a factor of salinity stress. Breeding groups of $C$. variegatus ( 1 male, 4 females) acclimated to $15 \mathrm{ppt}$, were direct transferred to flow-through aquaria $(18 \mathrm{~L})$ at the following salinities: 30,15 (Control), 8, 4, 2 and 0 ppt. Each salinity treatment consisted of two replicates, and the study was conducted for 2 weeks.

The sheepshead minnow is a broadcast spawner with negatively buoyant eggs. To prevent predation on the eggs, the fish were placed in floating breeding tanks $27.94 \mathrm{~cm} \mathrm{x}$ $15.24 \mathrm{~cm} \times 15.24 \mathrm{~cm}$ (Aquatic Ecosystems, Inc. Apopka, FL.). The breeding tanks were constructed of clear plastic, and slotted on the sides and bottom to allow the eggs to fall through and water to circulate. Plastic trays with nitex mesh bottoms were placed on the bottom of each aquaria to facilitate in egg recovery. Due to aggressive behavior, males 
and females were separated by a slotted, plastic divider. The divider was removed from 8:00 am til 12:00 pm each day to allow for mating.

Eggs were collected the morning following each mating prior to 8:00 am. Eggs were siphoned from trays and either further examined for hatching success or transferred to Protocol Safe-Fix II fixative (Fisher Scientific, Atlanta, GA) for dry weight analysis.

For the hatching studies, fertilized eggs $(<24 \mathrm{hrs}$. old $)$ from each salinity treatment were transferred to $600 \mathrm{ml}$ beakers with aerated water of the corresponding salinity. Each salinity treatment consisted of 4 replicates, with 10 eggs per replicate. Embryos were allowed to mature, hatch and grow-out for 7-days post-hatch. Mean dry weights (mg) were determined for each larvae following the grow-out period.

Eggs not used in the hatching study were preserved using a fixative, counted and weighed (dry weight in $\mathrm{mg}$ ) to determine the mean number of eggs per salinity treatment and mean egg weight.

Statistical Analysis

Statistical analysis followed the guidelines outlined by the U.S. EPA (U.S. EPA, 2002). Figures 2.2 and 2.3 outline the statistical approach used in these analyses. Data for length, weight, survival and hatchability were tested for normality and homogeneity of variance using Shapiro-Wilk's and Bartlett's tests, respectively. The estimation of the effects endpoints for normally distributed and homogenous data were made using a parametric ANOVA followed by Dunnett's test. When data were not normally distributed or homogenous, chronic data were analyzed using the nonparametric Steel's Many-one 
Rank test or the Wilcoxon Rank Sum test as appropriate. All statistical analyses were conducted using SPSS for Windows, version 14.0.

Results

Acute Toxicity of Salinity Changes to Adult Estuarine Fish Under Static Conditions

Mortality occurred within 24 hours in the rapid transfer of fish from the control salinity $(30 \mathrm{ppt})$ to the lowest salinity treatments $(0 \mathrm{ppt}, \mathrm{FW})$ for all species studied (Figure 2.4). When transferred from $30 \mathrm{ppt}$ to $0 \mathrm{ppt}$ there was $60 \%$ mortality in $C$. variegatus; $40 \%$ in P. latipinna; $10 \%$ in G. holbrooki and $100 \%$ in F. carpio. Of the three species tested, G. holbrooki has the greatest preference for freshwater conditions. Floridichthys carpio is the least tolerant of freshwater conditions (Figure 2.5). Survival for $C$. variegatus, $P$. latipinna, and $F$. carpio was significantly different from the control in the 0 ppt treatment at $\mathrm{p}<0.05$.

Acute Toxicity of Salinity Changes to Adult Estuarine Fish Under Flow-Through Conditions

No mortality or behavioral changes were observed in any of the gradual salinity change studies for $C$. variegatus, P. latipinna, and G. holbrooki, regardless of the acclimation salinity ( $15 \mathrm{ppt}$ or $30 \mathrm{ppt})$. However, the gradual change for both acclimation scenarios resulted in mortality for $F$. carpio in the 0 ppt treatment. In Scenario I (marine acclimation- $30 \mathrm{ppt}), 70 \%$ mortality occurred in the 0 ppt treatment by 96 hours. In Scenario II (estuarine acclimation-15 ppt), 50\% mortality was observed in the $0 \mathrm{ppt}$ treatment by 96 hours. The latter study was extended for $8 \mathrm{~d}$, at which $100 \%$ mortality 
occurred for the $0 \mathrm{ppt}$ treatment. For both Scenarios, survival of $F$. carpio at 0 ppt was significantly different from the controls at $\mathrm{p}<0.05$.

Fish Early Life Stage (ELS) Toxicity Study

Results for the 60-day C. variegatus study are presented in Table 2.1. Hatching success of $C$. variegatus eggs was significantly decreased $(\mathrm{p}<0.05)$ in the hyposaline treatments of 8,2 , and 0 ppt. Fry survival in the 0 and 2 ppt treatments at 9 days was significantly less than the control (15 ppt). Both the 28-day and 60-day survival of the larvae was significantly decreased in the 0,2 and 30 ppt treatments.

Table 2.2 illustrates the results of the early life stage study with P. latipinna. A significant decrease $(\mathrm{p}<0.05)$ in survival on days 7,28 and 60 occurred in the $0 \mathrm{ppt}$ treatment. All other salinity treatments showed no significant differences from the control (15 ppt).

Hyper Salinity Acute Studies

Results of the 9-day acute early life stage tests with $C$. variegatus varied with the origin of the organisms (Table 2.3). The Florida Bay stock showed no significant differences in hatching, survival, or growth in any of the treatments when compared to the 15 ppt control $(\mathrm{p}<0.05)$. In the non-Florida Bay Stock, no significant differences occurred in hatching success or 9-day survival in any of the salinity treatments; however, growth was significantly reduced. Larvae in the freshwater treatments (FW), 2 ppt, and $60 \mathrm{ppt}$ had significantly smaller mean length than the control ( $25 \mathrm{ppt})$. The mean weight in the freshwater treatment and the $60 \mathrm{ppt}$ treatment was also significantly lower than the control. 
Reproduction Studies

Significant effects on egg production, egg weight and hatched larvae weight were observed in the reproduction studies at $\mathrm{p}<0.05$.

In the embryo-larval hatching study, no significant differences in survival or hatching success in any of the salinity treatments were observed. However, the 7-day old larvae weighed significantly less than the control larvae in the 4 ppt and 8 ppt treatments. It should be noted here that while a small amount of eggs was produced in the FW treatment, none were fertilized and that treatment was not used in this study. Results of this study are presented in Figures 2.6, 2.7 and Tables 2.4, 2.5).

Fish fecundity (as mean number of eggs per 2-week period) was affected by salinity in the both the highest (30 ppt) and lowest (FW) treatment (Figure 2.8). Both treatments resulted in fewer number of eggs than the control salinity of $15 \mathrm{ppt}$. The mean dry weight $(\mathrm{mg})$ of the eggs was also significantly different $(\mathrm{p}<0.05)$ than the control in the $30 \mathrm{ppt}, 4 \mathrm{ppt}$, and $2 \mathrm{ppt}$ treatments. In all three of these treatments, the mean egg weight was significantly greater than the control (Figure 2.9).

\section{Discussion}

Parts of the Comprehensive Everglades Restoration Plan (CERP) propose to modify the South Dade Conveyance System (SDCS) and redirect freshwater back into the main slough entering Florida Bay (Lorenz and Serafy, 2006). Restoration related changes in the timing and delivery of freshwater can have direct and indirect effects on the aquatic biota in the area (Ault et al. 1999). 
Salinity has been shown to differentially influence the growth and development of many species of fish (Beouf and Payan, 2001). Effects on egg fertilization, yolk sac absorption, early development and growth have all been attributed to salinity as a causative factor (Beouf and Payan, 2001). The energetic costs of osmoregulation in teleost fishes have been estimated ranging from 10 to $>50 \%$ of the total energy budget of the organism (Beouf and Payan, 2001). There is a trend that the energetic costs of osmoregulation increase with the degree of change away from iso-osmotic conditions (Morgan and Iwama, 1991).

My research showed that acute, abrupt salinity changes had adverse effects on fish survival, growth and hatching success as a result of salinity stress. All species, to a varying degree and dependant upon life stage, exhibited sensitivity to extreme changes to hypo-and hypersaline conditions. In comparison to adults, the larvae and neonates of $C$. variegatus and $P$. latipinna were more tolerant to rapid upward and downward shifts in salinity. This finding supports field data for these two species in that they both spawn in shallow, nearshore areas of variable temperature and salinity and their offspring are subject to such conditions during growout. (Nordlie, 2000). Nordlie (2000) also reported that the reproduction for these species is maximized in the summer months, which coincides with the wet season in South Florida. As such, northeastern Florida Bay is subject to fluctuating and sometimes rapid inputs of freshwater. Therefore, the ability of young fish to withstand these changes becomes paramount. Unlike larvae and neonates, the adults of these species have a much greater ability to move out of areas that are experiencing a dramatic salinity shift. Thus, salinity could become a driver affecting the distribution of various life stages. 
The temporal nature of the salinity change was shown to have a pronounced effect and thus must also be taken into consideration when implementing the CERP. Although tolerant of a wide range of salinities ( 0 to $>125 \mathrm{ppt}$ ), when gradually acclimated, $C$. variegatus has shown a high degree of mortality when exposed to rapid changes in salinity (Serafy, 1997; Nordlie, 2006). Hence, the rate of salinity change that a fish experiences is a likely factor in their ability to tolerate variable salinity environments (Nordlie, 2006). As stated above, adult C. variegatus in the current study showed a higher overall sensitivity (as mortality) to salinity change than young fish. However, this only occurred during rapid change (direct transfer) events. Rapid change events can occur in northeastern Florida Bay in association with storm events and anthropogenic activities such as the opening of sluice gates. The more gradual change (over $24 \mathrm{hrs)}$ scenarios examined in this study showed that all species, except for F. carpio, could adequately adapt to the change. There is little life history information available on $F$. carpio, and previous work has suggested the use of $C$. variegatus as a surrogate due to these data gaps (Faunce and Serafy, 2002). This study showed that F. carpio has a much narrower salinity tolerance than $C$. variegatus and may serve as a good indicator for establishing a low salinity value for areas of Florida Bay.

For C. variegatus populations in Florida Bay, variable salinity conditions are an everpresent challenge. Both phenotypic plasticity and genetic selection within the species allows for adaptation to the erratic environmental conditions in the area. With the exception of full freshwater, C. variegatus breeding groups were able to successfully re produce in all salinities tested. Though some significant differences were found in fecundity and egg size over different salinities, the fact that successful fertilization, larval 
development, and hatching occurred indicates the plasticity of this species. In comparison to the C. variegatus embryos obtained from a commercial supplier, the Florida Bay stock exhibited a high degree of tolerance for salinity change. This response indicates that the local populations of $C$. variegatus have a genetically selected tolerance to wide scale salinity changes that is not found in non-Florida Bay populations. Holt and Holt (2003) showed that Spotted Seatrout eggs and larvae responses to salinity change were linked to a heritable adaptation to their local salinity regimes. It therefore becomes essential to prioritize the study of the responses of native and local organisms when making management decisions.

With respect to the CERP, maintenance of a salinity gradient supportive of mangrove and estuarine communities is required to restore critical South Florida ecosystems (Davis et al., 2005). Data gaps on the effects of water redistribution (or lack of redistribution) on bay communities must be addressed to maximize the restoration of Florida Bay and associated natural systems in this watershed, and to understand potential risks and reduce uncertainties concerning biological impacts of proposed CERP activities. Based on field sampling data, Lorenz (1999) postulated that the history the water management practices in south Florida has lowered both the abundance and biomass of the demersal fish community in mangrove habitat of northeastern Florida Bay. The toxicological salinity studies conducted herein indicate that rapid and prolonged changes in salinity will indeed affect the survival, growth and reproduction of key resident species of demersal fish in Florida Bay. The implications to higher trophic levels that depend upon these fish as a prey base is clear, and both anecdotal and scientific evidence exists to link the decline in 
prey base as a factor in the declines in such predatory species as wading birds, alligators, crocodiles, and piscivorous fishes (Lorenz, 1999).

Future studies are required to target reproduction and critical embryo-larval development as key areas for detecting long-term population effects of salinity change on fish populations in Florida Bay. Osmotic, metabolic and behavioral effects associated with salinity changes must also be evaluated. Further work on hypersaline effects is also necessary for a broader understanding of the full salinity regime of Florida Bay. 
Ault JS, Luo J, Smith, SG, Serafy JE, Wang J, Humston, R, Diaz GA (1999) A spatial dynamic multistock production model. Can J Fish Aquat Sci 56:4-25

Beouf G, Payan P (2001) How should salinity influence fish growth? Comp Biochem Physiol 130: 411-423.

Chen JC, Lin J, Chen C, Jin M (1996) Survival, growth and intermolt period of juvenile Peneaus chinensis reared at different combinations of salinity and temperature. $\mathrm{J}$ Exp Mar Biol Ecol 204: 169-178

Christensen JD, Monaco ME, Lowery TA (1997) An index to assess the sensitivity of Gulf of Mexico species to changes in estuarine salinity regimes. Gulf Res Reps 9: 219-229

Davis SM, Childers DL, Lorenz JJ, Wanless HR, Hopkins TE (2005) A conceptual model of ecological interactions in the mangrove estuaries of the Florida Everglades. Wetlands 25: 832-842

DBHYDRO Database. South Florida Water Management District, West Palm Beach, Florida. www.sfwmd.gov/org/ema/dbhydro/

Faunce CH, Serafy JE (2002) Fish utilization of mangrove fringe habitats within Southeastern Florida: Final Report. Submitted to: United States Department of the Interior, U.S.G.S.-Biological Resources Division, Florida/Caribbean Science Center, restoration Ecology Branch, Center for Coastal Geology \& Regional Marine Studies, St. Petersburg, Florida

Holt GJ, Holt SA (2003) Effects of variable salinity on reproduction and early life stages of Spotted Seatrout. In: Bortone SA(ed) Biology of the Spotted Sea Trout, CRC Press, LLC,Boca Raton, Florida, pp 135-146

Ley JA, Montague CL, McIvor CC (1994) Food habits of mangrove fishes: a comparison along estuarine gradients in northeastern Florida Bay. Bull Mar Sci 54:881-889

Lodge TE (2005) The everglades handbook: understanding the ecosystem, 2nd edn..CRC Press, Boca Raton, Florida

Lorenz JJ (1999) The response of fishes to physiochemical changes in the mangroves of northeast Florida Bay. Estuaries. 22 (2B): 500-517.

Lorenz JJ, Serafy JE (2006) Subtropical wetland fish assemblages and changing salinity regimes: Implications for everglades restoration. Hydrobiologia 561: 401-422 
Montagna PA, Alber M, Doering P, Connor MS (2002) Freshwater inflow: science, policy, management. Estuaries 25: 1243-1245

Morgan JD, Iwama G (1991) Effects of salinity on growth, metabolism and ion regulation in juvenile rainbow and steelhead trout (Onchyrhynchus mykiss) and fall Chinook salmon (Oncorhynchus tshawytscha). Can. J. Aquat. Sci. 48:2083 2094.

Nordlie FG (2000) Patterns of reproduction and development of selected resident teleosts of Florida salt marshes. Hydrobiologia 434: 165-182

Nordlie FG (2006) Physiochemical environments and tolerances of cyprinodontoid fishes found in estuaries and salt marshes of eastern North America. Rev Fish Biol Fisheries 16: 51-106

Serafy JE, Lindeman KC, Hopkins TE, Ault JS (1997) Effects of freshwater canal discharge on fish assemblages in a subtropical bay: field and laboratory observations. Mar Ecol Prog Ser 160: 161-172

Tsuzuki MY, Cavalli RO, Bianchini A (2003) Effect of salinity on survival, growth, and oxygen consumption of the pink shrimp Farfantepenaeus paulensis (PerezFarfante 1967). J Shell Res 22: 555-559

US EPA (2002) EPA-821-R-02-014.Short-term methods for estimating the chronic toxicity of effluents and receiving waters to marine and estuarine organisms. Washington DC

Varsamos S, Nebel C, Charmantier G (2005) Ontogeny of osmoregulation in postembryonic fish: a review. Comp Biochem Phys 141: 401-429 


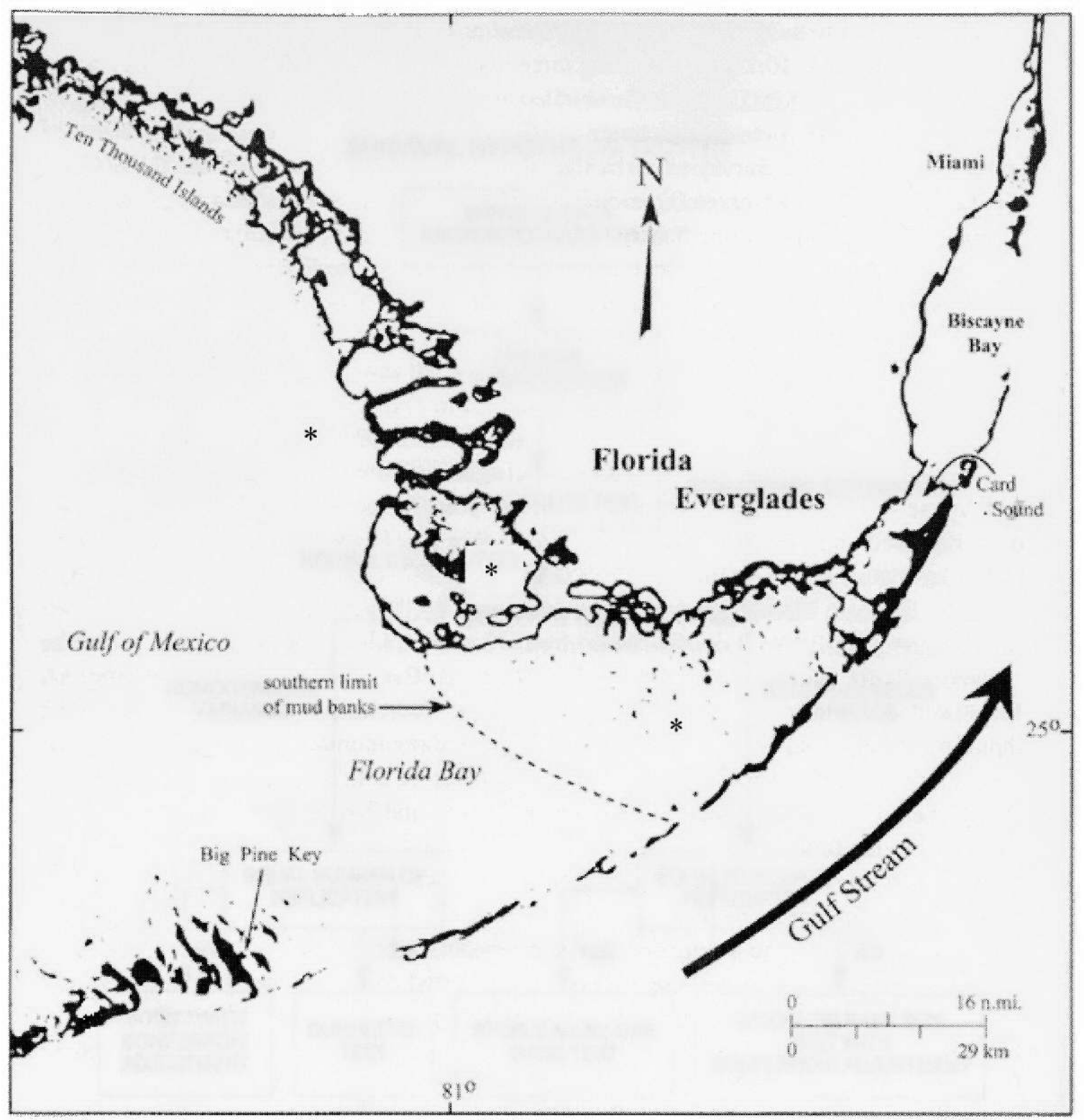

Figure 2.1 South Florida and Florida Bay (from USGS). 


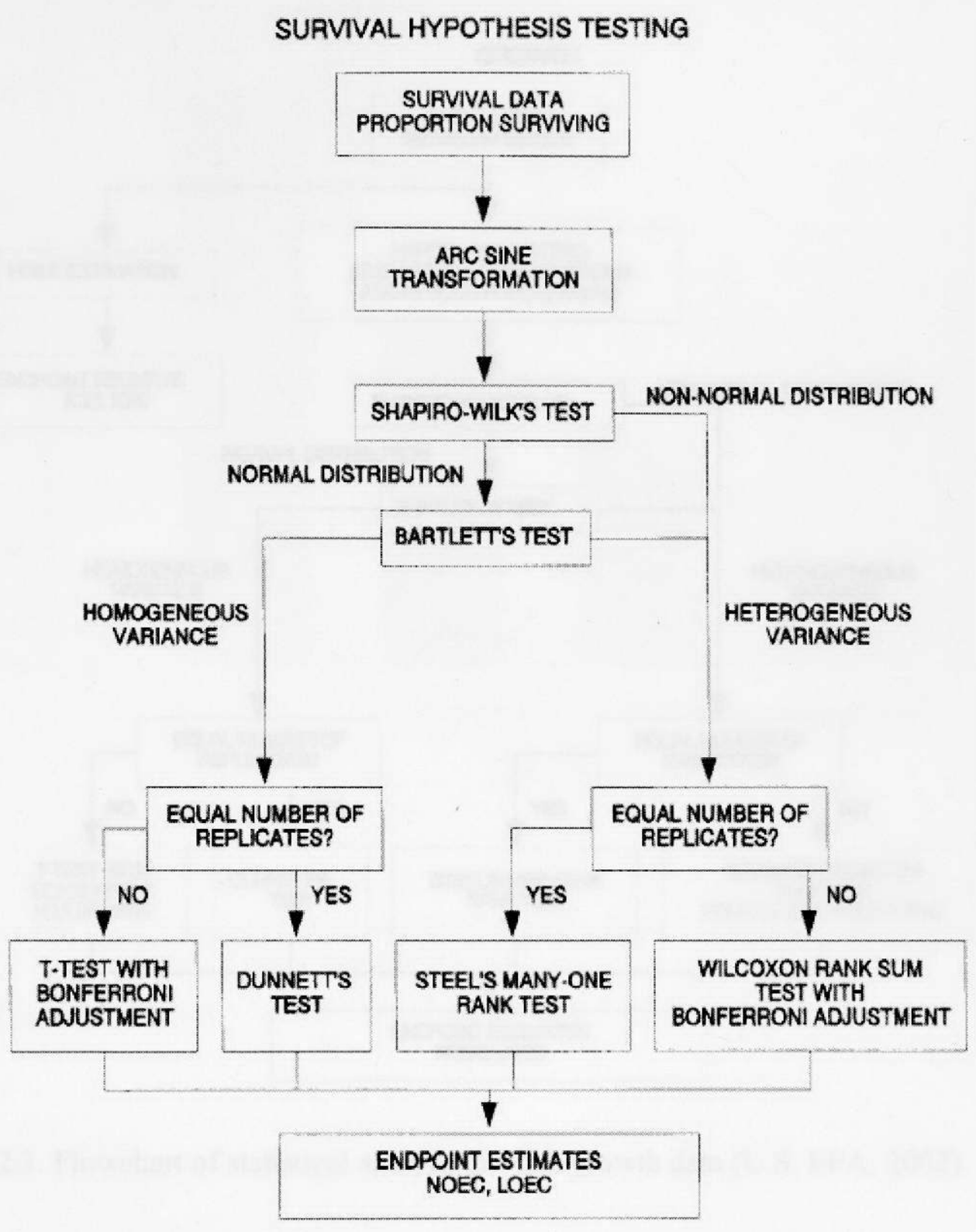

Figure 2.2. Flowchart for statistical analysis of fish survival data (U.S. EPA, 2002). 


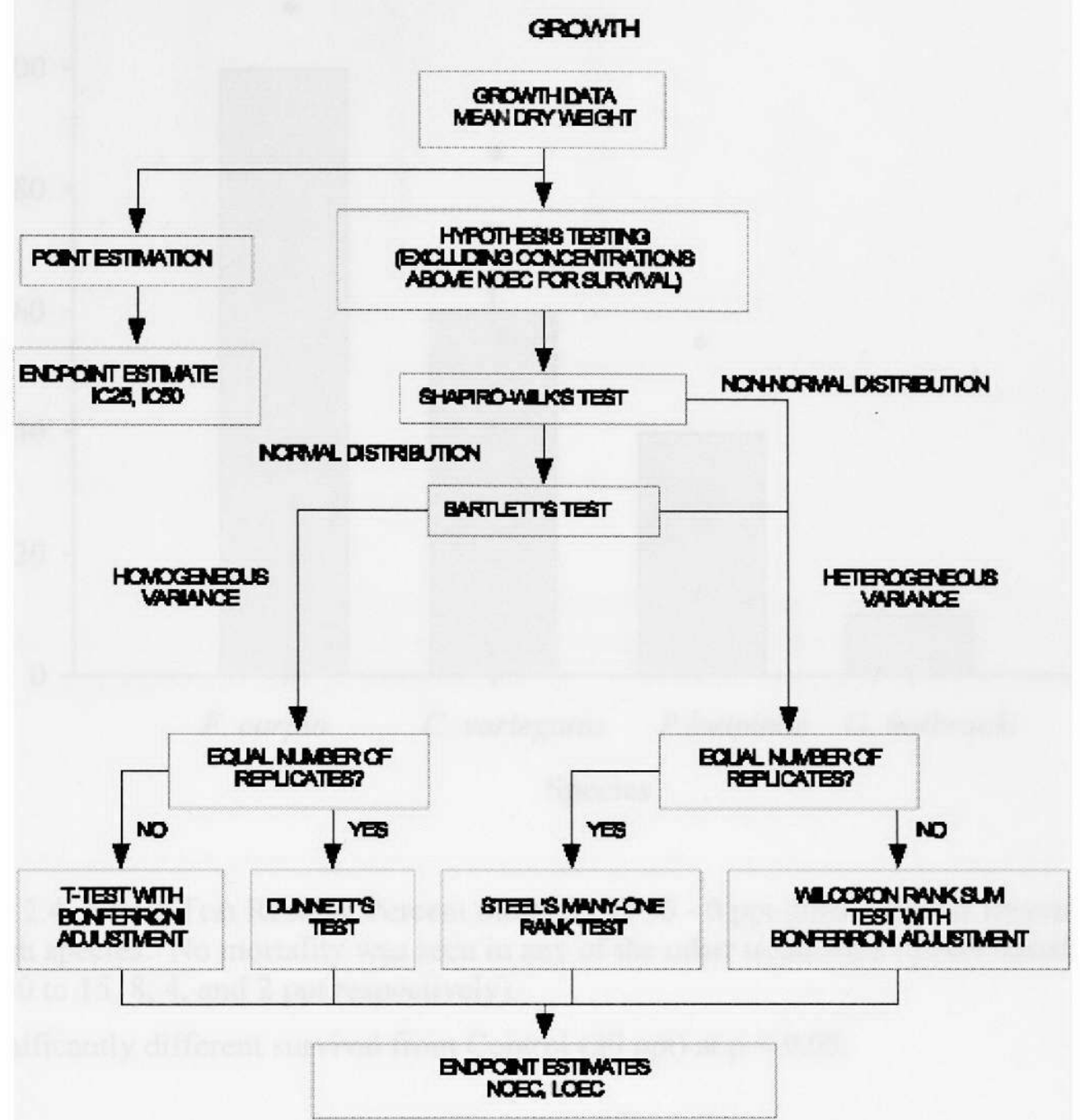

Figure 2.3. Flowchart of statistical analysis for fish growth data (U.S. EPA, 2002). 


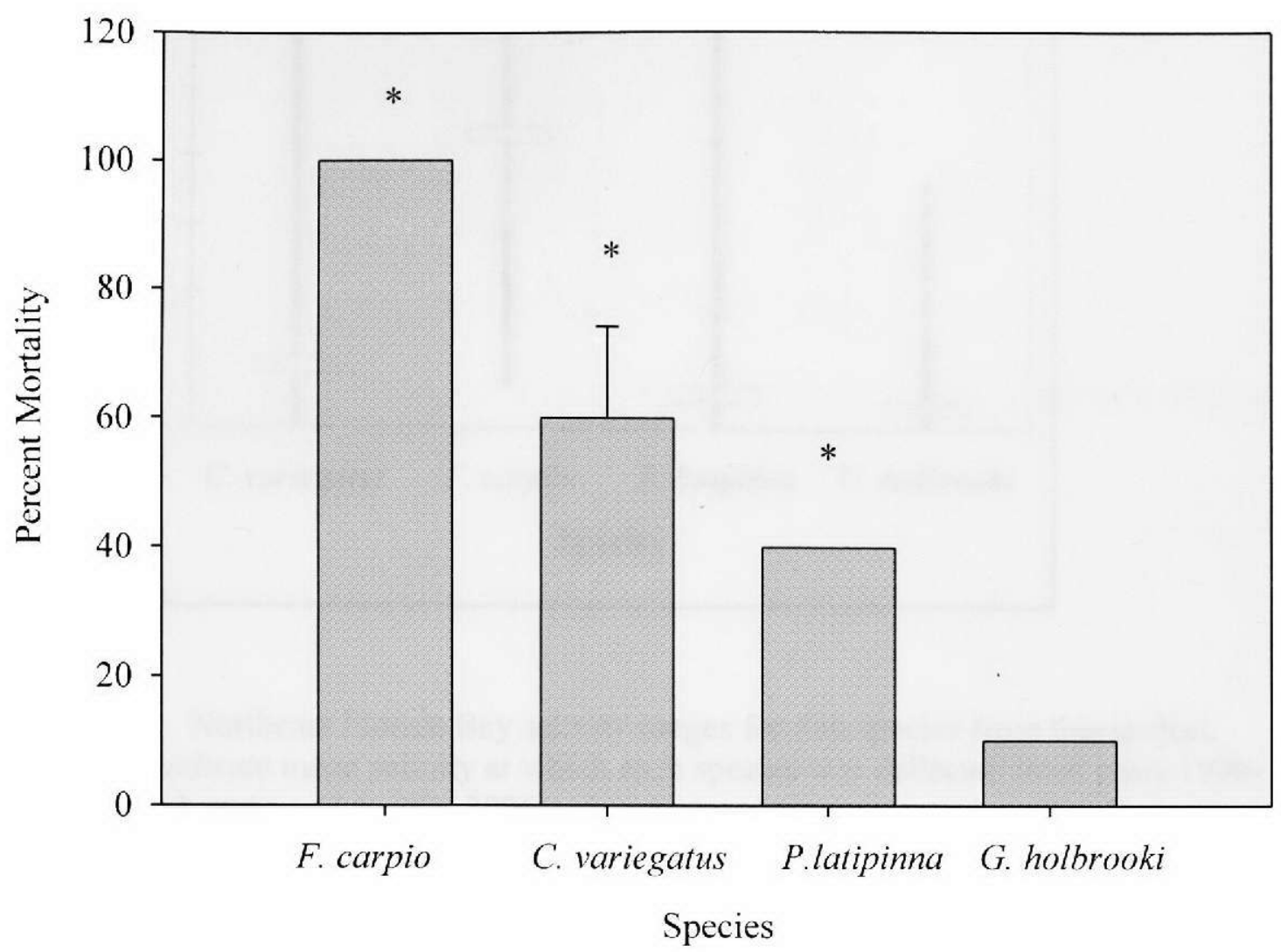

Figure 2.4. Static Test Results: Percent mortality at $30-0$ ppt direct transfer treatment for each species. No mortality was seen in any of the other treatments (direct transfer from 30 to $15,8,4$, and 2 ppt respectively).

* Significantly different survival from Control (30 ppt) at $\mathrm{p}<0.05$. 


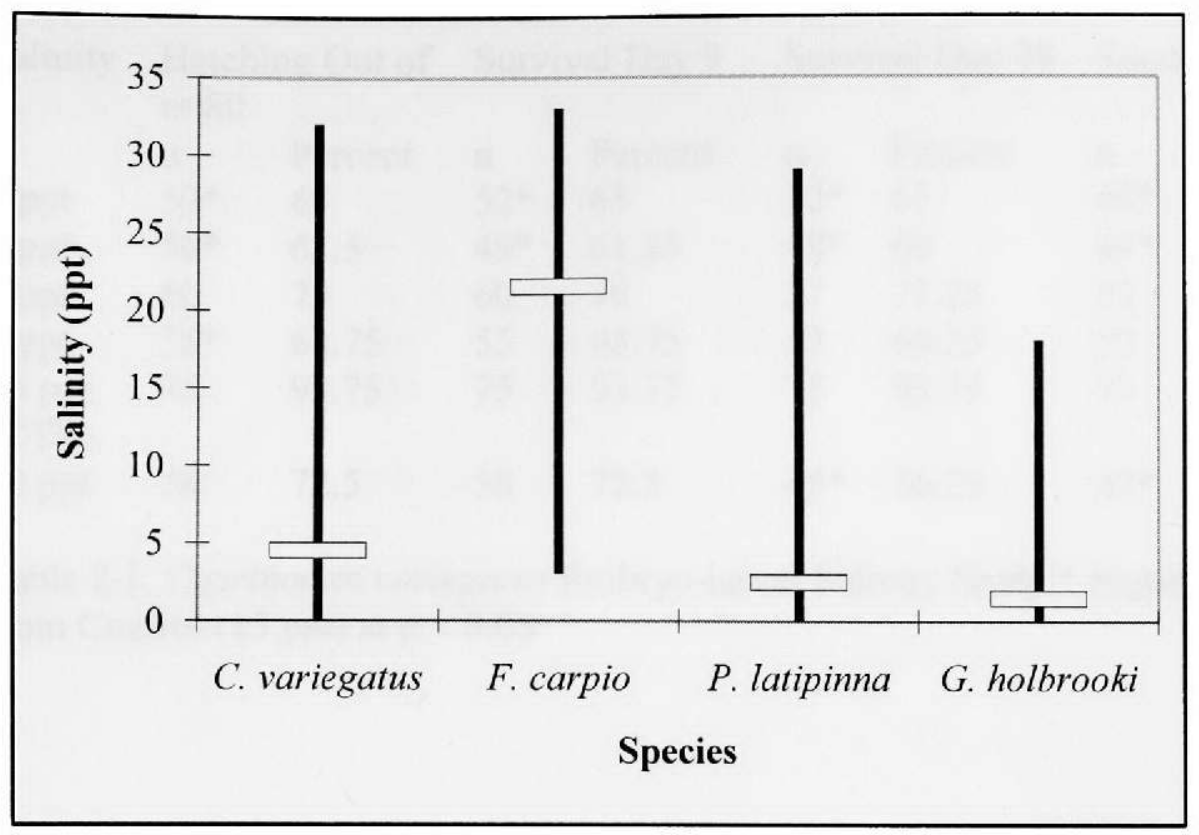

Figure 2.5. Northeast Florida Bay salinity ranges for fish species from this project. Crossbars indicate mean salinity at which each species was collected from years 19902006 (from Lorenz and Serafy, 2006). 
Salinity Hatching Out of Survival Day 9 Survival Day 28 Survival Day 60 $\mathrm{n}=80$

$\begin{array}{lllllllll} & \mathrm{n} & \text { Percent } & \mathrm{n} & \text { Percent } & \mathrm{n} & \text { Percent } & \mathrm{n} & \text { Percent } \\ 0 \mathrm{ppt} & 52^{*} & 65 & 52^{*} & 65 & 52^{*} & 65 & 49^{*} & 61.25 \\ 2 \mathrm{ppt} & 50^{*} & 62.5 & 49^{*} & 61.25 & 48^{*} & 60 & 44^{*} & 55 \\ 4 \mathrm{ppt} & 60 & 75 & 60 & 75 & 57 & 71.25 & 53 & 66.25 \\ 8 \mathrm{ppt} & 55^{*} & 68.75 & 55 & 68.75 & 53 & 66.25 & 53 & 66.25 \\ 15 \mathrm{ppt} & 75 & 93.75 & 75 & 93.75 & 75 & 93.75 & 73 & 91.25 \\ \text { (CTL) } & & & & & & & & \\ 30 \mathrm{ppt} & 58 & 72.5 & 58 & 72.5 & 45^{*} & 56.25 & 43^{*} & 53.75\end{array}$

Table 2.1. Cyprinodon variegatus Embryo-larval Salinity Study.* Significantly different from Control (15 ppt) at $\mathrm{p}<0.05$ 


\begin{tabular}{lllllll} 
Salinity & \multicolumn{2}{l}{ Survival Day 7} & \multicolumn{2}{l}{ Survival Day 28 } & \multicolumn{2}{l}{ Survival Day 60 } \\
& $\mathrm{n}=80$ & Percent & $\mathrm{n}$ & Percent & $\mathrm{n}$ & Percent \\
$0 \mathrm{ppt}$ & $66^{*}$ & 82.5 & $66^{*}$ & 82.5 & $62^{*}$ & 77. \\
$2 \mathrm{ppt}$ & 79 & 98.75 & 79 & 98.75 & 76 & 95 \\
$4 \mathrm{ppt}$ & 77 & 96.25 & 77 & 96.25 & 77 & 96.25 \\
$8 \mathrm{ppt}$ & 80 & 100 & 80 & 100 & 79 & 98.75 \\
$15 \mathrm{ppt}$ & 80 & 100 & 80 & 100 & 80 & 100 \\
(CTL) & & & & & & \\
$30 \mathrm{ppt}$ & 80 & 100 & 80 & 100 & 80 & 100
\end{tabular}

Table 2.2. Poecilia latipinna Chronic Neonate-fry Salinity Study. *Significantly different from Control $(15 \mathrm{ppt})$ at $\mathrm{p}<0.05$ 


\begin{tabular}{|c|c|c|c|c|c|c|}
\hline \multirow[t]{2}{*}{ Salinity } & \multicolumn{2}{|c|}{$\begin{array}{l}\text { Hatching Out of } \\
n=60\end{array}$} & \multicolumn{2}{|c|}{ Survival Day 9} & \multicolumn{2}{|c|}{ Growth (Avg.) } \\
\hline & $\mathrm{n}$ & Percent & $\mathrm{n}$ & Percent & $\begin{array}{l}\text { Weight } \\
(\mathrm{mg})\end{array}$ & $\begin{array}{l}\text { Length } \\
(\mathrm{mm})\end{array}$ \\
\hline $0 \mathrm{ppt}$ & 59 & 98.3 & 59 & 98.3 & 0.51 & 4.72 \\
\hline $2 \mathrm{ppt}$ & 60 & 100 & 60 & 100 & 0.47 & 4.91 \\
\hline $4 \mathrm{ppt}$ & 60 & 100 & 59 & 98.3 & 0.35 & 4.38 \\
\hline $8 \mathrm{ppt}$ & 60 & 100 & 60 & 100 & 0.30 & 4.43 \\
\hline $\begin{array}{l}15 \mathrm{ppt} \\
\text { (CTL) }\end{array}$ & 59 & 98.3 & 59 & 98.3 & 0.56 & 5.28 \\
\hline $20 \mathrm{ppt}$ & 60 & 100 & 60 & 100 & 0.71 & 5.73 \\
\hline $25 \mathrm{ppt}$ & 59 & 98.3 & 56 & 93.3 & 0.64 & 5.10 \\
\hline $30 \mathrm{ppt}$ & 60 & 100 & 60 & 100 & 0.64 & 5.01 \\
\hline $40 \mathrm{ppt}$ & 60 & 100 & 60 & 100 & 0.56 & 4.98 \\
\hline $50 \mathrm{ppt}$ & 56 & 93.3 & 51 & 85 & 0.57 & 4.82 \\
\hline $60 \mathrm{ppt}$ & 53 & 88.3 & 53 & 88.3 & 0.40 & 4.09 \\
\hline
\end{tabular}

a) Cyprinodon variegatus 9-Day Embryo-larval Study: Native Stock

No treatments were significantly different from Control (15 ppt) at $p<0.05$

Salinity Hatching Out of Survival Day 9 Growth (Avg.) $\mathrm{n}=60$

$\mathrm{n} \quad$ Percent $\mathrm{n}$ Percent Weight Length

$\begin{array}{lllllll}0 \mathrm{ppt} & 59 & 98.3 & 59 & 98.3 & 0.58^{*} & 5.63^{*} \\ 2 \mathrm{ppt} & 60 & 100 & 60 & 100 & 1.14 & 7.34^{*} \\ 4 \mathrm{ppt} & 60 & 100 & 60 & 100 & 1.23 & 8.41 \\ 8 \mathrm{ppt} & 59 & 98.3 & 58 & 96.7 & 1.10 & 8.27 \\ 15 \mathrm{ppt} & 60 & 100 & 58 & 96.7 & 1.23 & 8.42 \\ 20 \mathrm{ppt} & 60 & 100 & 60 & 100 & 1.24 & 8.36 \\ 25 \mathrm{ppt} & 59 & 98.3 & 58 & 96.7 & 1.07 & 7.96 \\ (\mathrm{CTL}) & & & & & & \\ 30 \mathrm{ppt} & 60 & 100 & 60 & 100 & 1.18 & 8.12 \\ 40 \mathrm{ppt} & 52 & 83.3 & 52 & 86.6 & 1.05 & 7.81 \\ 50 \mathrm{ppt} & 56 & 93.3 & 50 & 83.3 & 0.93 & 7.46 \\ 60 \mathrm{ppt} & 52 & 86.7 & 45 & 75 & 0.75^{*} & 6.96^{*}\end{array}$

b) Cyprinodon variegatus 9-Day Embryo-larval Study: Non-native Stock. *Significantly different from Control $(25 \mathrm{ppt})$ at $\mathrm{p}<0.05$.

Table 2.3. Results of Embryo-larval studies with native (a) and non-native stock (b). 


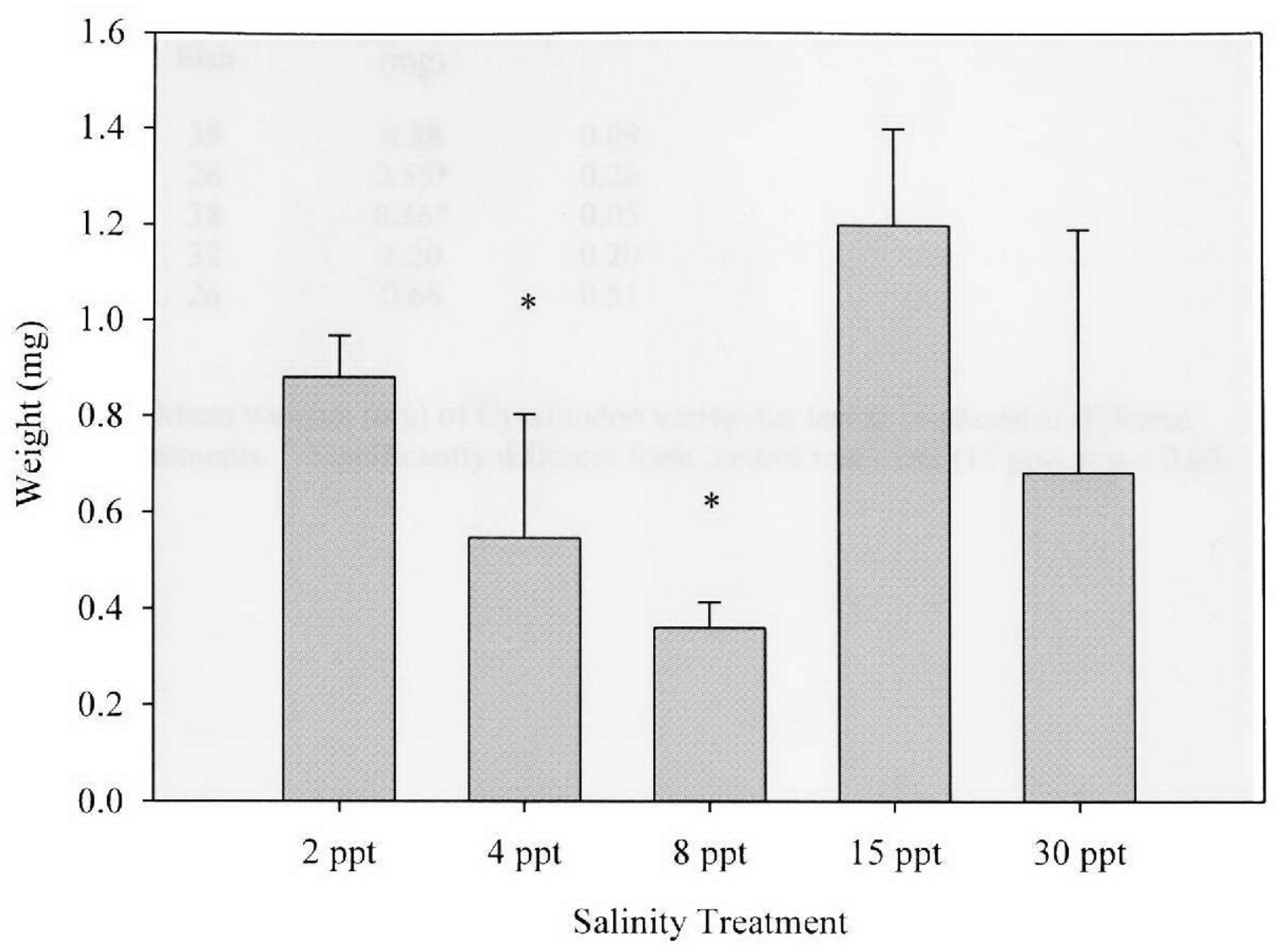

Figure 2.6. Mean weights (mg) of Cyprinodon variegatus larvae produced in different salinity treatments. * Significantly different from control treatment $(15 \mathrm{ppt})$ at $\mathrm{p}<0.05$. ( 4 ppt, $\mathrm{p}=0.0141 ; 8 \mathrm{ppt}, \mathrm{p}=0.0021$ ) 


$\begin{array}{cccc}\text { Salinity } & \begin{array}{c}\text { Number } \\ \text { Fish }\end{array} & \begin{array}{c}\text { Mean } \\ \text { Weight/TRT } \\ (\mathrm{mg})\end{array} & \text { St.Dev } \\ 2 \mathrm{ppt} & 39 & 0.88 & 0.09 \\ 4 \mathrm{ppt} & 26 & 0.55^{*} & 0.26 \\ 8 \mathrm{ppt} & 38 & 0.36^{*} & 0.05 \\ 15 \mathrm{ppt} & 32 & 1.20 & 0.20 \\ 30 \mathrm{ppt} & 26 & 0.68 & 0.51\end{array}$

Table 2.4. Mean weights ( $\mathrm{mg}$ ) of Cyprinodon variegatus larvae produced at different salinity treatments. ${ }^{*}$ Significantly different from control treatment $(15 \mathrm{ppt})$ at $\mathrm{p}<0.05$. 


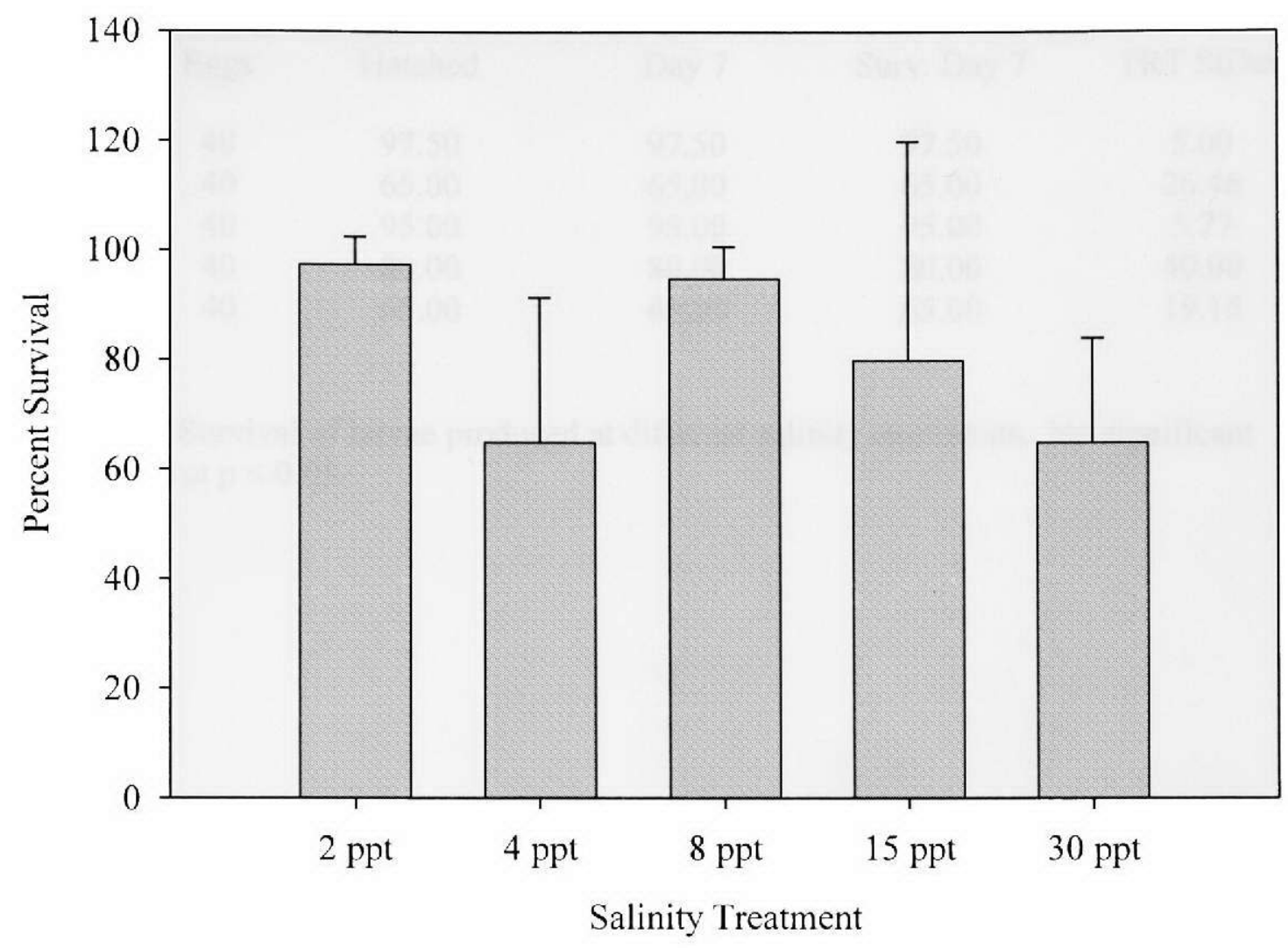

Figure 2.7. Survival of larvae produced at different salinity treatments. No significant differences at $\mathrm{p}<0.05$. 


$\begin{array}{cccccc}\text { Salinity } & \begin{array}{c}\text { Number } \\ \text { Eggs }\end{array} & \begin{array}{c}\text { Percent } \\ \text { Hatched }\end{array} & \begin{array}{c}\text { Percent Surv. } \\ \text { Day } 7\end{array} & \begin{array}{c}\text { TRT Mean } \\ \text { Surv. Day } 7\end{array} & \text { TRT StDev } \\ 2 \mathrm{ppt} & 40 & 97.50 & 97.50 & 97.50 & 5.00 \\ 4 \mathrm{ppt} & 40 & 65.00 & 65.00 & 65.00 & 26.46 \\ 8 \mathrm{ppt} & 40 & 95.00 & 95.00 & 95.00 & 5.77 \\ 15 \mathrm{ppt} & 40 & 80.00 & 80.00 & 80.00 & 40.00 \\ 30 \mathrm{ppt} & 40 & 65.00 & 65.00 & 65.00 & 19.15\end{array}$

Table 2.5. Survival of larvae produced at different salinity treatments. No significant differences at $\mathrm{p}<0.05$. 


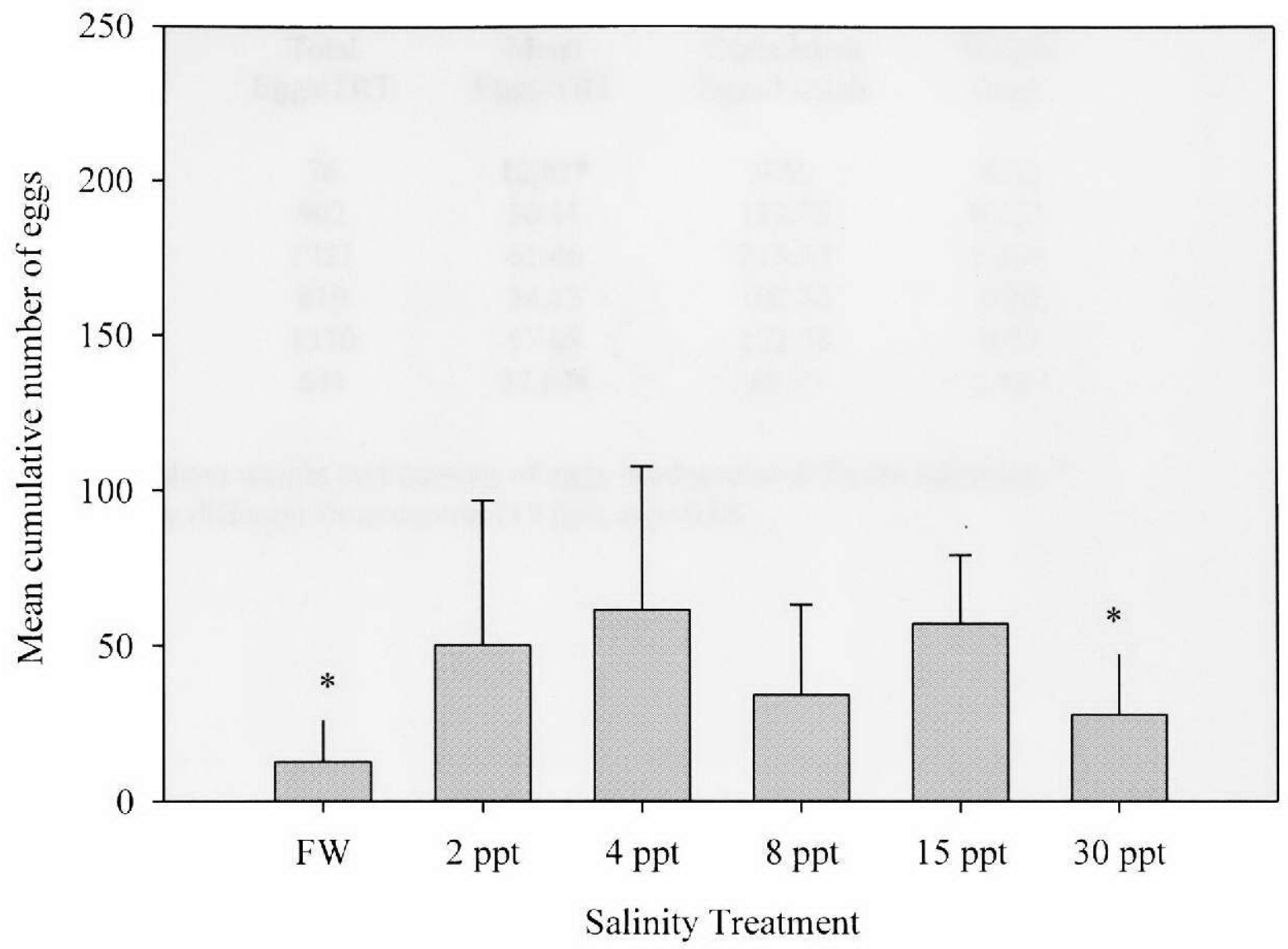

Figure 2.8. Mean cumulative number of eggs produced at different salinity treatments. * Significantly different from control $(15 \mathrm{ppt})$ at $\mathrm{p}<0.05$. ( FW, $\mathrm{p}=0.0263 ; 30 \mathrm{ppt}, \mathrm{p}=$ $0.0210)$. 


$\begin{array}{ccccc}\text { Salinity } & \begin{array}{c}\text { Total } \\ \text { Eggs/TRT }\end{array} & \begin{array}{c}\text { Mean } \\ \text { Eggs/TRT }\end{array} & \begin{array}{c}\text { Mean } \\ \text { Cumulative } \\ \text { Eggs/Female }\end{array} & \begin{array}{c}\text { Mean Egg } \\ \text { Weight } \\ (\mathrm{mg})\end{array} \\ \mathrm{FW} & 76 & 12.67^{*} & 9.50 & 0.22 \\ 2 \mathrm{ppt} & 902 & 50.11 & 112.75 & 0.33^{*} \\ 4 \mathrm{ppt} & 1721 & 61.46 & 215.13 & 0.33^{*} \\ 8 \mathrm{ppt} & 819 & 34.13 & 102.38 & 0.28 \\ 15 \mathrm{ppt} & 1370 & 57.08 & 171.25 & 0.27 \\ 30 \mathrm{ppt} & 641 & 27.87^{*} & 80.13 & 0.33^{*}\end{array}$

Table 2.6. Mean weight and number of eggs produced at different salinities. * Significantly different from control (15 ppt) at $\mathrm{p}<0.05$. 


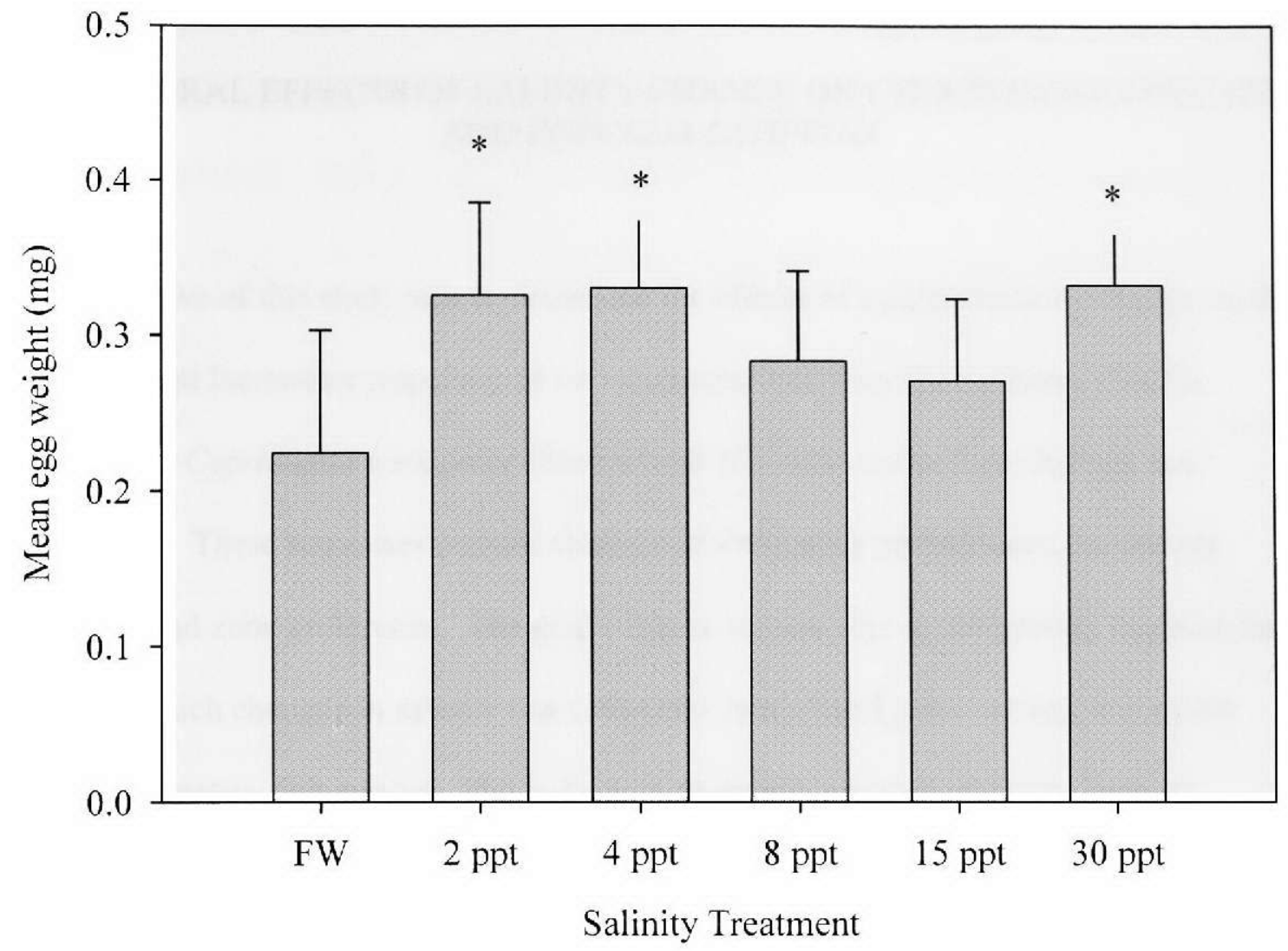

Figure 2.9. Mean egg weight $(\mathrm{mg})$ produced at different salinity treatments. * Significantly different from control $(15 \mathrm{ppt})$ at $\mathrm{p}<0.05$. 
Chapter III

\title{
BEHAVIORAL EFFECTS OF SALINITY CHANGE ON CYPRINODONVARIEGATUS AND POECELIA LATIPINNA
}

\begin{abstract}
The objective of this study was to determine the effects of a pulsed salinity change on the behavior and locomotor responses of two estuarine fish: Poecilia latipinna (Sailfin Molly) and Cyprinodon variegatus (Sheepshead Minnow) under flow-through test conditions. These responses include changes in swimming performance, locomotor behavior and zone preference. The goal of these studies is to quantitatively examine the ways in which changes in salinity can effects the established behavior and locomotor patterns of native fish species. The endpoints analyzed included velocity; distance moved; distance to a point; distance to a zone border; presence and time in zone; heading; turn angle; angular velocity; and meandering. Data were analyzed using the Before-After Control-Impact (BACI) model. Statistically significant differences in locomotor pattern endpoints ( $\mathrm{p}<0.05$, two-tailed test) were found for P. latipinna. The endpoints of mean meander, mean angular velocity, mean heading and mean turn angle showed generally higher values in the impact fish after the point source of freshwater was introduced. For the distance and time parameters, no statistical differences were found. For C. variegatus, no statistical differences between the control and impact fish were found between the before and after periods for any endpoint.
\end{abstract}


Introduction

Salinity is one of the strongest drivers for the abundance and distribution of aquatic organisms. Understanding the role that salinity plays in both physiological and behavioral responses is the focus of this dissertation and is of applied importance to management activities in northeastern Florida Bay. The goal of these studies is to quantitatively examine the ways in which changes in salinity can affect the established behavior and locomotor patterns of native fish species.

Laboratory bioassays, though relevant, are not and should not be the sole source information used to make relevant environmental management decisions. Behavioral endpoints are considered to be of great value for elucidating the sub-lethal effects of stressors (Olla et al 1980). Verplanck (1957) defined behavior as the "complex of observable, recordable, or measureable activities of a living animal." Many behavioral responses are the result of either biological, physical, or chemical stimuli and are considered adaptive in origin (Rand, 1985). When confronted with an adverse environmental condition, this adaptive behavior allows the animal to move to or maintain a favorable environment thereby eliminating the negative effects upon itself. However, behavioral changes manifested as a result of anthropogenic changes to the environment are considered non-adaptive (Olla et al 1980). Often, though not initially, departures from behavioral norms can have negative consequences on the individual organism or the population as a whole.

When confronted with an environmental perturbation. the initial response of an organism is a change in behavior, such as avoidance of a negative stimulus (Slobodki, 
1968). If such a behavioral response removes or mitigates the adverse effects of the stimuli, then the cost(s) to the organism is reduced or eliminated entirely. Olla et al. (1980) proposed that in order for an organism to successfully respond to a stimuli, three criteria must be met: (1) the organism must be able to sense the stimuli; (2) the organism must recognize the stimulus as deleterious; and (3) the organism must be able to respond appropriately. The response pathways of an animal exposed to an environmental disturbance are outlined in Figure 3.1.

Behavioral toxicity (Marcucella and Abramson, 1978; Rand 1985) describes a situation where a stressor (chemical or otherwise) precipitates a behavioral change in an organism that exceeds the normal variability for that organism. In an ecological context, those stressors that affect an organism's ability to survive, tolerate, or adapt to the environment are the most significant. Chemical stressors can alter both the sensory perception and motor activity of an organism. In fish, the sensory modalities include chemoreception, phototaxis and rheotaxis while the motor activities include locomotor patterns and swimming performance. Natural adaptive responses such as feeding behavior, courtship and mating rituals, preference/avoidance of certain environmental conditions, and territoriality can ultimately be affected by the introduction of a stressor to the aquatic environment. Hence, altered behavior in any of the above circumstances could not only reduce the fitness and/or survival of the individual, but could also have long ranging implications on the population level (Rand 1985).

The locomotor movement of an aquatic organism may be characterized as directed or undirected. Directed movement is in response to an orientative cue such as light, food odor, pheromones or an abiotic gradient (temperature, salinity). Conversely, 
undirected movement is random and not related to a directional stimulus (circadian and seasonal rhythms). Under natural conditions, directed movements lead to the distribution of organisms within a favorable environment or gradient and allow the organism to exist within conditions conducive to normal physiological performance. The adaptive response is also critical for the localization of food and prey and the identification of conspecifics, mates and nesting/spawning sites.

When exposed to a toxic substance in the environment, a fish may respond in several ways: avoidance, whereby the fish orients away from the substance; attraction, whereby the fish approaches the substance; or the fish may ignore the substance altogether. Though initially beneficial, avoidance of toxic substances (especially in sublethal concentrations) can also cause chronic problems as the fish may be forced into suboptimal conditions for long-term survival, feeding or reproduction.

Laboratory behavioral studies with salinity have been conducted for many taxa in relation to examining the effects of salinity on organism distribution. Some recent work by Jury et al. (1994) examined the behavioral effects of salinity change on American lobsters (Homarus americanus). Their studies were designed to establish (1) whether lobsters detected salinity changes that were on the same magnitude as occurred in estuaries, and (2) what locomotor responses (if any) the lobsters exhibited to such change. The lobsters were found to not only detect reductions in salinity, but also avoid them. An interesting outcome of the studies was the finding that there exists a gender difference in the behavioral response of the lobster to salinity changes. Female lobsters found lower salinities more aversive than males, leading the authors to conclude that gender-driven behavioral responses to salinity were, in part, responsible for the 
distribution and movements of lobsters in estuaries. Male lobsters have been show to dominate in the lower salinity estuarine habitats.

Much work has been done examining the effects of salinity change on the movements and distribution of crustacean larvae (Forward Jr., 1989). Behavioral responses to salinity gradients have been shown to dictate the location of zoeal larvae within the water column. However, there is less work that examines the rate and/or degree of salinity change required to elicit a behavioral response. Forward Jr. (1989) conducted behavioral studies on the larvae of two species of crab (Rhithropanopeus harrisii and Neopanope sayi) to determine the lowest rate and absolute amount of salinity change required to evoke a behavioral response. The determined rates were then compared to salinity gradients encountered within an estuarine environment. Sensitivities to salinity changes were found to be species specific and correlated to the different estuarine zones (upper vs. lower) that were the crab's habitats. Both species responded, in different degrees, to increases in salinity, however neither species exhibited a behavioral response to decreases in salinity. As increases in salinity usually occur lower in the water column, a behavioral response that directs the organisms away from higher salinity conditions ensures that the larvae stay off the bottom and away from benthic predators.

In northeastern Florida Bay, many of the small embayments and mangrove fringe areas experience a wide range of salinities with both pulsed and gradual changes from hypo- to hypersaline conditions. Fish in these areas are subjected to both freshwater inputs from rain and canal discharges as well as wind-driven intrusion of more saline water from the Bay. In this sense, water of a different salinity can be viewed as the 
introduction of a chemical agent into these areas. With the exception of extreme highs and lows, the average salinities in the embayments of northeastern Florida Bay fall within the tolerance ranges for many of the demersal fish species native to the area. However, upper and lower physiological tolerance limits are not necessarily the conditions for optimal performance. The exposure to sub-optimal salinities may be one of the most prevalent threats to fish in these areas. The behavioral changes that result from these exposures may not lead directly to death but may nonetheless cause major ecological disturbances. The lack of a forage fish base in this area, as a probable result of salinity stress, has been identified as a key driver in the success of higher trophic level species (Lorenz, 1999).

Due to the inherent variability and broad range of an organism's natural response to stimuli, behavioral toxicology studies require strict control and reliable, repeatable and quantifiable measures.

Materials and Methods

The objective of this study was to determine the effects of a pulsed salinity change on the behavior and locomotor pattern of two estuarine fish: Poecilia latipinna (Sailfin Molly) and Cyprinodon variegatus (Sheepshead Minnow) under flow-through test conditions. These species are common residents of northeastern Florida Bay and are representative of forage species important to higher trophic levels.

A behavioral analysis system with flow through tanks was used for this study (Figure 3.2). The behavior tank was constructed of 5/8" clear Plexiglas and measured 48 " 21 " 18 " (Figures 3.3 and 3.4). The outside of the tank, excluding the bottom was painted with white Paint for Plastic (Rustoleum Corp., Vernon Hills, IL) to reduce glare 
and reflection. The bottom of the tank was left clear as to let in light from below. The Plexiglas tanks were placed in recirculating water bath for temperature control if needed. The center of the bottom of the recirculating water bath was removed and replaced with $3 / 4$ " clear Plexiglas and sealed creating a 'light box'. The water bath and behavior tanks were mounted on a wooden frame and elevated to waist height. Two 4-foot fluorescent light fixtures (40 watts) were mounted beneath the light box to project light upwards. A high contrast black and white camera (Panasonic CCTV Camera WV-BP330) was mounted on the ceiling above the tanks to record behavior. The entire system was enclosed behind floor-to-ceiling blackout curtains to prevent the fish from being startled during a recording. Extraneous noise in the lab was kept to a minimum during all recordings.

Water of different salinities was pumped into the system via magnetic drive pumps and not recirculated. A $1 / 2$ " PVC bulkhead fitting was mounted at one end of the tank to provide drainage. Nitex mesh was siliconed over the drain hole to prevent animals from escaping. The dilution water was pumped from an aerated 55-gallon holding tank via a 450 gpm magnetic drive pump and delivered into the behavior tank via two plastic manifolds, mounted horizontally one above the other. (Figure 3.4). Each manifold had 8 valves which delivered water through a $1 / 8$ " nylon tube. The upper manifold projected water into the head of the tank whilst the lower manifold delivered water to the midfield of the tank. To prevent fish from accessing the delivery tubes, a "false bottom" (1/4" white opaque Plexiglas) was installed to cover the tubing. The "false bottom' was gently sloped (2" to 1 ") to aid in water flow. The delivery manifolds were separated from the filmed portion of the tank by a 5/8" thick Plexiglas divider painted 
white. Holes were drilled in the divider for each delivery tube. The end of each delivery tube was capped with a male luer locking nut (Cole-Parmer No. 30504-10) to direct flow and prevent the tube from sliding out of position. The flow rate of the delivery tubes was controlled by individual valves on the manifolds. The flow rate of 10-12 gpm was established to maintain a salinity gradient while not interfering with normal fish movement.

The test substance was delivered as a point source roughly $3 / 4$ of the way down from the apex the behavior tank. Water was delivered to the point source via a $350 \mathrm{gpm}$ magnetic drive pump submerged in an aerated 55-gallon holding tank. The point source delivery system was constructed $3 / 4$ " Nalgene tubing with a nylon elbow that was siliconed to the behavior tank wall and angled towards the bulkhead drain. A tubing clamp was used to control the point source at a flow rate of 10-12 gpm.

The dilution water was a stable salinity saltwater $(\sim 30 \mathrm{ppt}, \sim 45.0 \mathrm{mS}$ conductivity) pumped from a sub-surface well in North Miami, Florida. The test substance was freshwater $(0.2 \mathrm{ppt}, \sim 300 \mu \mathrm{S}$ conductivity) from the North Miami, Florida, municipal water supply. Both waters were vigorously aerated, passed through activated carbon, filtered (10-micrometers), UV Sterilized and then re-aerated before being used in these studies. The freshwater had a hardness of 50 to 90 milligrams per liter ( $\mathrm{mg} / \mathrm{L}$ ) as calcium carbonate $\left(\mathrm{CaCO}_{3}\right)$. The initial $\mathrm{pH}$ of the dilution water was between 7.0 - 8.0.

Fish were collected from the wild in Little Blackwater Sound, Florida. Animals were treated with Nitrofurazon $(20 \mathrm{mg} / \mathrm{l})$ on arrival in laboratory and kept in isolation of for two weeks before becoming part of the laboratory culture population. Animals were cultured under flowthrough conditions outdoors at $28^{\circ} \mathrm{C}\left(+/-2^{\circ} \mathrm{C}\right)$ and $30 \mathrm{ppt}$ salinity. 
Adult fish of uniform size were used in these studies; the longest fish was no more than twice the standard length of the shortest fish. Wet weights and standard lengths of the fish were measured and recorded at the end of the study (Table 3.1).

Fourteen days prior to test initiation, the study fish were brought inside to flowthrough holding tanks of stable salinity and temperature $\left(30 \mathrm{ppt}, 22^{\circ} \mathrm{C}\right)$. Fish were gradually acclimated to within 2 degrees Celsius (C) of the test temperature in laboratory culture water of $30 \mathrm{ppt}$.

To initiate studies, individual fish were introduced into the behavioral analysis system tanks in a stable salinity ( $30 \mathrm{ppt})$ with an established laminar flow of water. The curtains around the tank were closed after introduction, and all subsequent test activities (recording, water control, etc.) were conducted remotely. Laboratory noise was kept to a minimum during recording sessions. Fish were allowed to acclimate to the tank for 5 minutes unrecorded. After recordings were started, fish were allowed 7.5 minutes of swim time before the point source was turned on. For control runs, the point source delivered the same salinity water as in the entire tank creating a 'no-change' scenario. For experimental (impact) trials, the point source introduced freshwater $(0.2 \mathrm{ppt})$. The flow rates and design created a 'zone' of alternate salinity at one end of the tank to challenge fish (Figure 3.5). The fish were recorded an additional 7.5 minutes with the point source supplying water, for a total recorded time of 15 minutes for each behavioral trial.

Each study consisted of 20 fish: 10 fish for the control group and 10 fish for the impact group. All 20 fish were first exposed to the flow-through tank system with no salinity change to establish a behavioral baseline. After the baseline exposure, fish were exposed to the system a second time for the point-source trials. During this second 
exposure, 10 randomly selected fish were exposed to the 'no-change' scenario and served as the control group. The remaining 10 fish were exposed to a 'salinity-change' scenario and served as the impact group. A single fish occupied each behavior tank during each recording session.

The flow-through tank (s) was calibrated before each study for consistent flow rate and salinity concentrations during point source delivery (Figure 3.5). Salinity concentrations were recorded 3 times from each of 10 locations in the flow-through tank. The average salinity value for each point was recorded. Salinity values did not deviate between studies by more than 1 ppt. The average salinity for the 'no-change' scenarios was $30.3 \mathrm{ppt}$ throughout the entire arena. In the 'salinity-change' scenario, the salinity in the point source vector ranged from $4.5-14.6 \mathrm{ppt}$, while the rest of the behavior arena was maintained at salinities above $25 \mathrm{ppt}$ (Figure 3.5 ). Aeration was provided to the source water tanks to maintain dissolved oxygen concentrations greater than 80 percent of saturation.

Water temperature was ambient laboratory temperature, maintained at $22 \pm 1^{\circ} \mathrm{C}$. A 16-hour light and 8-hour dark photoperiod was maintained for fish while in holding for this study.

To reduce stress in transfer into the behavior arena, fish were netted and transferred underwater to a glass bowl while in the holding tank. The bowl was then transferred to the behavior arena and the fish was allowed to swim out. Fish were handled minimally throughout the holding and study periods.

Between each trial, the system was drained and refilled with the main source water (30 ppt). Salinity, conductivity, temperature and dissolved oxygen were verified 
before each trial. A second, marked aquarium was established at the same environmental conditions as the initial holding tank to receive post-trial fish and eliminate the chance of the same fish being recorded more than once. Post-trial fish were transferred into the second tank via the same method as described above.

Conductivity, salinity, temperature, ammonia concentration, $\mathrm{pH}$, total alkalinity, and total hardness of the saltwater and freshwater were measured at the start of the study.

Observations of behavior were recorded via a ceiling mounted camera and analyzed using Noldus Ethovison 3.0 software. With this system, the user defines the individual endpoints to use and assigns a sampling interval for recording each endpoint value. Due to the short length of these recordings ( 15 minutes), a one second sampling interval was chosen to retrieve as many data points as possible. Descriptive statistics (mean, standard deviation, standard error, etc.) were calculated for each endpoint at each time interval.

The endpoints analyzed included swim velocity; distance moved; distance to a point; distance to a zone border; presence and time in zone; heading; turn angle; angular velocity; meandering; and distance between objects (tank wall or point source delivery).

The endpoints used in these studies are described below and grouped categorically.

Distance and time:

This category comprises parameters which provide information about the position in space of an object relative to a user-defined zone or point. 
In zone: This parameter specifies if a fish is within a defined zone and is employed to analyze the usage of space by the fish. For these studies, In Zone was used to determine how much time the fish spent in the treated area.

Distance to zone border: The shortest distance between the fish and the border of a zone of interest at a given point in time. In these studies, the zone border was defined as the walls of the tank. A common fish behavior is 'walling', whereby the fish swims along the walls of the tank, usually in one direction.

Distance to point: The distance between the fish and a fixed point of interest (e.g. point source location) and is an indicator of spatial orientation.

In the case of these studies, for analysis of swimming behavior of the fish in a vector (plume) of alternate salinity, the vector itself was defined as a zone, while the point source (of alternate salinity) was regarded as a point. The endpoint was used to measure the fish's proximity towards the point source at any moment in time.

Distance moved: The distance 'traveled' by the center of gravity of the fish between two points in time. The distance moved parameter is used in the calculation of several other endpoints such as velocity and heading. Both the mean distance moved per recorded time interval ( 1 second) and the total distance moved during pre- and post- point source addition was analyzed.

Velocity: The distance moved by the fish per given unit of time.

Locomotor activities:

These endpoints describe the geometrical shape of the path traveled by the fish in the exposure system. 
Heading: The direction of movement of the fish relative to a user-defined reference line. The heading has a range from 0 to 360 degrees. The endpoint was used to determine the direction of movement of the fish relative to the point source and point source vector of alternate salinity.

Turn angle: The change in direction of the fish's movement between two consecutive samples. For these studies, turn angle was calculated as with a signed value (positive or negative) to distinguish right and Ieft-handed turns. A clockwise turn (right) was assigned a positive value, a counterclockwise turn (left) was assigned a negative value. Hence the relative turn angle ranged from $-180^{\circ}$ to $180^{\circ}$. The analysis of turn angles can aid in determining stereotypical movements of the fish.

Angular velocity: The speed of change in direction of movement of the fish per unit of time. Again, the angular velocity was determined relative to direction and assigned a positive or negative value for clockwise (positive) or counterclockwise (negative) movement. This endpoint is used to detect any abnormalities of movement (e.g. reaction to toxicant).

Meander: The change in the direction of movement of the fish relative to the distance moved (amount of turning per unit distance). For theses studies, meander was calculated relative to direction as described above with a range from $-180 \% \mathrm{~cm}$ to $180 \% \mathrm{~cm}$.

Statistical Analysis

Data were analyzed using the Before-After Control-Impact (BACI) model and JMP version 8.0.1 statistical software (SAS Institute, Inc., Cary, NC). The BACI model is used to assess whether an impact has occurred as a result of a stressor on a test system, and if an impact has occurred, determine which components/endpoints are affected and to 
what degree (Smith, 2002). In this model, data from two sites (control site and impact site) were paired and compared before and after an activity occurred.

Often used in the assessment of environmental impacts (Smith, 2002; StewartOaten, 2003; Trexler et al., 2005) before and after models fall into three main permutations. The simplest approach is using the Before-After (BA) model described by Green in 1979 (Smith, 2002). In this case, data collected from before an activity is compared to data collected after an activity using a two-sample test. Differences found between the before and after data are thus attributable to the activity and are viewed as an effect. One criticism of this design is that no control exists with which to compare the collected data. A second approach, which includes a control, is known as the BeforeAfter Control-Impact (BACI) model (Smith, 2002). A variant of the BA, the BACI design compares data collected from before and after an activity at a control site against an impact site. The third approach (BACIP), adds the element of pairing data points and calculating the differences between them to the BACI design. Data are collected based on pairs of observations and $\mathrm{N}$ pairs of samples are taken before the effect and after the effect at both sites. Stewart-Oaten (2003) referred to a 'tracking relationship' being established between the control (site) and impact (site) that would reflect potential changes as evidence of an effect. The differences between the pairs can then be compared for the period before the effect and after using a two sample test. If there is no impact, the differences in the before period should be similar to the differences in the after period. A t-test can be used to compare the differences for both assumed equal and unequal variances. Figure 3.6 is a graphical representation of the different beforeafter design approaches taken from Smith, 2002. 
For these studies, the 10 fish that had the same salinity water delivered by the point source serve as the control data set, whereas the 10 fish that had the point source deliver different salinity water serve as the impact data set. The time prior $(0-7.5$ minutes) to the point source being turned on is the before period whilst the time following the point source addition (7.5-15 minutes) is the after period. The data points are the mean value of each end point for the individual fish for both before and after periods. Using the endpoint of velocity as an example, the mean velocities of fishes in the control are compared to the mean velocities fishes in the impact for both before the point source addition and after it. If the differences between the means of the control versus the impact are dissimilar in the before and after periods, then a behavioral impact is indicated for that endpoint.

Results

Statistically significant differences in locomotor pattern endpoints $(\mathrm{p}<0.05$, twotailed test) were found for P. latipinna (Table 3.2). The endpoints of mean meander, mean angular velocity, mean heading and mean turn angle showed generally higher values in the impact fish after the point source of freshwater was introduced (Figure 3.7). Such pattern changes are indicative of hyperlocomotion, a common reaction by a fish to a sublethal stressor as shown in numerous chemical behavior studies (McKim et al, 1987). For the distance and time parameters, no statistical differences were found.

For C. variegatus, no statistical differences between the control and impact fish were found between the before and after periods for any endpoint (Table 3.3) 


\section{Discussion}

The behavioral effects of toxicants have been recorded in many groups of aquatic taxa (Little and Finger, 1990; Bernot et al., 2005) and provide critical information on sublethal effects that can alter feeding and anti-predator behaviors. Behavioral effects are often observed prior to physiological effects and can foreshadow more severe downstream effects (Bernot, 2005). In an ecological context, impairment of such behaviors as locomotion, predator avoidance and foraging/feeding can ultimately lead to reduced fitness for the organism. Changes in locomotor behavior, especially, can make aquatic organisms more or less susceptible to predation. By linking biochemical factors with physiological effects, behavioral endpoints can provide insight into both the individual and potential community level effects of a contaminant (Kane, et al., 2004). Juvenile recruitment can be affected by behavioral changes and thus result in both population and community changes over time (Bridges, 1997).

Both P. latipinna and C. variegatus are found in the shallows of northeastern Florida Bay and occupy similar salinity-preference niches. The mean salinity that $P$. latipinna has been collected in is approximately $4 \mathrm{ppt}$ while that for C. variegatus is approximately 5 ppt (Lorenz and Serafy, 2006). However, C. variegatus has a greater range of salinity tolerance than $P$. latipinna, especially in its tolerance for higher salinities. Haney and Nordlie (1997) showed that the metabolic rate of gradually acclimated C. variegatus was only affected at salinities above 40 ppt. C.variegatus are egg layers, whilst $P$. latipinna are livebearers. Both species have similar feeding habits and are omnivorous, being known to feed on algae, detritus and small invertebrates (Hassan-Williams et al., 2007). 
The lack of an effect of salinity change on responses of $C$. variegatus suggests that, at least on the short-term scale of the salinity change used in these studies (under 15 minutes), this species will tolerate osmoregulatory changes. Longer exposure to salinity changes may result in different behavioral patterns, as previous work on this dissertation (see Chapter 2), showed C. variegatus to be physiologically sensitive (growth and survival effects) to salinity changes. In the toxicological studies, the fish had no escape from the changed salinity and thus were forced into a situation to either compensate or not. In Florida Bay, unless the fish are physically trapped in an area due to a barrier, it is likely that fish will move to avoid osmotic stress. It should be noted here that for physiological studies involving a gradual change in salinity, there was no difference in survival for adults of the two species used in these behavioral studies. Hence, given time to acclimate to the change, one would expect behavioral changes and/or avoidance of an area not to occur.

Alternately, lack of a measureable behavioral effect on C. variegatus may be the result of the concentration of the salinity gradient used in these studies. Due to the design of the exposure system, a shallow concentration gradient was produced. In studies with copper and the goldfish, Carassius auratus, Kleerekoper et al., (1972) found that the magnitude of the concentration gradient (shallow verses steep) affected the attraction/avoidance response of the fish. Shallow gradients of copper (with much higher concentrations) attracted fish whilst steeper, less concentrated gradients repelled fish (Kleerekoper et al., 1972). The salinity gradient presented in these studies may not have been dramatic enough to elicit a response in C. variegatus. 
It is interesting that $P$. latipinna exhibited an increase in locomotor activity when challenged with a drop in salinity in these behavioral studies. Due to the short time frame of each behavioral trial ( 15 minutes), it is likely that the activity changes observed here are the result of a 'first response' after sensing a change in the environment. Flashy and quick movements in a fish are often associated with panic and/or stress. Saline stress has been shown to increase serotonin levels in fish, which in turn regulates cortisol levels that play a role in salinity adaptation (Kahn and Deschaux, 1997). In this case, the recorded change in behavior of $P$. latipinna could be evidence of a more sensitive osmoregulatory response as compared to $C$. variegatus. As mentioned above, P. latipinna has a narrower salinity tolerance range than that of $C$. variegatus. Perhaps this refined response, and potentially quicker physiological adaptation, contributed to the greater success of $P$. latipinna in the previously mentioned toxicological studies. Early detection and reaction to salinity changes in P. latipinna may also aid in mitigating osmoregulatory stress by avoiding area of changing salinity.

In terms of Florida Bay, understanding the behavioral and physiological responses of native fish to salinity change can help elucidate the potential impacts to demersal fish community structure from both gradual and rapid/pulsed change events. As highlighted in the physiological toxicity studies, $C$. variegatus and $P$. latipinna showed marked differences in response to acute and abrupt salinity change based on age and life stage. $P$. latipinna showed greater physiological robustness to downwards shifts in salinity, as well as more refined detection of such changes in behavioral studies when compared to $C$. variegatus. Hence, $P$. latipinna may be more likely to inhabit areas of northeastern 
Florida Bay and inland habitats that are subject to rapid downwards shifts in salinity than C. variegatus would.

Behavioral toxicity studies can be used to complement and add a level of realism to both acute and chronic toxicity studies as well as the regulatory actions associated with such studies. The subtle, sub-lethal effects highlighted in behavioral studies are often precluded by the design of the toxicity study (Atchison et al, 1987). Regulatory agencies in the United States and abroad base water quality criteria wholly or in part on the results of standard toxicity tests with endpoints such as growth, survival, and reproduction in aquatic organisms. Combining behavioral with toxicity studies can present a broader view of an organism's response to toxicant allowing for better management and protection of aquatic life.

Acknowledgments: Many thanks go to Dr. Eric P. Smith, Chair, Department of Statistics, and Virginia Tech for his statistical guidance for this project. 


\section{References}

Atchison GJ, Henry MG and MB Sandheinrich. 1987. Effects of metals on fish behavior: a review. Environ Biol Fishes. 18 (1):11-25.

Bernot RJ, Kennedy EE, and GA Lamberti. 2005. Effects of ionic liquids on the survival, movement, and feeding behavior of the freshwater snail Physa acuta. Environmental Toxicology and Chemistry, Vol. 24, No. 7, pp. 1759-1765.

Bridges CM. 1997. Tadpole swimming performance and activity affected by acute exposure to sublethal levels of carbaryl. Environ. Toxicol. Chem. 16(9): 1935-1939.

Forward RB Jr. 1989. Behavioral responses of crustacean larvae to rates of salinity change. Biol. Bull. 176: 229-238.

Haney DC and Nordlie FG (1997).Influence of environmental salinity on routine metabolic rate and critical oxygen tension of Cyprinodon variegatus. Physiol. Zool. 70 (1997), pp. 511-518.

Hassan-Williams, C. Bonner TC. (2007) Texas freshwater fishes. Texas State UniversitySan Marcos: Biology Department/ Aquatic Station. http://www.bio.txstate.edu/ tbonner/txfishes/

Jury SH, Kinnison MT, Huntting Howell W, Watson WH III. 1994. The behavior of lobsters in response to reduced salinity. J Exp Mar Biol Ecol. 180:1 pp 23-37.

Kane AS, Salierno JD, Gipson GT, Molteno TCA, Hunter C. 2004. A video-based movement analysis system to quantify behavioral stress responses of fish. Wat. Res. 38: $3993-4001$.

Khan NA and P Deschaux. 1997. Role of serotonin in fish immunomodulation. J. Exper Biol 200, 1833-1838.

Kleerekoper H, Westlake GF, Matis JH and P.J. Gensler. 1972. Orientation of goldfish (Carassius auratus) in response to a shallow gradient of a sublethal concentration of copper in an open field. J. Fish. Res. Board Can. 29: 45-54.

Little E, Finger S. 1990. Swimming behavior as an indicator of sublethal toxicity in fish. Environ Toxicol Chem 9:13-19.

Lorenz, J. J. 1999. The responses of fishes to physicochemical changes in the mangroves of northeastern Florida Bay. Estuaries 22: 500-517.

Lorenz, J. J. and J. E. Serafy. 2006. Subtroprical wetland fish assemblages and changing salinity regimes: Implications for everglades restoration. Hydrobiologia 569: 401-422. 
Marcucella H. \& C.I. Abramson. 1978. Behavioral toxicology and teleost fish. In: D.I. Mostofsky (ed.) The Behavior of Fish and Other Aquatic Animals, Academic Press, New York, pp. 33-77.

McKim JM, Bradbury SP, and GJ Niemit. 1987. Fish Acute Toxicity Syndromes and Their Use in the QSAR Approach to Hazard Assessment. Environmental Health Perspectives Vol. 71, pp. 171-186.

Olla, B.L., W.H. Pearson \& A.L. Studholme. 1980. Applicability of behavioral measures in environmental stress assessment. Rapp. P. V. Reun. Cons. Int. Explor. Mer 179: 162173.

Rand, G.M. 1985. Behavior. In: G.M. Rand \& S.R. Petrocelli (eds) Fundamentals of Aquatic Toxicology: Methods and Applications. Hemisphere Publishing Corp., New York pp. 221-263.

Smith EP. 2002. BACI design. In: El-Shaarawi AH and Piegorsch WW (eds) Encyclopedia of Environmetrics Volume 1. John Wiley \& Sons, Ltd, Chichester, pp 141148.

Stewart-Oaten, Allan. 2003. Using Before-After-Control-Impact in Environmental Assessment: Purpose, Theoretical Basis, and Practical Problems. MMS OCS Study 2003035. Coastal Research Center, Marine Science Institute, University of California, Santa Barbara, California. MMS Cooperative Agreement Numbers 14-35-0001-30471 \& 14-350001-30761. 116 pages.

Trexler JC, Loftus WF, Perry S. 2005. Disturbance frequency and community structure in a twenty-five year intervention study. Oecologia (2005) 145: 140-152.

Verplanck, W. S. A glossary of some terms used in the objective science of behavior. Psychol. Rev., 1957, 64, 1-42. 


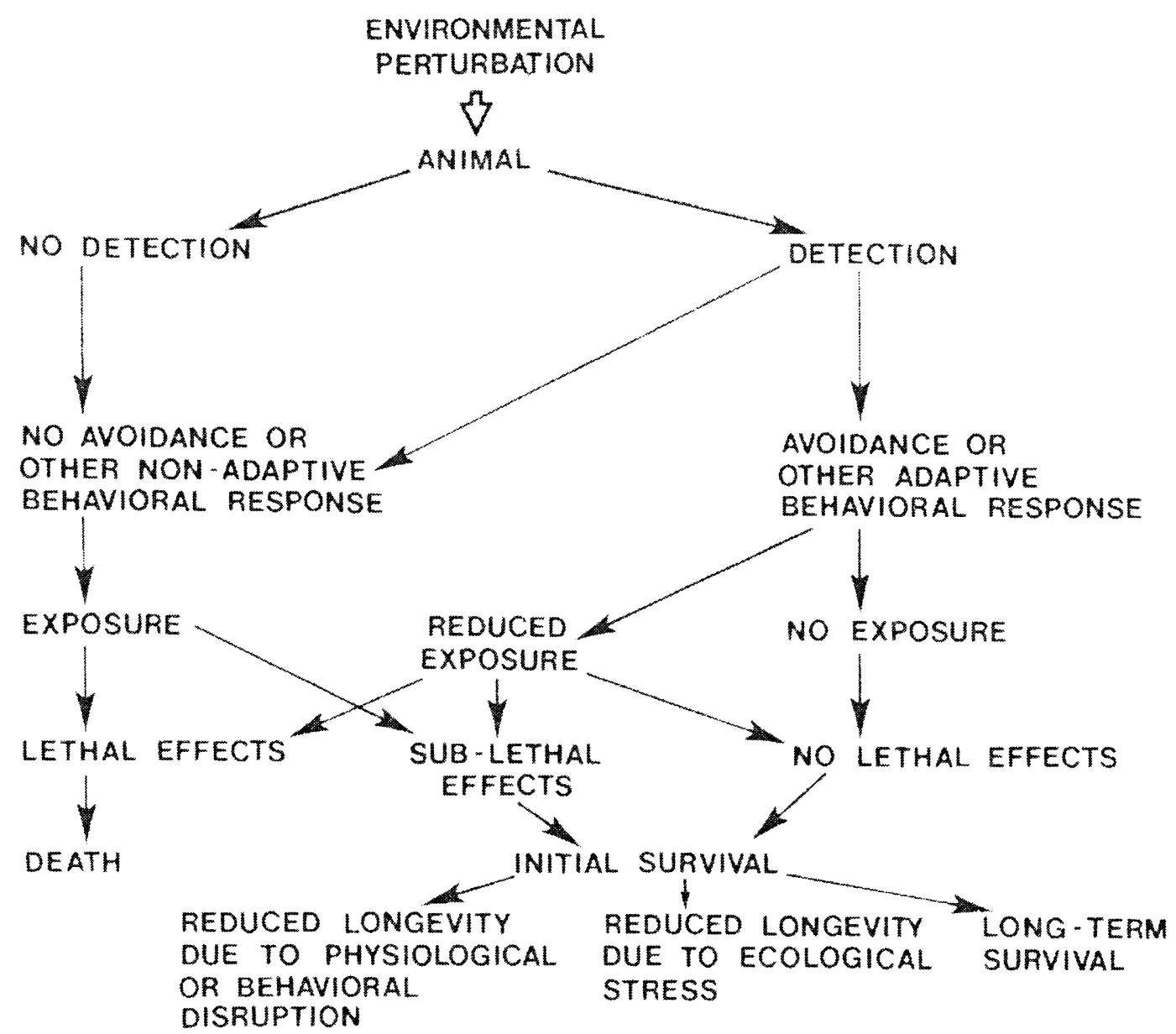

Figure 3.1: Flow chart of behavioral responses to environmental perturbation and possible consequences. From Olla et al. 1980. 


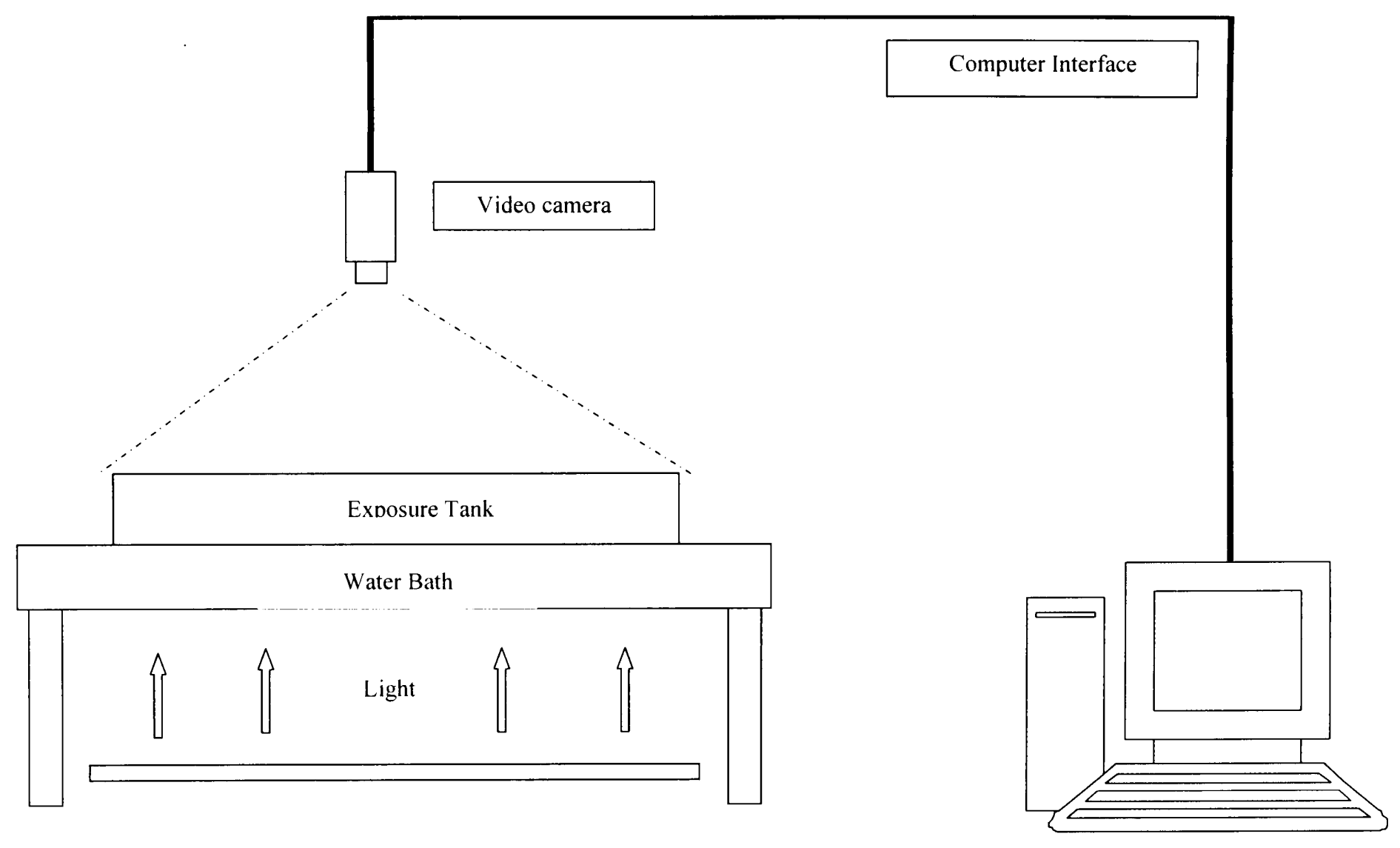

Figure 3.2: Behavioral analysis system 


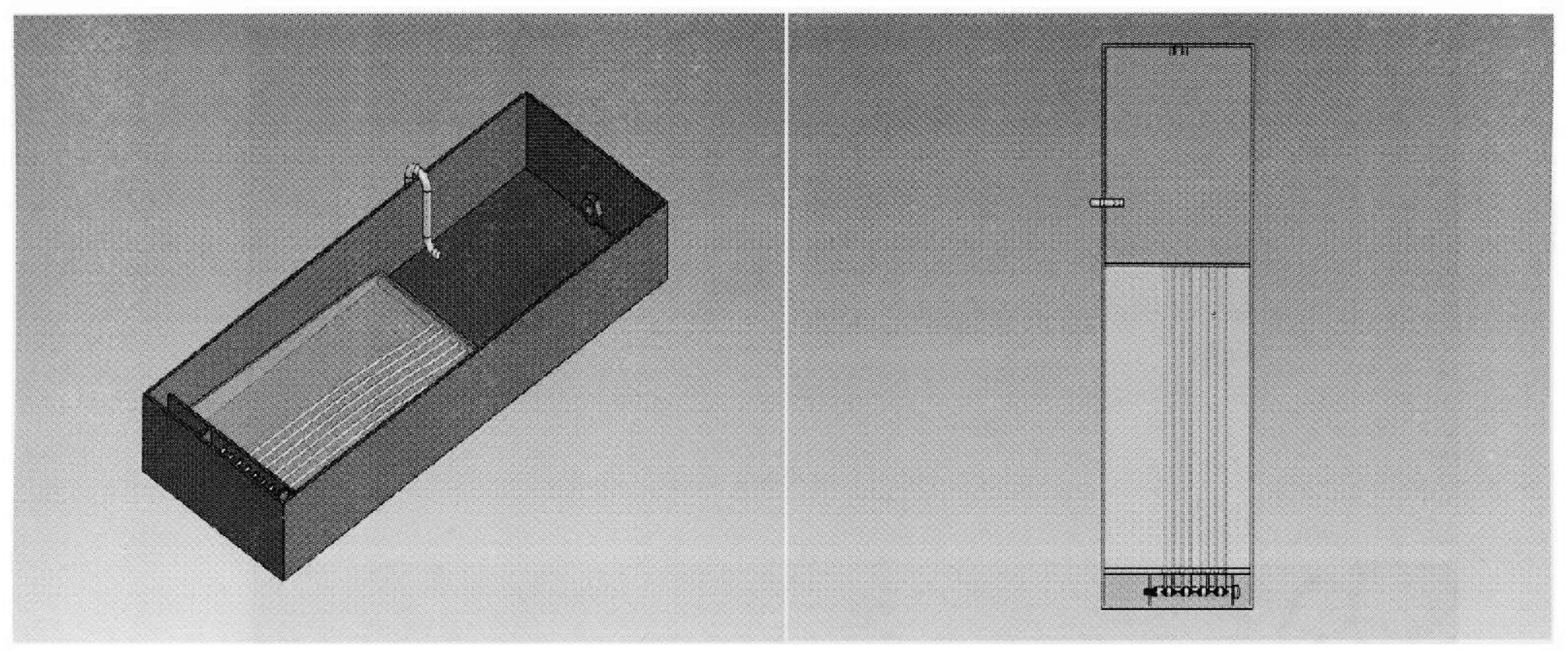

Figure 3.3: (L) Three-dimensional view of behavior tank with water delivery tubes exposed. (R) Top view of with water deliver tubes and manifold exposed. 

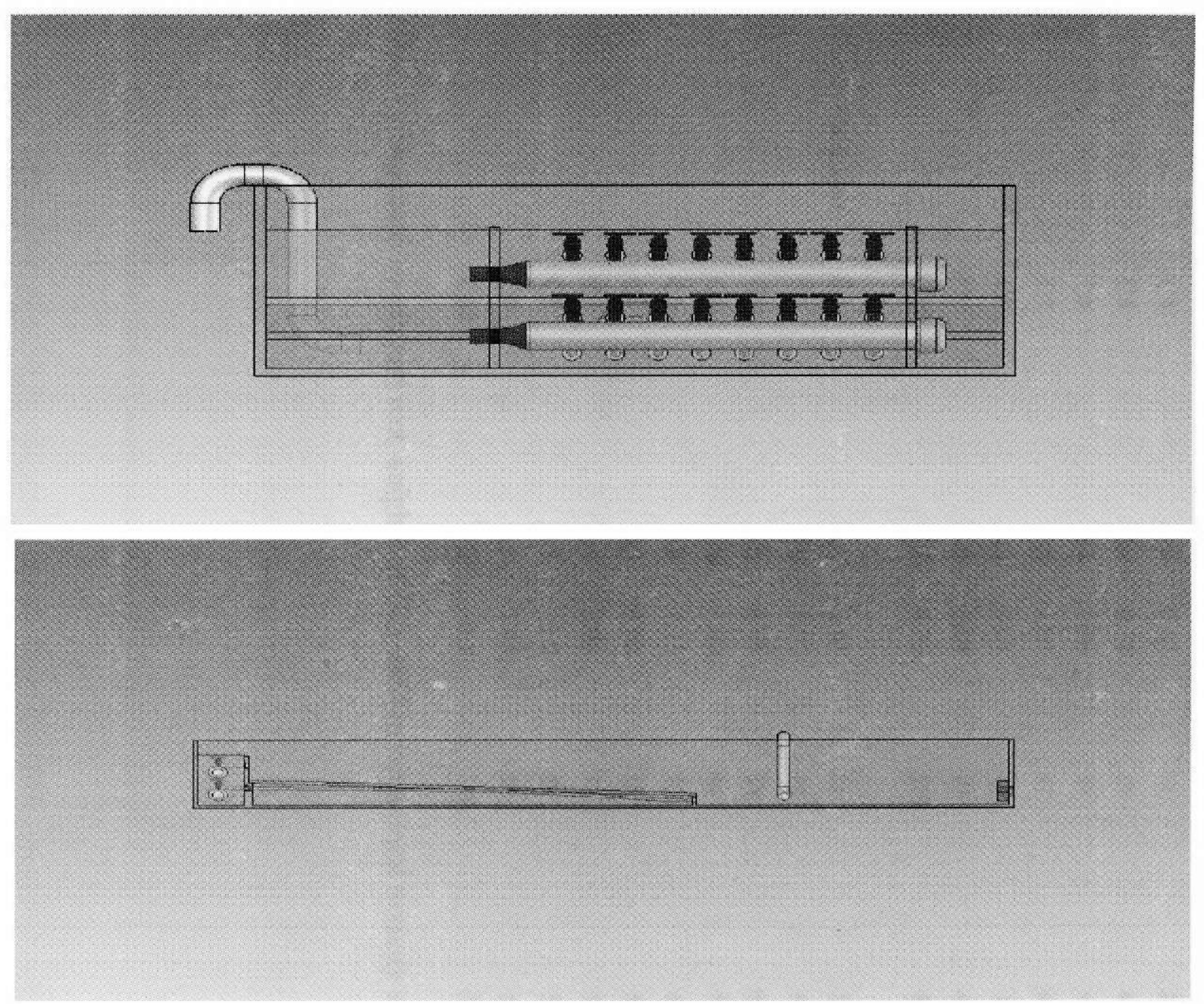

Figure 3.4: Lateral views of delivery manifold (top) and flow through tank with sloping false bottom (below). 


\begin{tabular}{|c|c|c|c|c|c|c|}
\hline \multirow{3}{*}{$\begin{array}{l}\text { Species } \\
\text { Cyprinodon } \\
\text { variegatus }\end{array}$} & \multirow{3}{*}{$\begin{array}{l}\text { Control } \\
\text { fish } \\
\mathrm{Cl}\end{array}$} & \multirow{3}{*}{$\begin{array}{l}\text { Standard } \\
\text { length }(\mathbf{c m}) \\
\\
4.5\end{array}$} & \multirow{3}{*}{$\begin{array}{l}\text { Wet weight } \\
\text { (g) } \\
0.78\end{array}$} & \multirow{3}{*}{$\begin{array}{l}\text { Impact } \\
\text { fish } \\
\text { I1 }\end{array}$} & \multirow{3}{*}{$\begin{array}{l}\text { Standard } \\
\text { length } \\
\text { (cm) } \\
\\
\\
\end{array}$} & \multirow{3}{*}{ 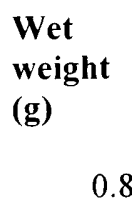 } \\
\hline & & & & & & \\
\hline & & & & & & \\
\hline & $\mathrm{C} 2$ & 4.3 & 0.74 & 12 & 4.7 & 0.81 \\
\hline & $\mathrm{C} 3$ & 4.3 & 0.75 & 13 & 4.6 & 0.77 \\
\hline & $\mathrm{C} 4$ & 4.9 & 0.82 & I4 & 4.8 & 0.81 \\
\hline & $\mathrm{C} 5$ & 4.4 & 0.78 & 15 & 4.2 & 0.72 \\
\hline & C6 & 5.1 & 1.06 & I6 & 4.1 & 0.7 \\
\hline & $\mathrm{C7}$ & 5.2 & 1.07 & 17 & 4.2 & 0.72 \\
\hline & $\mathrm{C} 8$ & 4.9 & 0.89 & I8 & 4.2 & 0.75 \\
\hline & $\mathrm{C} 9$ & 4.8 & 0.88 & 19 & 4.8 & 0.86 \\
\hline & $\mathrm{C} 10$ & 4.1 & 0.71 & I10 & 5.0 & 0.98 \\
\hline Poecilia latipinna & $\mathrm{Cl}$ & 5.3 & 0.91 & Il & 5.3 & 0.92 \\
\hline & $\mathrm{C} 2$ & 5.9 & 1.23 & I2 & 5.8 & 1.11 \\
\hline & $\mathrm{C} 3$ & 5.5 & 0.96 & I3 & 6.1 & 1.37 \\
\hline & $\mathrm{C} 4$ & 5.8 & 1.09 & $\mathrm{I} 4$ & 5.3 & 0.92 \\
\hline & $\mathrm{C} 5$ & 5.8 & 1.13 & 15 & 5.9 & 1.2 \\
\hline & C6 & 5.3 & 0.93 & I6 & 5.9 & 1.22 \\
\hline & $\mathrm{C} 7$ & 5.4 & 0.96 & 17 & 5.6 & 1.01 \\
\hline & $\mathrm{C} 8$ & 5.3 & 0.9 & 18 & 5.7 & 1.03 \\
\hline & C9 & 6.2 & 1.45 & 19 & 5.7 & 1.09 \\
\hline & $\mathrm{C} 10$ & 5.2 & 0.9 & 110 & 5.6 & 1.01 \\
\hline
\end{tabular}

Table 3.1 Standard length and wet weights of fish used in behavioral toxicity studies. 


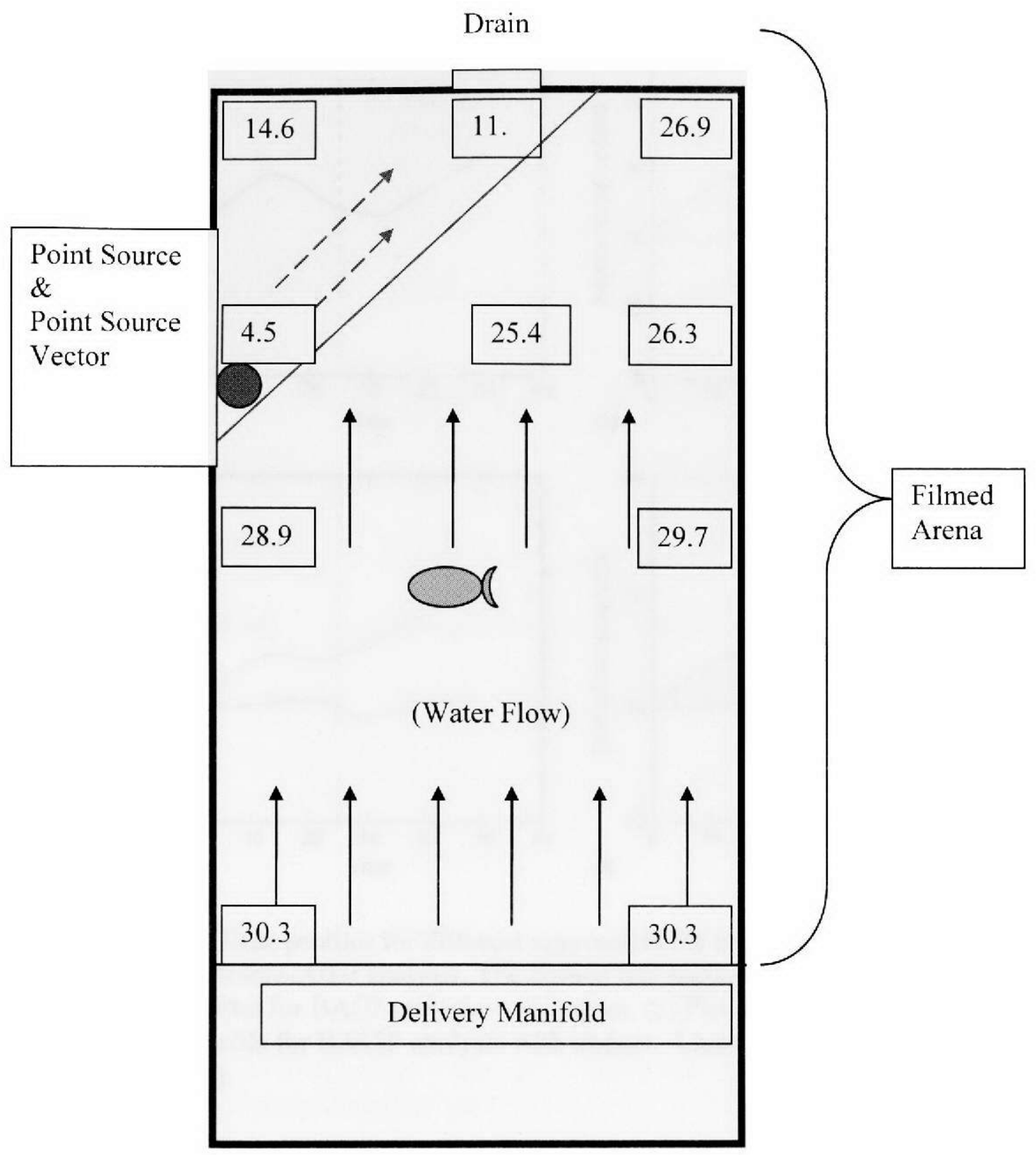

Figure 3.5: Location of salinity change vector in behavior tank. Numbers indicate average salinities (ppt) in each location during the addition of the freshwater point source. 

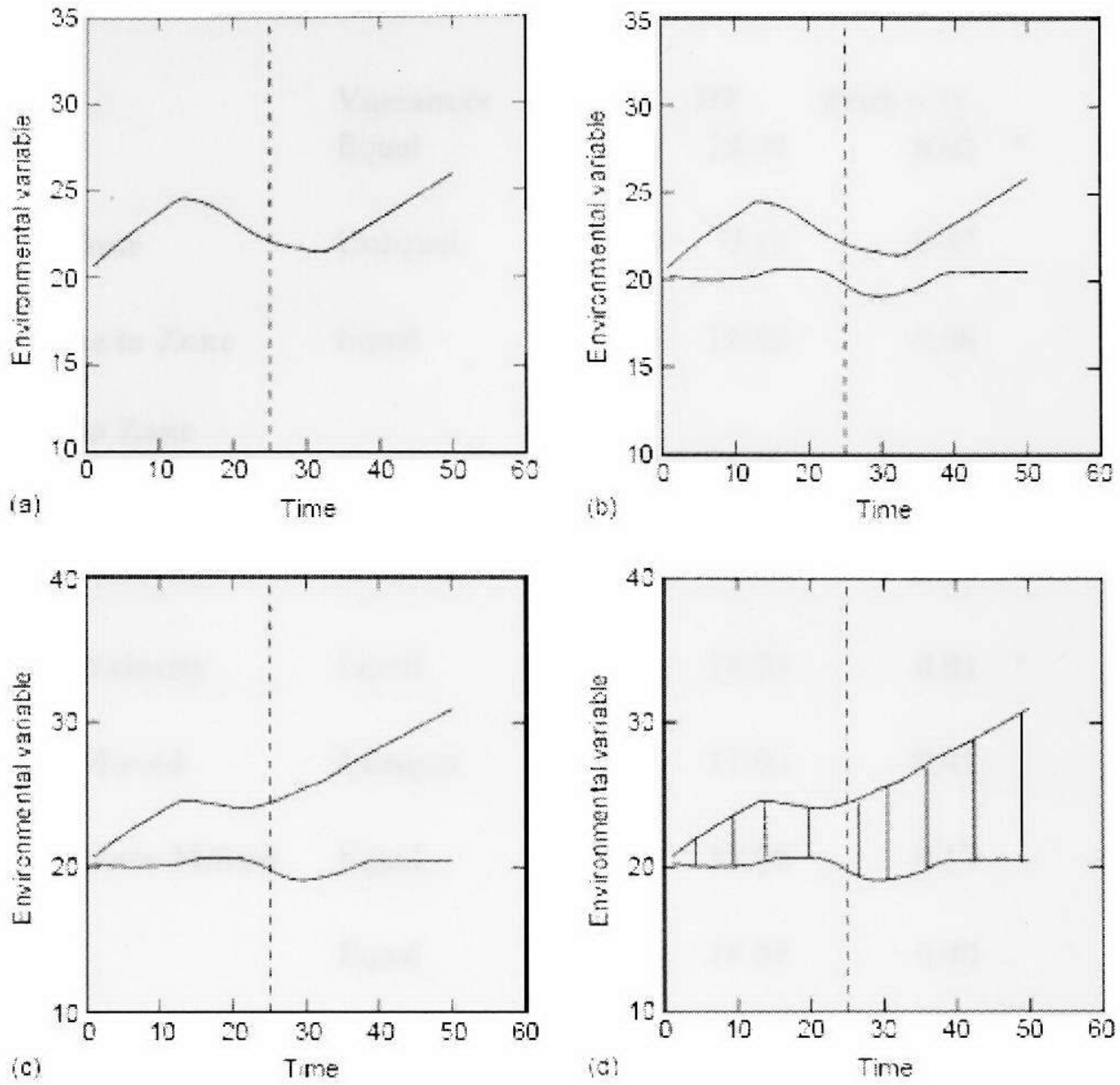

Figure 3.6. Data profiles for different approaches for impact assessment. (a) Data profile pattern for Before-After analysis. The dashed line indicates the time of activity/event. (b) Plot for BACI analysis - no impact. (c) Plot of BACI analysis - with impact. (d) Data profile for BACIP analysis with impact. Lines indicate pairs of samples. (From Smith, 2002). 


\begin{tabular}{|c|c|c|c|c|}
\hline Endpoint & Variances & t Ratio & DF & $\operatorname{Prob}>|\mathbf{t}|$ \\
\hline Mean Meander & Equal & -2.62 & 18.00 & 0.02 \\
\hline Mean Time in Zone & Unequal & -2.04 & 9.12 & 0.07 \\
\hline Mean Total Time in Zone & Equal & -1.85 & 18.00 & 0.08 \\
\hline $\begin{array}{l}\text { Mean Distance to Zone } \\
\text { Border }\end{array}$ & Equal & 1.42 & 18.00 & 0.17 \\
\hline Mean Distance to Point & Unequal & -1.75 & 9.45 & 0.11 \\
\hline Mean Angular Velocity & Equal & -2.99 & 18.00 & 0.01 \\
\hline Mean Distance Moved & Unequal & 0.86 & 11.92 & 0.41 \\
\hline Mean Total Distance Moved & Equal & 1.43 & 18.00 & 0.17 \\
\hline Mean Velocity & Equal & 0.86 & 18.00 & 0.40 \\
\hline Mean Heading & Unequal & -2.59 & 11.54 & 0.02 \\
\hline Mean Turn Angle & Equal & -2.18 & 18.00 & 0.04 \\
\hline
\end{tabular}

Table 3. 2. Summary of BACI analysis data for Poecilia latipinna. Significant differences $(\mathrm{p}<0.05)$ are indicated by an * 


\begin{tabular}{|c|c|c|c|c|}
\hline Endpoint & Variances & t Ratio & DF & $\begin{array}{l}\text { Prob > } \\
|t|\end{array}$ \\
\hline Mean Meander & Equal & -0.412 & 18 & 0.66 \\
\hline Mean Time in Zone & Equal & -0.48472 & 18 & 0.63 \\
\hline Mean Total Time in Zone & Equal & -1.22417 & 18 & 0.24 \\
\hline Mean Distance to Zone Border & Equal & -0.00824 & 18 & 0.99 \\
\hline Mean Distance to Point & Equal & -1.14983 & 18 & 0.27 \\
\hline Mean Angular Velocity & Equal & -0.43624 & 18 & 0.67 \\
\hline Mean Distance Moved & Equal & -0.52819 & 18 & 0.60 \\
\hline Mean Total Distance Moved & Equal & -1.12414 & 18 & 0.28 \\
\hline Mean Velocity & Equal & -0.058 & 18 & 0.95 \\
\hline Mean Heading & Equal & -0.42135 & 18 & 0.68 \\
\hline Mean Turn Angle & Equal & -0.74959 & 18 & 0.46 \\
\hline
\end{tabular}

Table 3. 3. Summary of BACI analysis data for Cyprinodon variegatus. No significant differences were found 


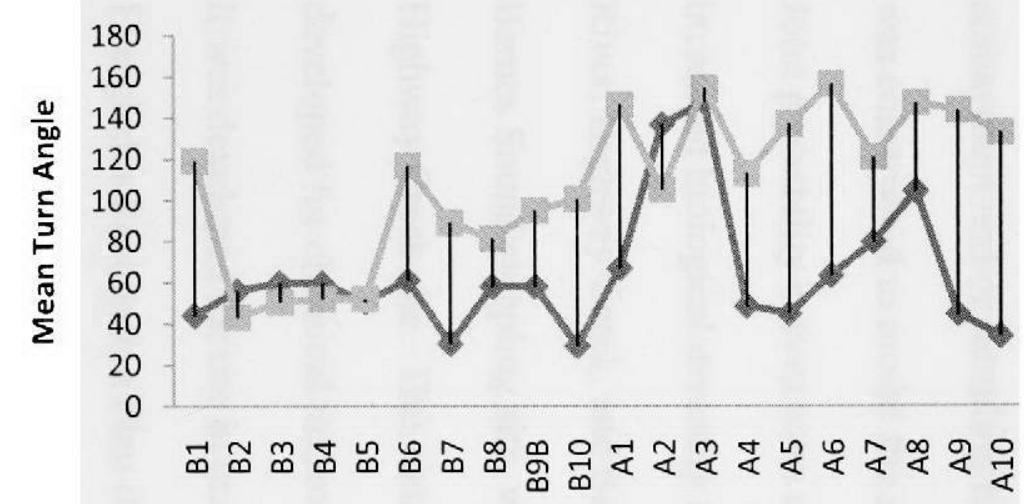

Fish

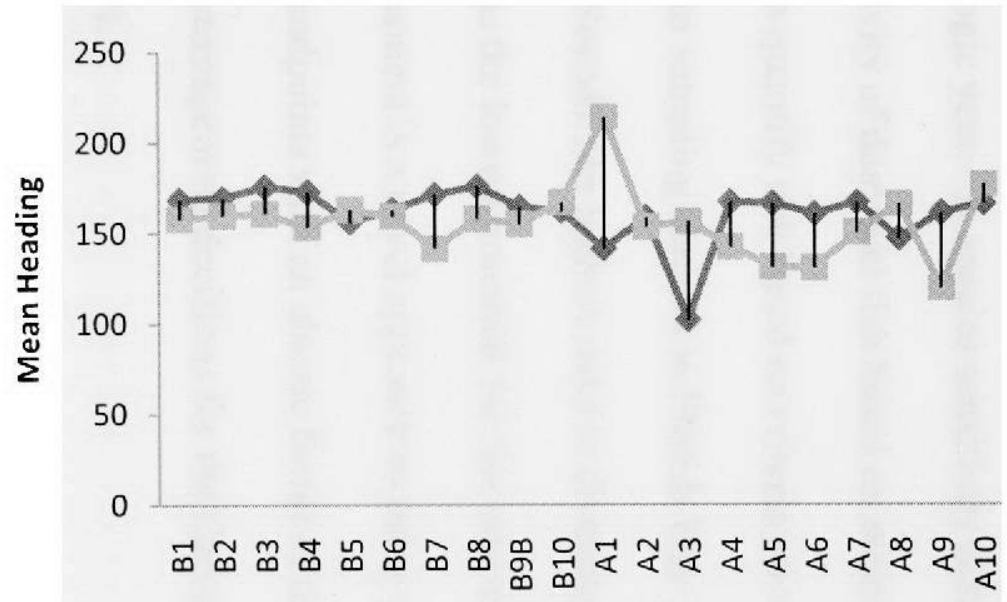

Fish

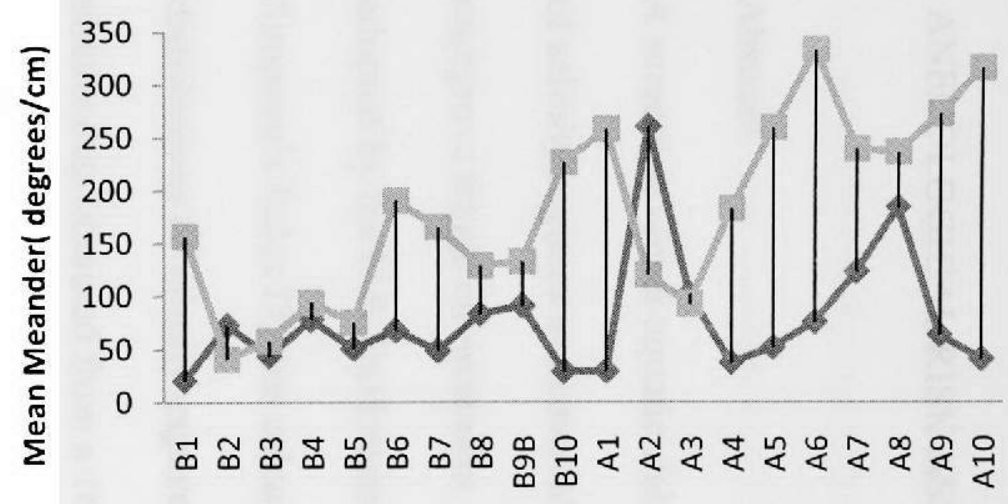

Fish

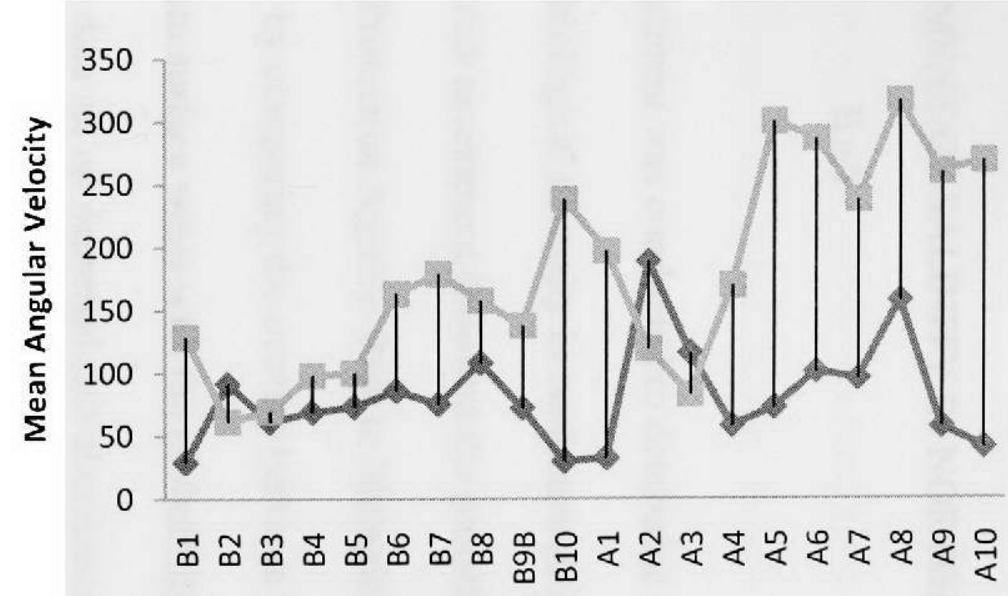

Fish

Figure 3.7. Statistically significant locomotor endpoints for $P$. latipinna $(\mathrm{p}<0.05)$. The diamond shape indicates the Control data, whereas the square marker indicates Impact data. Vertical lines connect paired data points for BACI analysis 


\section{ANECOLOGICAL RISK ASSESSMENT OF SALINITY IN NORTHEAST FLORIDA}

\section{BAY}

Abstract

A screening -level aquatic risk assessment was conducted to determine the potential risk of salinity regimes to demersal fish biological diversity in northeastern Florida Bay's mangrove fringe environment. The risk assessment followed the probabilistic framework adopted by the U.S. Environmental Protection Agency. Risk to biological diversity (as Simpson's Index D) was calculated by comparing the overlap between the probability distributions of salinity exposure from surface water with the probability distribution of effects data obtained from a 16 year data set on demersal fish abundance and distribution. Salinity concentrations in surface waters of northeast Florida Bay were summarized by embayment and/or sampling hydrologic year. A species sensitivity distribution (SSD) was constructed to model the sensitivity of demersal fish based on mean salinity affinity. Joint probability curves were used to quantify risk based on criteria set to be protective of increased biological diversity for four sampling stations in Florida Bay (Joe Bay. Taylor River, Highway Creek, and Barnes Sound).The highest risks to diversity were at the Barnes Sound sampling site, whereas the lowest potential for risk was associated with the Highway Creek site. This risk assessment is a novel approach to using a methodology developed for chemical toxicology endpoints with an abiotic factor of the environment. It was developed for use in making management decisions for the Comprehensive Everglades Restoration Plan (CERP). 
Introduction

Biological changes in the South Florida hydroscape have been linked to changes in the complex hydrologic patterns of the natural system resulting from water management projects to control floods and water distribution (Science Subgroup, 1996). Therefore, the basic premise behind all restoration activities identified by the Interagency Restoration Task Force for south Florida is that hydrologic restoration is a prerequisite to achieve ecosystem restoration and a sustainable south Florida ecosystem. The Comprehensive Everglades Restoration Plan (CERP) was thus formulated to reconstruct some key features of the natural hydrologic system by restoring the hydrology of predrainage conditions through re-establishment of historical flows through the Everglades to the estuaries.

In Florida Bay, the inflow of freshwater was affected by the South Dade Conveyance System (SDCS), a system of canals, pumps, and other water control structures. This changed the spatial and temporal distribution of salinity. As a result of reduced freshwater flow and salinity changes, there have been reductions in the abundance of pink shrimp, piscivorous fish (snook, redfish), alligator, American crocodiles, and wading birds (McIvor et al., 1994). Many of these groups rely on small demersal fish in Florida Bay as a food source. Therefore, changes in the population of small demersal fish in Florida Bay have been suggested as the cause of declines in these important taxa. The distribution, abundances, and presence or absence of small demersal fish communities are strongly influenced by salinity changes. Salinity changes will thus be a stressor and a limiting factor which may directly affect small demersal fish, and indirectly affect the biota in Florida Bay which depends on these fish. 
Salinity patterns in Florida Bay have been examined in several studies in order to evaluate their potential effects on aquatic communities (McIvor et al., 1994; Lorenz and Serafy 2006). Additionally, demersal fish communities have been investigated by scientists because they play a key role in estuaries and are good indicators of changes in physico-chemical conditions of water (Bachman and Rand, 2008).

The use of monitoring data on salinity patterns and biological responses of representative demersal fish communities have not been extensively investigated by scientists, regulators, and natural resource managers in an ecological risk context. Furthermore, scientists, regulators, and natural resource managers have relatively few tools or procedures to assist them in predicting the risks of salinity changes on native demersal fish communities. This section focuses on the use of an ecological risk assessment (ERA) approach as a decision support tool to assess the risk of salinity changes to aquatic biota in northeast Florida Bay. It will discuss the general approach and methods and an example will be presented of an ERA to evaluate risk as a result of salinity changes in Florida Bay. The salinity ERA approach is intended to assess potential risks of salinity changes in surface water and not to determine the actual causes of declines in the populations of native invertebrates, fish or plants that may be prevalent in Florida Bay. Assessment of the potential impact of salinity on aquatic communities acknowledges that other chemical and non-chemical factors (e.g., temperature, contaminants, development,) may be direct, indirect, or interacting stressors which can alter habitats and affect populations. The latter factors are not being considered here.

ERAs in aquatic ecosystems have traditionally focused on risks of single and/or multiple contaminant stressors (e.g., pesticides, metals) to individual organisms or 
populations of key trophic groups (e.g., fish, zooplankton, phytoplankton, macroinvertebrates, vascular plants). Ecological risk assessment is a process that evaluates the likelihood that adverse ecological effects have occurred, may occur, or are occurring as a result of exposure to one or more stressors (U.S. EPA, 1992; 1998). As stated in the most recent U.S. EPA guidelines for ERAs, it is used to systematically evaluate and organize data, information, assumptions, and uncertainties in order to help understand and predict the relationships between stressors and ecological effects in a way that is useful for environmental decision making. An assessment may involve chemical, physical, or biological stressors, and a single and multiple stressors may be considered (U.S. EPA, 1998). In the present context, "adverse ecological effects" are understood to be anthropogenically-influenced salinity changes considered undesirable because they could alter valued structural or functional characteristics of ecosystems.

An ERA is a three-phase scientific process (Figure 4.1) which follows the U.S. EPA framework (U.S. EPA, 1992; 1998): problem formulation, risk analyses, and risk characterization. Problem formulation defines the problem and plan for analyzing and characterizing the risk. Data on stressor characteristics, ecosystem(s) at risk, potential ecological effects, and ecosystem and receptor(s) characteristics are described in this phase. From these data, assessment (i.e., the environmental value we are trying to protect) and measurement (i.e., tools used to measure effects on assessment endpoints) and a conceptual model are developed to prepare the analysis plan. (i.e., where risk hypotheses are evaluated). The conceptual model at the completion of problem formulation uses information on the ecosystems at risk, stressor characteristics, biological effects, and relationships between endpoints to define exposure and effects scenarios. 
The objective of the conceptual model is to formulate hypotheses to determine how the stressor may affect the exposed ecosystem(s).

Phase II of the ERA is risk analysis, and it characterizes two major components of risk: exposure and effects. Characterizing exposure includes: results of measurements of exposure to indicate distributions and amount (intensity) at points of potential contact with receptor(s), and spatial and temporal distributions of exposure to the stressor. Characterizing effects includes: results of measurements showing the responses of endpoints to variations in exposure, response analysis (quantitative analysis of data), and defining the relationship between magnitude and duration of exposure and the endpoint effects.

Risk characterization is the final phase where the results of the analysis phase are synthesized to estimate and describe risks. It uses the results of the analysis of exposure (occurrence and magnitude) and the severity of effects resulting from such exposures to develop risk estimates for the ecological entities listed as assessment endpoints. The final step in risk characterization is describing and interpreting results of risk characterization for communication to the risk manager.

In the evolution of the ERA process for contaminants, the first approach was the calculation of a hazard quotient (HQ) which is the quotient of an estimate of the measured (or predicted) exposure concentration (i.e., in water, sediment) divided by the threshold or safe-level determined from a concentration-response relationship. Screening benchmarks such as U.S. EPA water and sediment quality criteria for contaminants have been typically used as thresholds. Hazard quotients are therefore point estimates used to protect species. The simple HQ approach is classically used to rebut presumptions of a 
potential for adverse effects and it is typically used with contaminants in the early stage of an ecological risk assessment. If the quotient exceeds 1, an adverse effect (i.e., hazard) is expected to occur and cannot be rebutted. The HQ approach is conservative for contaminants and very protective. Since the HQ approach is based on point estimates it cannot be used to establish risk, which implies likelihood and is defined by probabilities. Risk is a product of likelihood of exposure and consequence (or magnitude of the effect). Risk is therefore expressed as probability of harm to a biological component of the environment. In the approach described in this section, risk to aquatic biota as a result of salinity change will be developed. For salinity, there are no screening benchmarks and because of the potential variability of salinity in a system a probabilistic approach will be more applicable.

Over the last twenty years ecological risk assessment has used probabilistic risk assessment (PRA) methods (Suter, 2007). PRA allows the inclusion of estimates of uncertainty as well as the stochastic properties of exposures and biological responses. This approach includes recognition that there are no situations where there is no risk of effect and there are few, if any, situations of complete certainty that an effect will occur. There is, in fact, a continuum of potential exposure and effect scenarios. This enables a natural resource manager to make decisions on the degree of overlap between the exposure and effects functions that are acceptable. For example, a natural resource decision manager can determine that a certain percentage of the species in a specific aquatic system must be protected. Based on the results of a PRA, a natural resource manager could predict the probability that this could be achieved. The manager may suggest that the concentration of contaminants (or salinity change) associated with this 
level of protection be exceeded only $\mathrm{x} \%$ of the time. For contaminants, like pesticides, application rates and patterns can be adjusted to obtain a high degree of certainty that the desired level of protection will be obtained.

The CERP includes extensive water management operational changes, structural changes to improve how and when water is delivered to the Everglades and removal of canals and levees that prevent natural overland sheet flow. Monitoring data are presently being generated to determine ecosystem conditions, identify cause-effect relationships and problems, and to evaluate restoration activities. The CERP monitoring and assessment plan (MA) identifies and describes key performance measures as indicators of the natural and man-made systems that are characteristic of a healthy system that will be used to assess restoration success.

Under the Southern Estuary Module of RECOVER (Restoration, Coordination and Verification) one hypothesis is that the return (or restoration) of natural salinity regimes along the shoreline as a result of CERP will increase diversity and density of fish assemblages along the mangrove shorelines of Florida Bay and Biscayne Bay (RECOVER, 2008). RECOVER is a support program within the CERP designed to assess, evaluate and improve the Plan during its implementation. The use of a PRA approach will be a valuable tool to assist scientists and natural resource managers with the performance measures used by RECOVER under CERP to determine how salinity changes affect the health of fish assemblages in the Florida Bay ecosystem.

General Probabilistic Risk Assessment (PRA) Approach and Methods

The specific risk characterization methods for conducting probabilistic ERAs have been extensively used by the U.S.EPA and discussed in detail with contaminants 
(ECOFRAM 1999; Giddings et al. 2000; Giesy et al. 1999; SETAC 1994; Solomon et al. 1996; Hall et al., 1998, 1999, 2000; Schuler and Rand, 2008). PRA can incorporate principles of population dynamics, community resiliency and recovery, and functional redundancy in ecosystems. This approach acknowledges that occasionally exceedence of an adverse exposure condition (e.g., high toxic contaminant concentration) to a sensitive species may be accepted if the effected species can recover, is not critical to the function of the system under investigation and is not important as an endangered or threatened species or one of economic importance.

PRAs have had limited use for evaluating other non-contaminant stressors (Hart et al. 2003) although Bayesian probability methods have recently received considerable attention for a number of ecological issues including salinity changes (Sadoddin et al. 2005; Hickey et al. 2008). Bayesian networks can predict oxygen demand on the basis of carbon input (Borsuk et al. 2001a), nutrient reduction strategies for estuaries (Borsuk et al. 2001b), and levels of cyanobacteria (Stow et al. 1997).

Using probabilistic risk assessment in Risk Characterization-Phase III of the U.S.EPA ERA characterizes risk by comparing environmental exposure concentrations (either actual or modeled for stressor(s)) with a distribution of species sensitivity response (or toxicity) data (ECOFRAM 1999). The overlap of the distributions is proportional to the degree (or magnitude) of risk. A major advantage of this approach is that it uses all species response data and when combined with the exposure distributions from a site allows a quantitative estimation of risk to aquatic organisms. The response data (or measurement endpoints) are typically from laboratory studies. For contaminants, the response data used in the distributions are survival, growth and reproduction of 
species tested singly in the laboratory and the assessment endpoint (environmental value to be protected) usually includes community and ecosystem structural and functional attributes in the field. Although the PRA approach is a valuable tool for a natural resource manager the data needed may not always be available therefore it will also serve to identify important data gaps.

To link measurement and assessment endpoints, species sensitivity distributions (SSDs) are used which were developed to estimate water quality standards that would protect some percentage of species in the environment. SSD curves are exposureresponse models that use a large laboratory data set of species responses (or test endpoint values) with emphasis on using local or site-specific data. Therefore, a percentile (or proportion) of the distribution of responses for different species can be used to represent a concentration that may affect that percentage of the exposed community. For example, the SSD may be used to estimate a level of effect associated with a given level of exposure or to estimate the level of exposure corresponding to a level of effect (Suter, 2007).

It is assumed that the laboratory data used in the SSD can also be used to protect single species in the field and that an appropriate level of single-species protection will also protect populations, communities and ecosystems although many species to be exposed have not been tested. A major requirement of the SSD method is that enough species have to be tested to define the SSD and that they are representative of the receiving community. The U.S.EPA uses eight species from eight different families in developing SSDs for water quality criteria (Stephan et al. 1985) but in the Netherlands they use as few as four species in an SSD (Aldenberg and Slob 1993). When few data are 
available for developing SSDs significant uncertainty is added to the extrapolation.

Variance due to laboratory test conditions and test protocols are another source of uncertainty for interpretation of SSDs. In contrast, the salinity approach described below uses data of responses from the field for developing the SSD. This not only eliminates some of the uncertainty in the SSD but also provides a more accurate indication of risk since the distribution of salinity responses are being compared to actual environmental salinity exposure distributions at a field site.

All response data for SSDs are assumed to fit a log-logistic distribution and responses are plotted against rank-assigned percentiles but other functions may be used (ECOFRAM 1999; de Zwart 2002). Any statistical software used for regression analysis can be used to fit the distribution and calculate percentiles. Although the assumptions of the SSD method have been criticized (Forbes and Forbes 1993; Smith and Cairns 1993) recent investigators showed that SSD curves resulting from laboratory data were similar to those from semi-field mesocosm data which supports the SSD method for predicting safe concentrations (Hose and Brink 2004; Schroer et al.2004; Van den Brink et al. 2002).

The last step in the PRA may also consist of applying use of joint probability curves (JPCs, or exceedence profiles). JPCs characterize "the relationship between magnitude of effect and the probability of occurrence for that effect" (ECOFRAM 1999, Solomon et al. 2000). Both exposure and response distributions are converted to straight line transformations of probability functions using probit transformation. JPCs are used to determine the probability of exceeding a concentration associated with a particular response (or effect). A point on the JPC for a sampling site thus represents the probability 
(\%) of the surface water exposure concentrations (e.g., of a contaminant or salinity) exceeding the response endpoint for $\mathrm{x} \%$ of the species. The curve represents the foundation of PRA because it establishes the proportion of species that will be affected and the frequency or percentage of time for such effects based on the available exposure observations (Solomon et al. 2000). This approach provides a means of comparing relative potential risk at sites when the response and exposure information are adequate.

Figures 4.2 and 4.3 provide an example of the PRA approach using the joint probability method. In Figure 4.2, the exposure concentrations and responses (effects) are characterized by regression lines and are used to generate a joint probability curve (JPC) of the exceedence data (Figure 4.4). In Figure 4.2, the concentration value at which $10 \%$ of the species responses will be exceeded is approximately $60 \mu \mathrm{g} / \mathrm{L}$. Around $95 \%$ of the exposures (e.g., water concentrations of a contaminant or salinity) would be equal too or less than this value. In addition, $5 \%$ of the time this value (or exceedence value for exposure) will be exceeded. The lower the concentration value, the higher the protection because a smaller number of species would be affected. However, there is a higher probability of exceeding this value. For example, in Figure 4.3 the probability of exposures exceeding the responses for $10 \%$ of the species responses is roughly $50 \%$. Figure 4.4 illustrates the decision making interpretation of a JPC, with risk decreasing as the curve approaches the axes.

Another approach to quantifying risk is to calculate the area under the curve (AUC) from the joint probability functions. The AUC is mathematically equivalent to the mean risk, and can be used to compare and rank risk curves (Giddings et al. 2005). The AUC can be expressed as a percentage estimating risk likelihood. 
There are four major sources of uncertainty in an ecological risk assessment: stochasticity (natural variation), lack of information (i.e., data gaps), human and analytical error, and flawed model assumptions (Suter, 1993). The nature of uncertainties in the findings is discussed in light of the exposure and response analysis and risk characterization.

An Ecological Risk Assessment of Salinity in Northeast Florida Bay using the U.S.EPA Framework and PRA Approach

The present paper proposes a modified framework for an environmental risk assessment of salinity in northeast Florida Bay. I have used the U.S. EPA paradigm for risk assessment as the conceptual and procedural framework for this analysis. The EPA framework was designed for use with chemical and metal toxicants. Effects data are usually generated in the laboratory from a series of acute and chronic toxicity tests on various organisms representing single or multiple taxa.

With many contaminants, the determination of negative effects and risk is straightforward and characterized by a measureable endpoint such as an LC50 (lethal concentration whereby $50 \%$ mortality observed). The LC50 is but one endpoint amongst several acute, chronic and sublethal endpoints generated by toxicity studies and used in risk assessments. Exposure values that exceed the LC50 or other endpoint are considered conditions of risk whereas those exposure values that fall below the endpoint are considered to pose less risk. The percent and distribution of the exceedences are then used to calculate the risk in a given scenario.

For estuarine fish, salinity presents a two-tailed challenge for risk assessment. Exposure values that exceed as well as fall below the salinity tolerance range must be 
considered. In this case, it is not adequate to only consider the exceedences. Hence, modifications were made to the U.S. EPA risk framework for the analysis of salinity risk.

The following terminology was used in this risk assessment and may prove helpful to the reader.

Diversity as Simpson's Index (D) -- A robust measure of biological diversity where $0<\mathrm{D}$ $<1$. As the value of D increases, diversity decreases (Magurran, 2004).

Salinity guild - The numerical designation of salinity designed for this ERA and based upon the categories used in the Venice System for salinity classification (1959). The range is $1-5$ (Table 4.1).

Desired Conditions/Criteria - The salinity conditions related to higher diversity as defined by $\mathrm{D}<0.5$.

Salinity affinity - The mean salinity at which a particular species was collected from 1990-2006 from the National Audubon Society data set for northeast Florida Bay.

Hydrologic (Hydro) year (HY) - The 365 or 366 day period starting June 1 and ending May 31, coordinated with the wet-dry cycle in this subtropical landscape.

Problem Formulation

Study Area and Ecosystem at Potential Risk

Florida Bay is a large, shallow (average depth 6-9 feet), subtropical estuary on the southern coast of Florida that, along with the Gulf of Mexico, receives water from the Everglades system (Lodge, 2005). The Bay (and its natural tributaries) is within the boundaries of Everglades National Park (Figure 4.5). In the past century, the ecology, hydrology and water quality of the Florida Bay ecosystem has been altered by anthropogenic activities (Science Subgroup, 1996). Increased levels of salinity have been detected in northeast Florida Bay surface water (Davis and Ogden, 1994) as a result of changes in freshwater flow patterns in the area due to anthropogenic manipulation of the Everglades system. 
Although salinity has been identified as a driver for organism distribution and abundance, a quantitative aquatic risk assessment has not been conducted for salinity in south Florida aquatic ecosystems. Recent chemical ERAs have been performed for fresh and saltwater environments in south Florida that determined risk from levels of pesticides and other contaminants in surface waters, sediments and biota (Carriger and Rand, 2008a \& 2008b; Schuler et al., 2008; Schuler and Rand, 2008). Ecological risk assessments have been conducted for salinity (Hart et al., 2003) as a result of saltwater intrusion in Australian terrestrial systems, but for estuarine systems like northeast Florida Bay, the potential ecological risk is largely unquantified.

This risk assessment will build upon, and contribute to, the existing body of work from many researchers on the patterns, effects and implications of salinity change in Florida Bay in the context of the CERP. Of particular importance to this risk assessment is the data set collected the National Audubon Society, Tavernier Science Center (Lorenz and Serafy, 2006 and additional unpublished data provided by the authors). This data set is comprised of demersal fish monitoring data and salinity from multiple locations in northeast Florida Bay sampled seasonally over a 16 year timeframe. Results from this monitoring study indicate that the reduction of freshwater flow into the Bay has reduced the demersal fish population and that restoration of freshwater inflows may aid in the rebound of these populations (Lorenz and Serafy, 2006).

Assessment and Measurement Endpoints

The U.S.EPA (1998) provides three criteria for the selection of assessment endpoints: (1) ecological relevance, (2) susceptibility to the potential stressor (i.e., salinity change), and (3) relevance to management goals. In this analysis, diversity and 
abundance (Simpson's index as D) of small demersal fish assemblages in Florida Bay are the environmental values worthy of protection and are therefore the assessment endpoints. Small demersal fish are an important food base in the diet of piscivorous fish, alligators, crocodiles and wading birds (McIvor et al., 1994; Lorenz and Serafy, 2006). In addition, this assessment endpoint is consistent with the performance measures, restoration expectations and targets under the CERP Southern Estuaries Module (RECOVER, 2008).

Conceptual model

The primary objective was to conduct an ecological risk assessment to quantify the likelihood and extent that adverse effects (as a decrease in biological diversity of demersal fish) will occur from exposure to various salinity regimes using the U.S. Environmental Protection Agency (U.S. EPA) Ecological Risk Assessment Framework. Within this context, the objectives were to determine: (1) where and when are the effects likely to be greatest; and (2) which salinity communities are at greatest risk? Risk Analysis

Exposure Assessment

The exposure assessment was designed to examine the co-occurrence of the stressor salinity in surface waters of Florida Bay with the ecological responses (or effects) discussed below. For exposure, data on daily salinity concentrations (in ppt) in Florida Bay were obtained by using actual measured concentrations (AMCs) in surface waters from monitoring studies from 1990 to 2006 . The data were collected by the National Audubon Society, Tavernier Science Center, and provided by Everglades National Park. 
For construction of the SSD, data from up to 21 sampling sites over the 16 year monitoring program were used. Exposure data were obtained from AMCs of salinity on the day of and at the site of fish collection.

Four sites (Figure 4.6) were chosen as germane to this risk assessment: Joe Bay (JB); Taylor River (TR); Highway Creek (HC); and Barnes Sound (BS). These sites, located in northeast Florida Bay, are habitat for a variety of demersal fish, have experienced high fluctuations in salinity, and are critical feeding grounds for higher trophic level species. They were selected, amongst other similar sites, due to their use in current monitoring studies with the National Audubon Society and Everglades National Park to allow for alignment of this risk assessment with ongoing CERP projects (Lorenz, 1999; Bartell et al., 2004). For each of the above mentioned sampling sites, six hydro year (HY) periods at 3-year increments were analyzed: 1990-1991, 1993-1994, 19961997, 1999-2000, 2002-2003, and 2005-2006. For the JPCs, daily AMC salinity values for each hydro year and sampling site were ranked from smallest to largest. Due the interannual variability within these measurements, the ranked salinity values were assigned a numerical salinity guild (1-5) based upon the Venice Classification (1959) system for salinity as shown in Table 4.1.

Probability distributions of exposure data for the salinity guilds at the different sites were prepared based on the AMCs at each site to evaluate spatial and temporal trends.

Salinity guild values were ranked to develop cumulative distributions (Giddings et al. 2000). Guilds were ranked from smallest to highest and assigned a centile ranking (j) at each site using the equation: 


$$
\text { j } \times 100 /(n+1)
$$

where $\mathrm{j}$ is the rank number assigned to the individual data point and $\mathrm{n}$ is the total number of sample observations at each site. When at least four guild values were available at each site, a log-logistic distribution for salinity exposure data was developed at the site (Hall Jr. et al. 2000). Linear regression was performed using the algorithms found in PRAT-1 software (Solomon et al., 2000).

Response (Effects) Assessment

For the purpose of the SSD, the term 'mean salinity affinity' is used to describe the salinity at which a particular species was most often collected over the course of 16 years of monitoring. The affinity of a given species is used as the response as predicated upon by the driver of environmental exposure. The field data were collected by the National Audubon Society, Tavernier Science Center and provided by Everglades National Park. The dataset was comprised of the species identification and abundance of fish collected at specific dates for each location from the years $1990-2006$ for the same sites as described above (see Appendix A for individual species data). To calculate ranks for all species salinity affinity response data were ordered by concentration according to the same equation in exposure assessment. The calculated ranks were fit to a log-logistic distribution and the resulting SSD was plotted graphically using Microsoft Excel 2007. For a distribution to be considered for analysis, at least four suitable species endpoints (mean salinity affinity responses) had to be available (Aldenberg and Slob 1993).

For generation of the JPCs, the response used was biological diversity as expressed as Simpson's Index D. To calculate D, the abundance and species of fish collected during each HY was tabulated. Each HY contained 6-8 monthly sampling 
events. Simpson's D was calculated for each sampling event within each HY for the sites and HYs listed above using the following equation:

$$
\mathrm{D}=\Sigma\left(\mathrm{n}_{\mathrm{i}}\left(\mathrm{n}_{\mathrm{i}}-1\right)\right) /(\mathrm{N}(\mathrm{N}-1)
$$

where $\mathrm{n}_{\mathrm{i}}$ is the number of individuals in the $i$ th species and $\mathrm{N}$ is the total number of individuals (Magurran, 2004). Calculations were performed using Microsoft Excel 2007 with software developed by Danoff-Burg and Chen (2005). Fish data were screened to only include fish with a total length no greater than $6.5 \mathrm{~cm}$. This value was selected to screen for the size of fish that comprise up to $90 \%$ of the demersal fish community found in the study area (Lorenz and Serafy, 2006).

Traditionally, laboratory endpoints (e.g. LC50, EC50, NOEC) with measureable units (e.g. mg/L) are used as the response data for generating a JPC. The LC50 is used to compare exposed organisms with unexposed organisms to establish criteria for deleterious effects. Inherent in this endpoint is the assumption that any concentration above this value will have greater effects (as \% mortality) towards the group of organisms tested. I employed the LC50 as the conceptual and procedural basis for using a measure of diversity as an effects endpoint.

As mentioned above, $\mathrm{D}$ is a value between 0 and 1 . As $\mathrm{D}$ increases towards 1 , diversity decreases. For this risk assessment I established a value of D less than or equal to 0.50 as the desired criteria for biological diversity. Conceptually this is akin to the LC50 derived from toxicity studies. D-values greater than 0.5 were categorized as above the desired criteria (as would an LC75) and were not used in this risk assessment. To interface with the exposure data and place $\mathrm{D}$ in the context of salinity, the $\mathrm{D}$-values were paired with the salinity guild corresponding to the average salinity for the 60 days 
antecedent to the sampling event for which they were calculated (Data presented in Appendix B). Lorenz (1999) found that a determining factor in fish abundance and distribution in the study area was the mean salinity for the 60 days prior to sampling. The resulting guild values were ranked and treated the same way as the exposure data to create probability distributions.

Risk Characterization

The potential risk of salinity changes at sites in Florida Bay was examined by integrating the probability distributions of the salinity guild exposure concentrations with the effects distribution of diversity (as salinity guild) for each site and hydro year. From the resulting distributions, the degree of overlap between the salinity guild exposure distributions from surface water field data and the salinity guilds that were correlated to increased diversity were determined.

For each JPC generated, the AUC was calculated to yield a measure of risk. The trapezoid rule was used for the AUC calculation in this risk assessment. In this method, the curve was divided into a series of trapezoids based on each data point. The individual area of each trapezoid (A) was calculated using the formula:

$$
A=\left(Y_{n}+Y_{n-1}\right) / 2 *\left(X_{n}-X_{n-1}\right)
$$

Where $Y_{n}$ is the $Y$-column value for the JPC at the $n$th cell and $X_{n}$ is the $X$-column value at the $n$th cell (Liengme, 2002). The sum of the trapezoids is the AUC and is expressed as percent risk. 


\section{Uncertainties}

\section{Effects}

Sources of uncertainty in the exposure analysis are the spatial and temporal limits inherent in the database used for this project and the assumption that the salinities recorded are representative of consistent trends. The entire database spans 16 years and up to 21 sites which include many small embayments with individual hydropatterns. However, for consistency with other on-going projects, this risk assessment employed a subset of sampling sites and hydro years.

Exposure

The potential effects of single action or joint action of salinity with other biotic and/ or abiotic factors such as temperature, dissolved oxygen, water depth, food availability or predation on determining fish diversity, distribution and abundance was not considered in the effects analysis. The goal of this ERA was to examine salinity as a single driver for biological diversity since salinity regimes in the area can be controlled (to a degree) through water management activities whereas other biotic/abiotic factors are less easily regulated.

Results

Species Sensitivity Distribution

The SSD was constructed for 42 demersal fish species collected over a 16 year period in northeast Florida Bay (Figure 4.7). The SSD represents the mean salinity affinity for each species sampled, and species are organized according to salinity category. Though estuarine fish have a wide range of salinity tolerance, the mean salinity affinity is reflective of the most common 'preference' for each species. Based on the 
SSD, the $90^{\text {th }}$ centile is 13.4 ppt. Hence, $90 \%$ of the species collected are commonly found at this salinity or below. The $10^{\text {th }}$ centile is 0.209 ppt. Below this salinity less than $10 \%$ of the sampled fish populations are commonly found. Summary tables of salinity conditions for each sampling location are provided in Tables $4.2-4.5$. The percent of salinity values between $5-15 \mathrm{ppt}$ and between $0.5-13.4 \mathrm{ppt}$ are provided for consideration in the context of the Florida Bay/Florida Keys Feasibility Study (FBFKFS) salinity targets, which will be discussed in later in this paper.

Probability distributions

The JPCs constructed for each sampling site are presented in Figures 4.8-4.11. The $y$-axis for each curve marks the percent of time that the desired criteria are not met either because salinities exceed or fall below the desired range. The $x$-axis represents the percent of desired criteria that is met. The percentiles used to for the risk assessment are developed by the resource manager and/ or regulatory agency as acceptable for the management goals. In this case, I have assigned a conservative value of $80 \%$ for the protection of the desired conditions (i.e. increased diversity). The JPC can than be used to determine what percent of the HY was protective of $80 \%$ of the desired conditions. Figure 4.8 is the JPC for Joe Bay. For the hydro year 1993-1994, $80 \%$ of the desired criteria (x-axis) corresponds to a point on the curve that indicates that roughly $10 \%$ of the year the desired conditions were not me. Hence, 1993-1994 can be considered a year of low risk as compared to other years by meeting desired conditions slightly over $90 \%$ of the time.

Tables 4.6-4.9 summarize the information in the JPCs. I assigned a value of $>$ $80 \%$ of the HY as a target for these tables. The percent time of the HY that is protective 
of $80 \%$ of the desired condition is listed in the central column of each table. Hydro years that were protective of desired conditions greater than $80 \%$ of the time are highlighted (read as $80 \%$ protective of higher diversity for $\geq 80 \%$ of the HY).

An additional way to interpret the JPC is through calculation of the area under the curve. The AUCs, presented as 'percent mean risk', are provided in the right-most column of each table. Note that all AUCs under 50\% correspond to the same HYs and locations as those that are $80 \%$ protective of diversity greater than $80 \%$ of the hydro year. Discussion and Recommendations

Environmental risk assessment is an analytical tool employed by regulatory agencies to support the decision-making process for environmental stewardship. As such, the ERA can be used to address protection goals and identify those scenarios that likely contribute to 'risk' to a given system.

Declines in seagrass beds, coral communities, and wading bird and fish populations in Florida Bay and the Everglades have been linked to contaminant exposure and changes in the hydrological patterns of the natural system as a result of water management projects to control floods and water distribution (Science Subgroup, 1996). Changes in plant and animal assemblages resulting from habitat alteration/ destruction and salinity changes have also been observed (Davis and Ogden, 1994). Consequently, alterations in the hydrological system are thought to be the main cause of declines of fish and wildlife populations due to habitat changes. The Comprehensive Everglades Restoration Plan (CERP) was formulated as part of the Water Resources Development Act (1996) with the goal of restoring hydrologic conditions that support biodiversity, 
ensure the quality of the remaining habitats and foster sustainable development for the region.

Though a large body of work exists on the effects of salinity on fish species, much of these data are for nonnative species. Especially in regards to salinity, upper and lower tolerances derived in a laboratory (or seen in the field) often exceed those that are biologically beneficial to the organism (Haney et al., 1999; Kefford et al., 2004). It is also known that salinity tolerance can be an inheritable trait and site-specific to a given population of fish (Holt and Holt, 2003; Bachman and Rand, 2008). One goal of this aquatic risk assessment was to focus on south Florida species and tailor the PRA to the CERP and, in particular, northeast Florida Bay. As such, the ENP/Audubon field data provided the 'real-time' response of native and local species to the salinity regimes in this area based on multiple years of data. This factor alone makes this ERA unique as traditionally laboratory derived effects data are used in generating risk assessments.

Currently, the Florida Bay/Florida Keys Feasibility Study (FBFKFS) outlines target salinity ranges for areas of northeast Florida Bay as part of the CERP (Rudnick. 2005). These targets were chosen based on paleoecological data for the area and 'best professional judgment (Rudnick, 2005). The Joe Bay (JB). Barnes Sound (BS) and Highway Creek (HC) sites are all within the boundaries of a zone that has a restoration target salinity range of 5-15 ppt (Figure 4.5). The Taylor River (TR) site is more inland than the other three sites and as such is not included in the FBFKFS salinity zones.

This probabilistic ecological risk assessment focused on data from four sampling sites for 6 hydro years spanning a 16 year period. Several conclusions on risk were reached. The highest potential risk to biological diversity associated with salinity was 
seen in Barnes Sound. The mean salinities for this site were all greater than 16.58 (range 16.58 to $20.82 \mathrm{ppt}$ ) and BS had the least amount of hydro years that were protective of biological diversity based upon the criteria selected $(80 \%$ protection for $\geq 80 \%$ of the HY). The salinity guild categories that corresponded to the low risk years were categories 4 and $5(18.00-30.00+p p t)$. The lowest potential risk of salinity to demersal fish diversity was at the Highway Creek sampling site, with only 1 out of 6 years not meeting the protection criteria selected. Mean salinities ranged from 1.96 to $17.15 \mathrm{ppt}$ for this site and low risk values ranged from 30.8 to $45.24 \%$. For HC, four of the five years had salinity guilds values in categories 2 to 3 (range $1.00-17.99 \mathrm{ppt}$ ) that met the desired criteria. The fifth year had a guild value in category 4 (18.00 -29.99 ppt). The Joe Bay and Taylor River sites both showed low risk 3 out of 6 hydro years. For Joe Bay, the mean salinities ranged from 1.81 to $28.51 \mathrm{ppt}$ and low risk values ranged from 22.43 to $46.89 \%$. Salinities that met requirements for the $80 \%$ of the desired criteria fell into guild categories $2 \& 3$ for Joe Bay. The Taylor River site had mean salinities ranging from 2.35 to $24.77 \mathrm{ppt}$. and low risk values of 45.47 to $48.86 \%$. The corresponding salinity guilds for the low risk years all fell within guild category $2(1.00-4.99 \mathrm{ppt})$.

The majority of low risk years for Joe Bay, Highway Creek and Taylor River coincided with HYs that included significant portions of the year with low salinities indicating that freshwater and oligohaline conditions may be favorable to increased diversity. For all three sites, the majority of low risk years also corresponded to a greater percentage of the HY between 0.0 and $13.4 \mathrm{ppt}$ (the range for the $90^{\text {th }}$ centile determined from the SSD). However, in Joe Bay, those years that had a higher percentage of the HY at salinities $<0.5 \mathrm{ppt}$ corresponded to the years of highest risk. While freshwater 
conditions appear to be related to increased diversity, extended freshwater conditions can have adverse effects at this site. Conversely, the Taylor River site (which is more inland and receives freshwater from the Taylor Slough) showed lowest risk for the majority of years that had the highest percentage of $<0.5$ ppt conditions. The highest risk (at TR) was seen in the majority of HYs that had a higher frequency of salinities $>13.4 \mathrm{ppt}$, indicting that very low salinity/freshwater is a driver of diversity at this site. At the Barnes Sound site, the higher salinity years showed less risk, and were related to those years which had a higher percentage of the HY $>13.4 \mathrm{ppt}$ (the SSD $90^{\text {th }}$ centile).

Based on the SSD, a salinity value of $5.00 \mathrm{ppt}$ is equal to the $75^{\text {th }}$ centile. Therefore, targeting a range of 5-15 ppt for these areas (as suggested by the FBFKFS) could likely create adverse conditions for $75 \%$ of the fish species commonly found in the area. The 16-year sampling data indicates that these areas are dominated by freshwater and oligohaline species. If one of the management goals for the area is to increase diversity and density of species along the coastal areas of northeast Florida Bay, than tools such as this SSD, which takes into account field recorded responses to environmental conditions, should be used along with other performance measure of ecosystem health and historical data in the decision making process.

In the context of the FBFKFS, this risk assessment approach has shown that the proposed salinity targets may not meet the requirements for increased biological diversity in the sampling sites analyzed. Three of the four sites (JB, HC, and TR) exhibited a higher frequency of meeting the requirements for increased diversity within a salinity range that encompassed freshwater, oligohaline and mesohaline salinities. Based on the data generated in this ERA, the proposed salinity target of 5-15 ppt for these areas is too 
narrow and may exclude those species that have more affinity for freshwater and oligohaline conditions. The duration of freshwater conditions also contributed to the risk for Joe Bay, thus consideration should be given to length of the freshwater conditions in these areas that are proximal to the Bay rather than inland like the TR site. Barnes Sound had overall higher salinities, with the years of lowest risk at BS corresponding to salinities greater than the $90^{\text {th }}$ centile in the SSD. In the case of BS, management decisions need to be made as to whether target salinities will favor the freshwater, oligohaline and mesohaline as indicted by the SSDs $90^{\text {th }}$ centile, or different salinity categories such as meso- and polyhaline. The data analyzed for this risk assessment indicate that increased diversity can be achieved with higher salinities in this area.

In the case of management decisions for northeast Bay, the SSD and ERA are tools that can be used to establish salinity criteria that are protective of a majority of the demersal fish population. Using field responses in lieu of laboratory data in the ERA can assure greater certainty in risk prediction when the primary measure of exposure is from actual salinity monitoring in Florida Bay and not model predicted values.

This is a novel approach to risk assessment using a natural abiotic component of an ecological system that has become altered due to anthropogenic activities, and as such can be viewed similar to a contaminant. Using the U.S. EPA framework, I have shown that a risk assessment using salinity is feasible and can be used as a supplemental tool to environmental regulators/agencies in the decision making process for the CERP.

Environmental risk assessment plays an important role in the regulatory decision making process. However, risk assessments should be viewed as but one part of a larger process that factors in scientific predictions alongside economic, political, and social 
concerns (Johnson et al., 2007). The valuation placed upon ecosystems or their functional components, the amount of risk that is deemed 'acceptable', and the feasibly both economically \& technologically of mitigating the risk all play a role in driving the decision making of resource managers and regulators.

Acknowledgments: I wish to thank Everglades National Park and Jerome J. Lorenz of the National Audubon Society for use of the monitoring data employed in this environmental risk assessment. 


\section{References}

Aldenberg, T., W. Slob. 1993. Confidence limits for hazardous concentrations based on logistically distributed NOEC toxicity data. Ecotoxicology and Environmental Safety 25:48-63.

Bachman, P.M. and G.M. Rand. 2008. Effects of salinity on native estuarine fish species in South Florida. Ecotoxicology 17 (7): 591-597.

Bartell, S.M., Lorenz, J.J., Nuttle, W.K. 2004. Ecological models for ENP evaluation of CERP activities: Roseate Spoonbill Habitat Suitability Index model. Report to South Florida Research Center, Everglades National Park, Homestead, FL.

Borsuk, M.E., D. Higdon, C.A. Stow, and K.H. Reckhow. 2001a. A Bayesian hierarchical model to predict benthic oxygen demand from organic matter loading in estuaries and coastal zones. Ecological Modelling 143: 165-181.

Borsuk, M., R. Clemen, L. Maguire, and K. Reckhow. 2001b. Stakeholder values and scientific modeling in the Neuse river watershed. Group Decision and Negotiation 10: $355-373$.

Carriger J.F. and G.M. Rand. 2008a. Aquatic risk assessment of pesticides in surface waters in and adjacent to the Everglades and Biscayne National Parks: I. Hazard assessment and problem formulation. Ecotoxicology 17 (7): 660-679.

Carriger J.F. and G.M. Rand. 2008a. Aquatic risk assessment of pesticides in surface waters in and adjacent to the Everglades and Biscayne National Parks: II. Probabilistic analyses. Ecotoxicology 17 (7): 680-696.

Danoff-Burg, J.A.and Chen, X. 2005. Abundance curve calculator. Columbia University. http://www.columbia.edu/itc/cerc/danoff-burg/MBD_Links.html

Davis S.M. and J.C. Ogden. 1994. Everglades: the ecosystem and its restoration. St. Lucie Press, Delray Beach, Florida, USA.

De Zwart, D. 2002. Observed regularities in species sensitivity distributions for aquatic species. In, L. Posthuma, G.W. Suter II, and T.P. Traas (eds.), Species Sensitivity Distributions in Ecotoxicology. Lewis Publishers, Boca Raton, FL USA.

ECOFRAM. 1999. Ecological Committee on FIFRA Risk Assessment Methods: Report of the Aquatic Workgroup. U.S. Environmental Protection Agency, Office of Pesticide Programs, Washington, DC USA.

Forbes, T.L., and V.E. Forbes. 1993. A critique of the use of distribution-based extrapolation models in ecotoxicology. Functional Ecology 7: 249-254. 
Giddings, J.M., L.W. Hall, Jr., and K.R. Solomon. 2000. Ecological risks of diazinon from agricultural use in the Sacramento-San Joaquin River Basins, California. Risk Analysis 20 (5): 545-572.

Giddings, J.M., T.A. Anderson, L.W. Hall, Jr., A.J. Hosmer, R.J. Kendall, R.P. Richards, K.R. Solomon and W.M. Williams. 2005. Atrazine in North American surface waters: A probabilistic aquatic ecological risk assessment. Pensacola (FL): Society of Environmental Toxicology and Chemistry (SETAC). 432 p.

Giesy, J.P., K.R. Solomon, J.R. Coats, K.R. Dixon, J.M. Giddings, and E.E. Kenaga. 1999. Chlorpyrifos: Ecological risk assessment in North American aquatic environments. Reviews of Environmental Contamination and Toxicology 160: 1129.

Hall, Jr., L.W., M.C. Scott, and W.D. Killen. 1998. Ecological risk assessment of copper and cadmium in surface waters of Chesapeake Bay watershed. Environmental Toxicology and Chemistry 17 (6): 1172-1189.

Hall, Jr., L.W., M.C. Scott, W.D. Killen, and M.A. Unger. 2000. A probabilistic ecological risk assessment of tributyltin in surface waters of the Chesapeake Bay watershed. Human and Ecological Risk Assessment 6 (1): 141-179.

Hall, M.O., M.J. Durako, J.W. Fourqurean, and J.C. Zieman. 1999. Decadal changes in seagrass distribution and abundance in Florida Bay. Estuaries 22 (2B): 445-459.

Haney, D.C., Nordlie, F.G., and J. Binello. 1999. Influence of simulated tidal changes in ambient salinity on routine metabolic rate in Cyprinodon variegatus. Copeia.199 (2): $509-514$.

Hart, B.T., P.S. Lake, J.A. Webb, and M.R. Grace. 2003. Ecological risk to aquatic systems from salinity increases. Australian Journal of Botany 51 (6): 689-702.

Hickey, G. L., B. J. Kefford, J. E. Dunlop, and P. S. Craig. 2008. Making species salinity sensitivity distributions reflective of naturally occurring communities: Using rapid testing and Bayesian statistics. Environmental Toxicology and Chemistry 27:2403-2411.

Holt, G.J. and S.A.Holt. (2003) Effects of variable salinity on reproduction and early life stages of Spotted Seatrout. In: Bortone SA(ed) Biology of the Spotted Sea Trout, CRC Press, LLC,Boca Raton, Florida, pp 135-146.

Hose GC and PJ Van den Brink. 2004. Confirming the species-sensitivity distribution concept for endosulfan using laboratory, mesocosm, and field data. Archives of Environmental Contamination and Toxicology 47, 511-520. 
Johnson, K.L., Raybould, A.F., Hudson, M.D. and G.M. Poppy. 2007. How does scientific risk assessment of GM crops fit within the wider risk analysis? Trends in Plant Science. 12 (1):1-5.

Kefford, B.J., Papas, P.J., Metzeling, L., and D. Nugegoda. 2004. Do laboratory salinity tolerances of freshwater animals correspond with their field salinity? Environmental Pollution. 129, 355-362.

Liengme, B. 2002. A Guide to Microsoft Excel 2002 for Scientists and Engineers, 3ed. Elsevier Butterworth-Heinemann. Burlington, MA USA.

Lodge, T.E. 2005. The everglades handbook: understanding the ecosystem, 2nd ed. CRC Press, Boca Raton, Florida

Lorenz, J.J. 1999. The response of fishes to physicochemical changes in the mangroves of northeast Florida Bay. Estuaries 22: 500-517.

Lorenz, J. J. and J. E. Serafy. 2006. Subtroprical wetland fish assemblages and changing salinity regimes: Implications for everglades restoration. Hydrobiologia 569: 401422 .

Magurran AE. 2004. Measuring Biological Diversity. Blackwell Publishing. Malden, MA. USA.

McIvor, C.C., Ley, J.A., and R.D. Bjork. 1994. Changes in freshwater inflow from the Everglades to Florida Bay including effects on biota and biotic processes: a review in Ogden, J.C., and Davis, S.M., editors, Everglades: The ecosystem and its restoration: St. Lucie Press, Del Ray, FL, pp.117-146.

RECOVER. 2008. CERP System-wide Performance Measure Southern Estuaries Performance Measure :Salinity .Last Date Revised: September 2008. Restoration Coordination and Verification Program, c/o United States Army Corps of Engineers, Jacksonville District, Jacksonville, Florida, and South Florida Water Management District, West Palm Beach, Florida.

Rudnick, D. 2005. Florida Bay and Florida Keys Feasibility Study Performance Measure Documentation Report. Last date reviewed: October 2005. South Florida Water Management District, West Palm Beach, Florida.

Sadoddin, A., R.A. Letcher, A.J. Jakeman, and L.T.H. Newham. 2005. A Bayesian decision network approach for assessing the ecological impacts of salinity management. Mathematics and Computers in Simulation 69 (1-2): 162-176. 
Schroer, A. F. W., J. D. M. Belgers, T. C. M. Brock, A. M. Matser, S. J. Maund, and P. J. Van den Brink. 2004. Comparison of laboratory single species and field population-level effects of the pyrethroid insecticide lambda-cyhalothrin on freshwater invertebrates. Archives of Environmental Contamination and Toxicology 46: 324-335.

Schuler, L.J., and G.M. Rand. 2008. Aquatic risk assessment of herbicides in freshwater ecosystems of south Florida. Archives of Environmental Contamination and Toxicology 54: 571-583.

Schuler, L.J., Hoang, T.C. and G.M. Rand. 2008. Aquatic risk assessment of copper in freshwater and saltwater ecosystems of South Florida. Ecotoxicology 17 (7): 642659.

Science Subgroup. 1996. South Florida Ecosystem Restoration: Scientific Information Needs. Report to the Working Group of the South Florida Ecosystem Restoration Task Force. Miami, FL.

SETAC. 1994. Pesticide Risk and Mitigation: Final Report of the Aquatic Risk Assessment and Mitigation Dialogue Group. Society of Environmental Toxicology and Chemistry, Foundation for Environmental Education, Pensacola, FL.

Smith, E.P., and J. Cairns, Jr. 1993. Extrapolation methods for setting ecological standards for water quality, statistical and ecological concerns. Ecotoxicology 2: 203-219.

Solomon, K.R., D.B. Baker, R.P. Richards, K.R. Dixon, S.J. Klaine, T.W. La Point, R.J. Kendall, C.P. Weisskopf, J.M. Giddings, J.P., Giesy, L.W. Hall, Jr., and W.M. Williams. 1996. Ecological risk assessment of atrazine in North American surface waters. Environmental Toxicology and Chemistry 15 (1): 31-76.

Solomon, K.R., J. Giesy, and P. Jones. 2000. Probabilistic risk assessment of agrochemicals in the environment. Crop Protection 19: 649-655.

Stow, C.A., S.R. Carpenter, and R.C. Lathrop. 1997. A Bayesian observation error model to predict cyanobacterial biovolume from spring total phosphorus in Lake Mendota, Wisconsin. Canadian Journal of Fisheries and Aquatic Sciences 54: 464-473.

Stephan, C.E. 1985. Are the "Guidelines for Deriving National Water Quality Criteria for the Protection of Aquatic Life and Its Uses" based on sound judgments? In Cardwell, R.D., R. Purdy, and R.C. Bahner (eds), Aquatic Toxicology and Hazard Assessment, Seventh Symposium. American Society for Testing and Materials, Philadelphia, PA, USA: pp. 515-526. 
Suter II, G.W. 1993. Ecological Risk Assessment. Lewis Publishers, Boca Raton, FL.

Suter II, G.W. 2007. Ecological Risk Assessment. Second edition. CRC Press, Boca Raton, FL.

U.S.EPA. 1992. Framework for Ecological Risk Assessment. EPA-630-R-92-001. United States Environmental Protection Agency, Risk Assessment Forum, Washington D.C.

U.S.EPA. 1998. Guidelines for ecological risk assessment. EPA/630/R-95/002F. United States Environmental Protection Agency, Office of Water, Washington, D.C.

Van den Brink, P.J., T.C.M. Brock, and L. Posthuma. 2002. The value of the species sensitivity distribution concept for predicting field effects: (Non-)confirmation of the concept using semifield experiments. In L. Posthuma, G.W. Suter II, T.P. Traas (eds), Species Sensitivity Distributions in Ecotoxicology, Lewis Publishers, Boca Raton, FL.

Venice system. 1959. Final resolution of the symposium on the classification of brackish waters. Archo Oceanogr. Limnol., 11 (suppl): 243-248. 


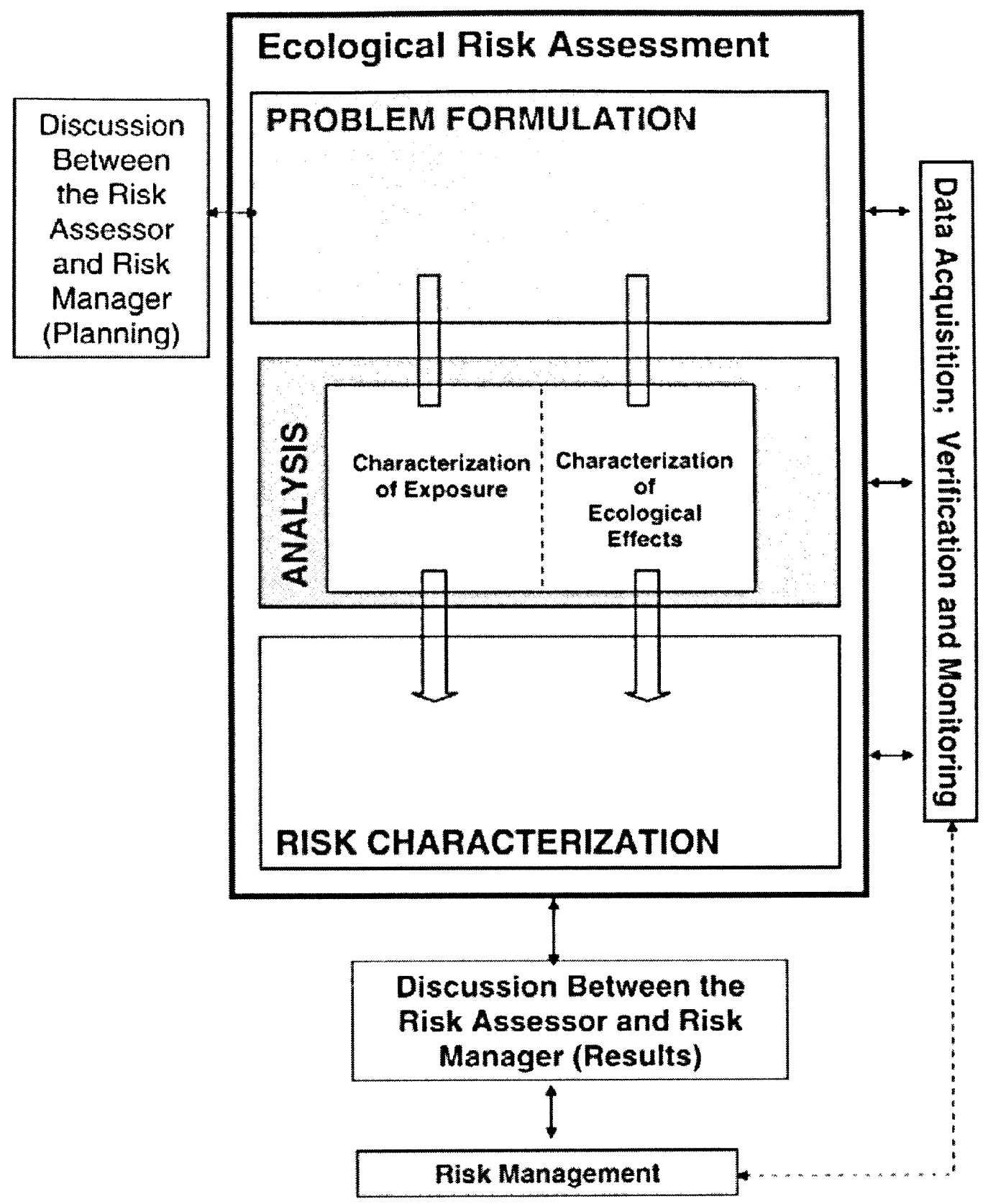

Figure 4.1. The U.S. EPA's (1992) frame work for Ecological Risk Assessment (ERA). 


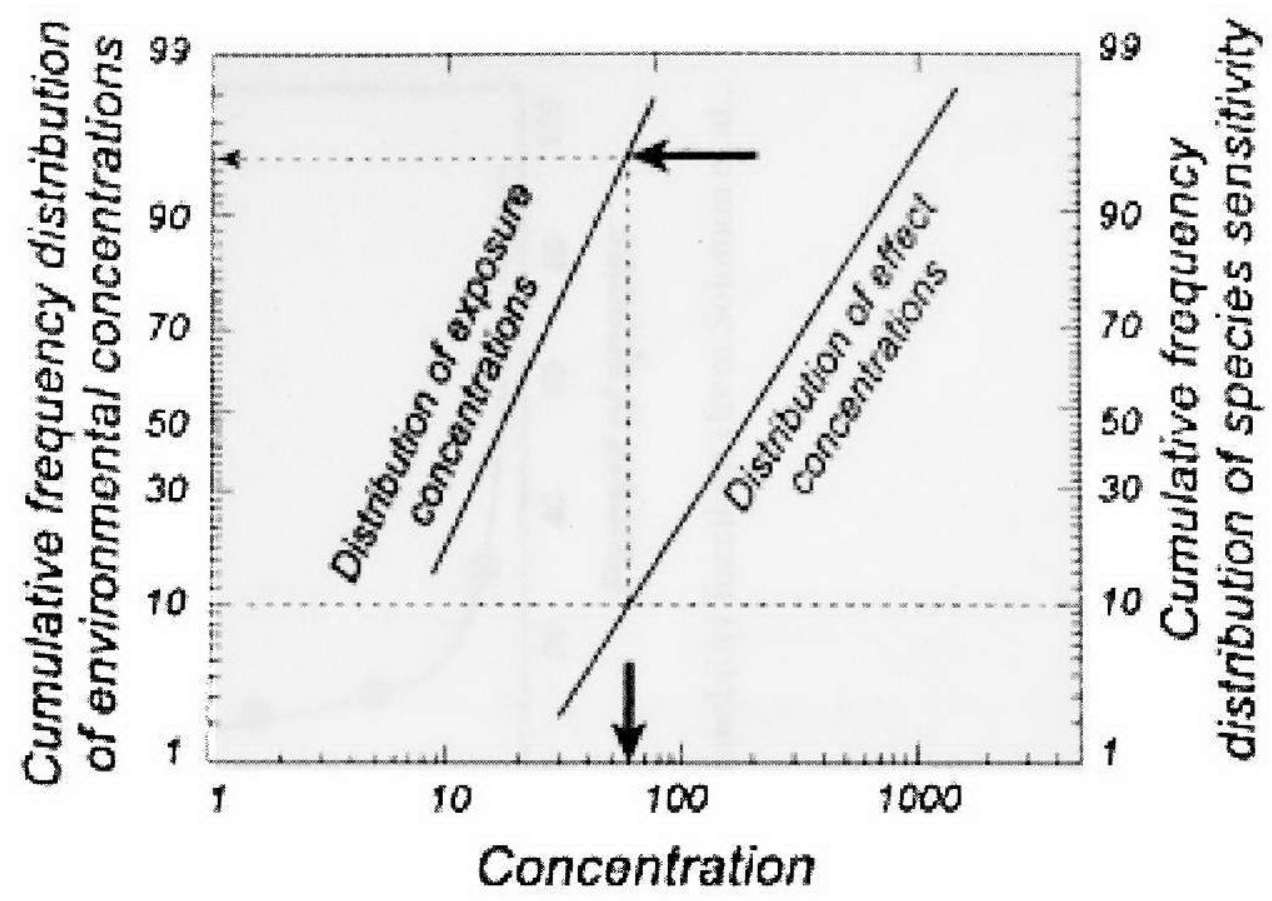

Figure 4.2. Linearized probability distributions of exposure and response (effect) data (from Solomon et al., 2000). 


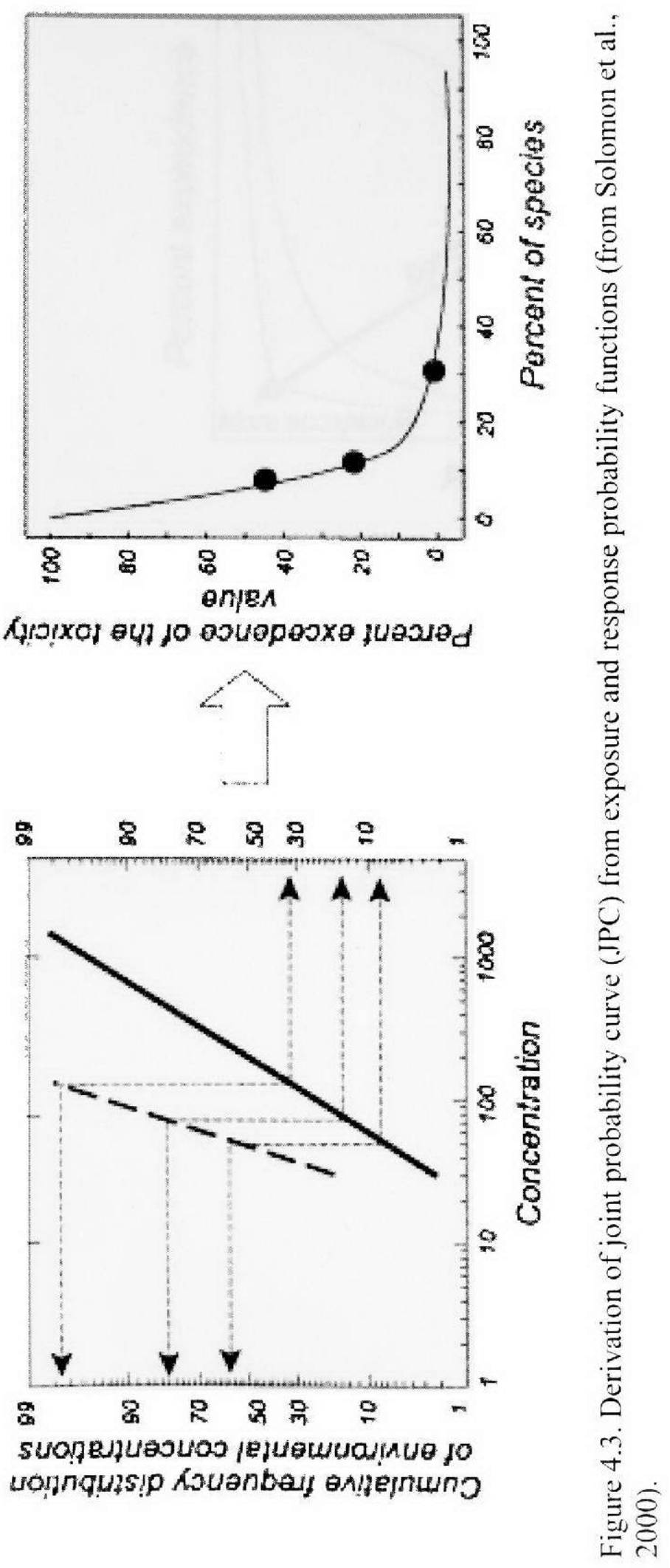




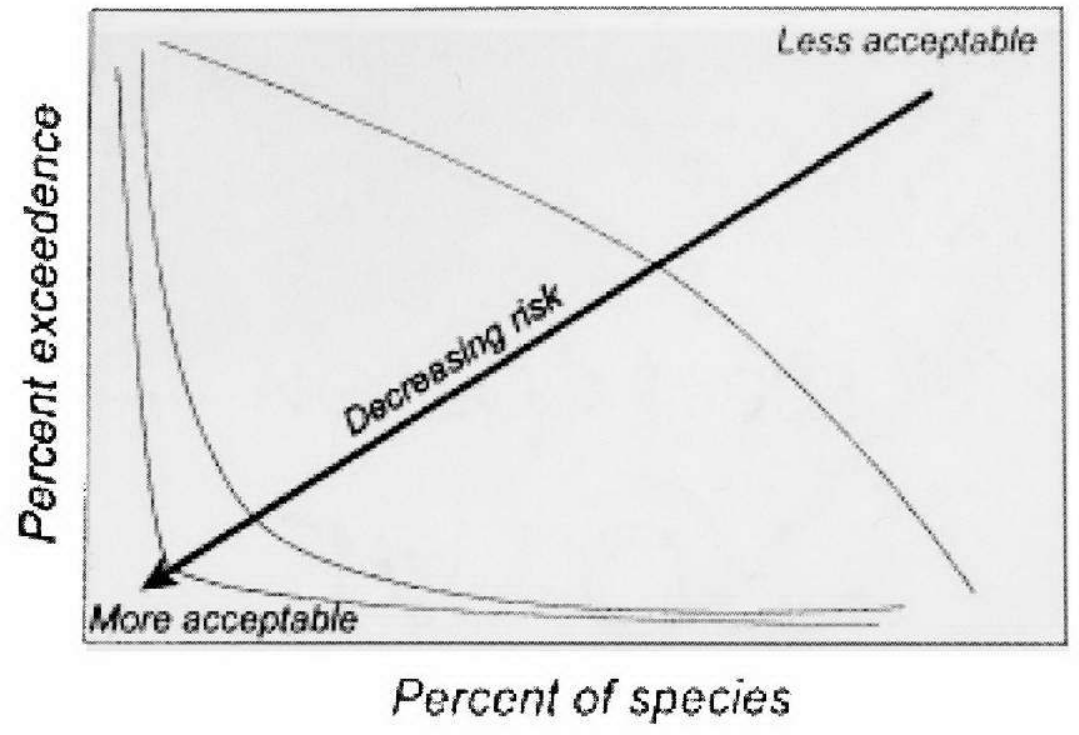

Figure 4.4. Interpretation of JPC in decision making (from Solomon et al., 2000). 


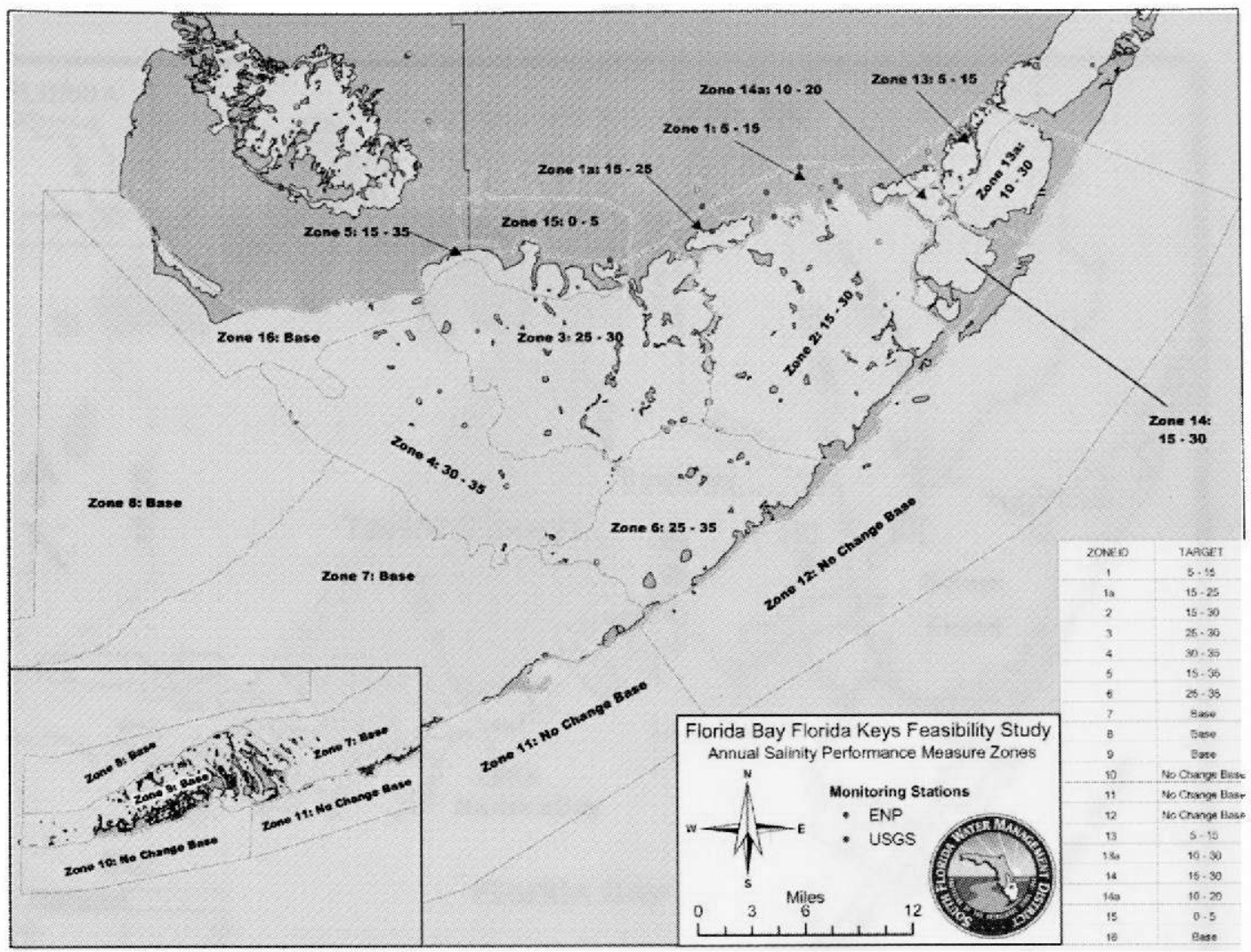

Figure 4.5. Florida Bay map illustrating embayments and target salinity zones from the Florida bay/Florida Keys Feasibility Study (Rudnick, 2005). 


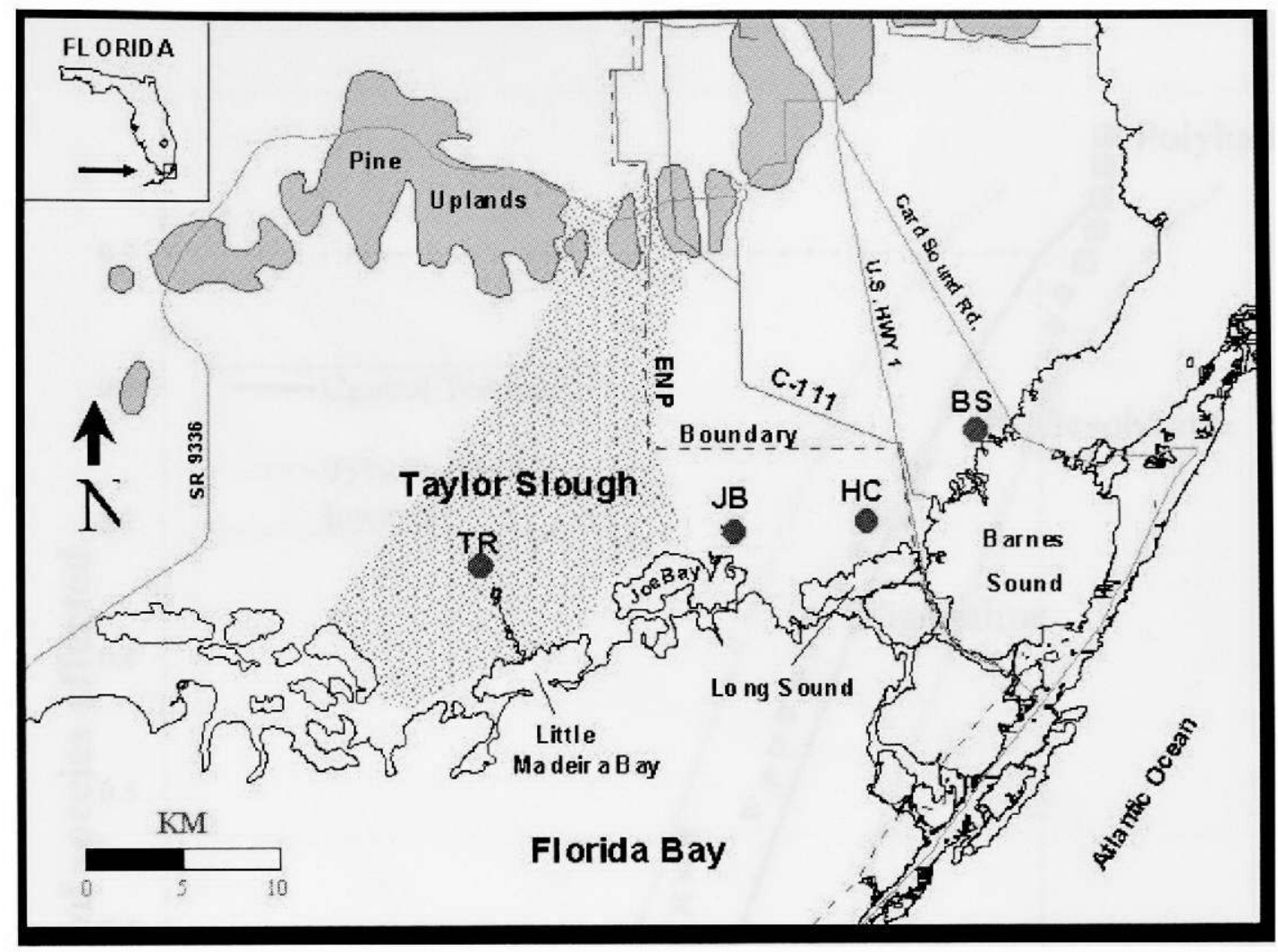

Figure 4.6 Audubon Sampling sites. JB: Joe Bay; HC: Highway Creek; BS: Barnes Sound; TR: Taylor River. (from Bartell et al. 2004.) 


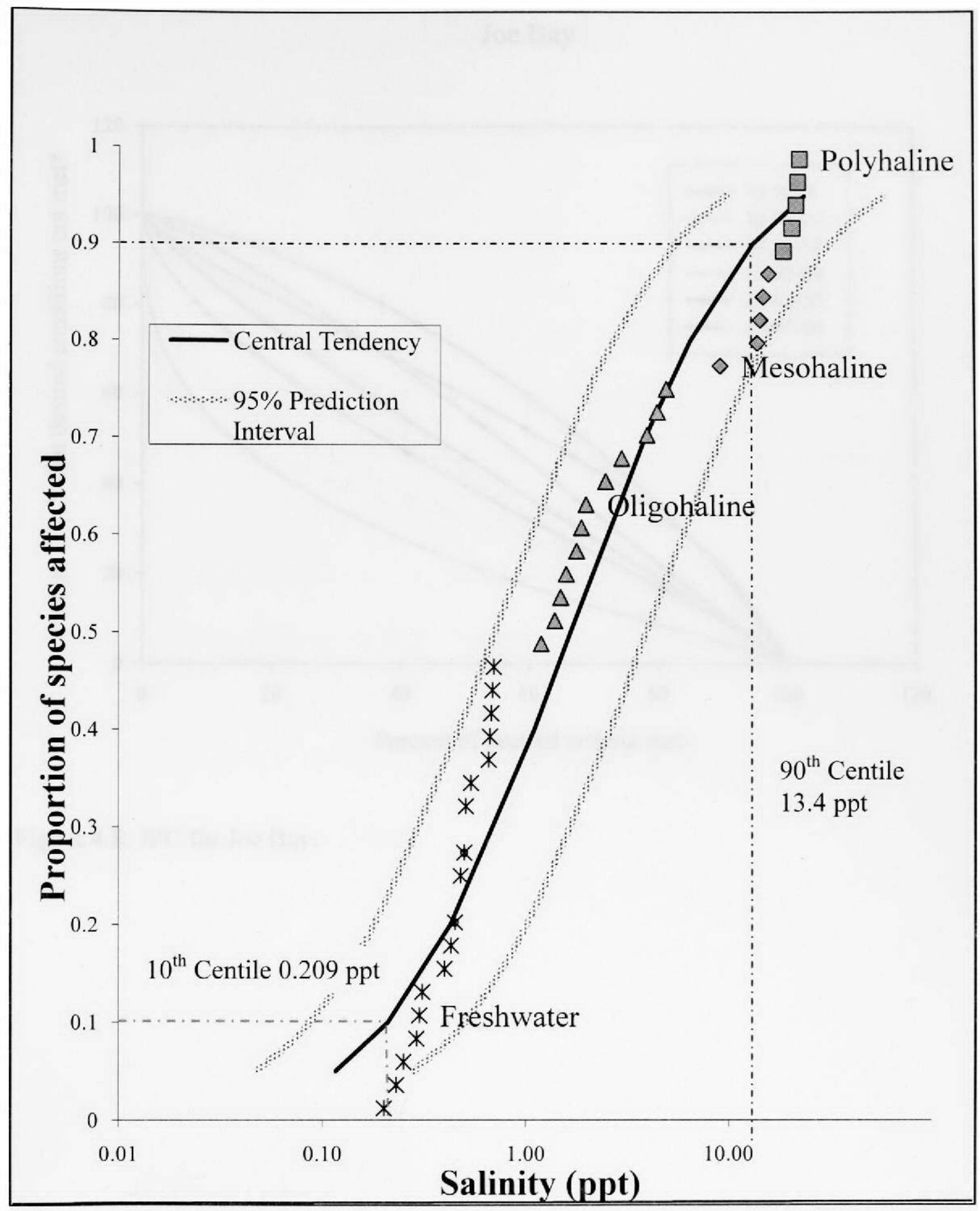

Figure 4.7. Species Sensitivity Distribution (SSD) for mean salinity affinity for demersal fishes in northeast Florida Bay. 
Joe Bay

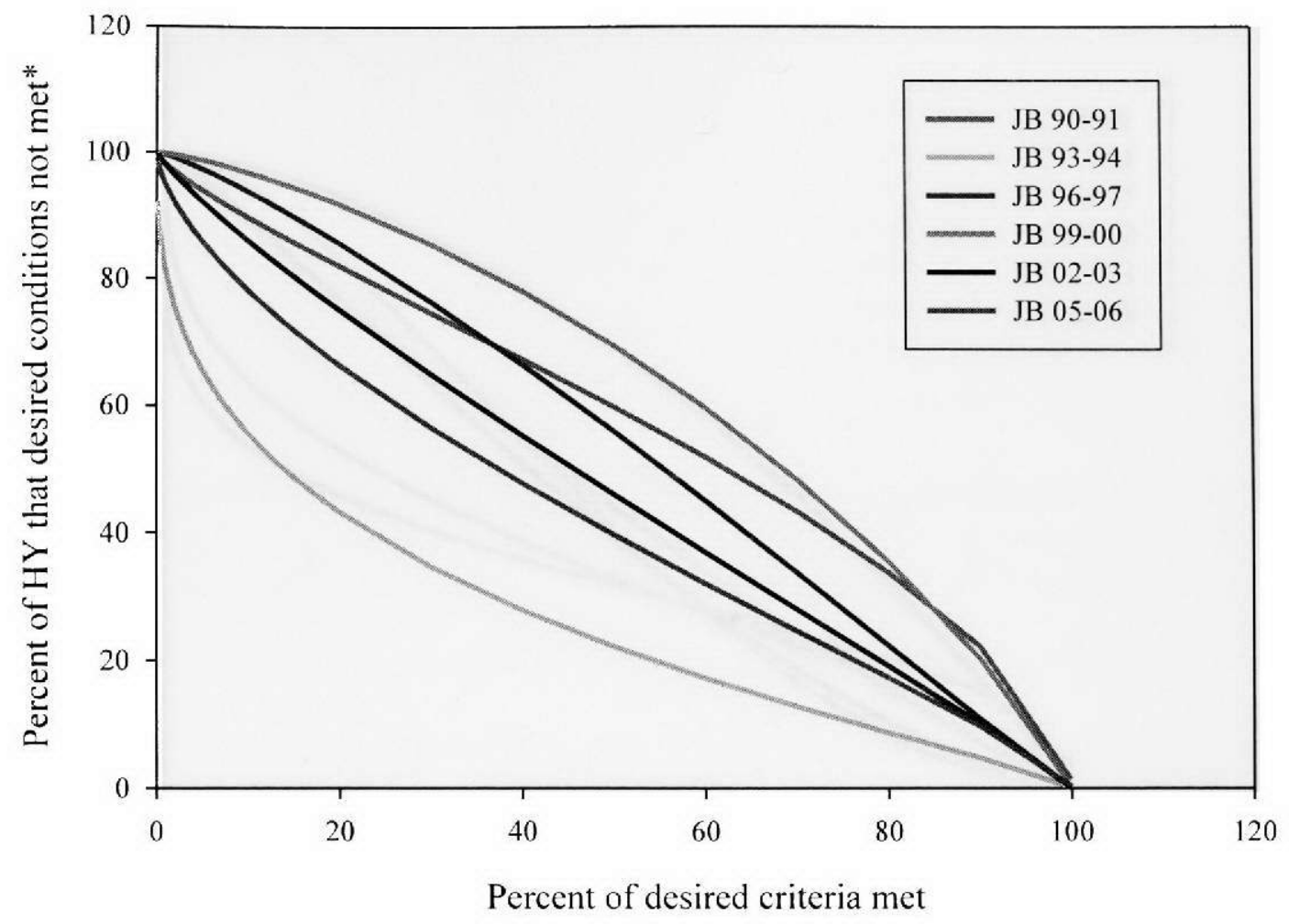

Figure 4.8. JPC for Joe Bay. 


\section{Highway Creek}

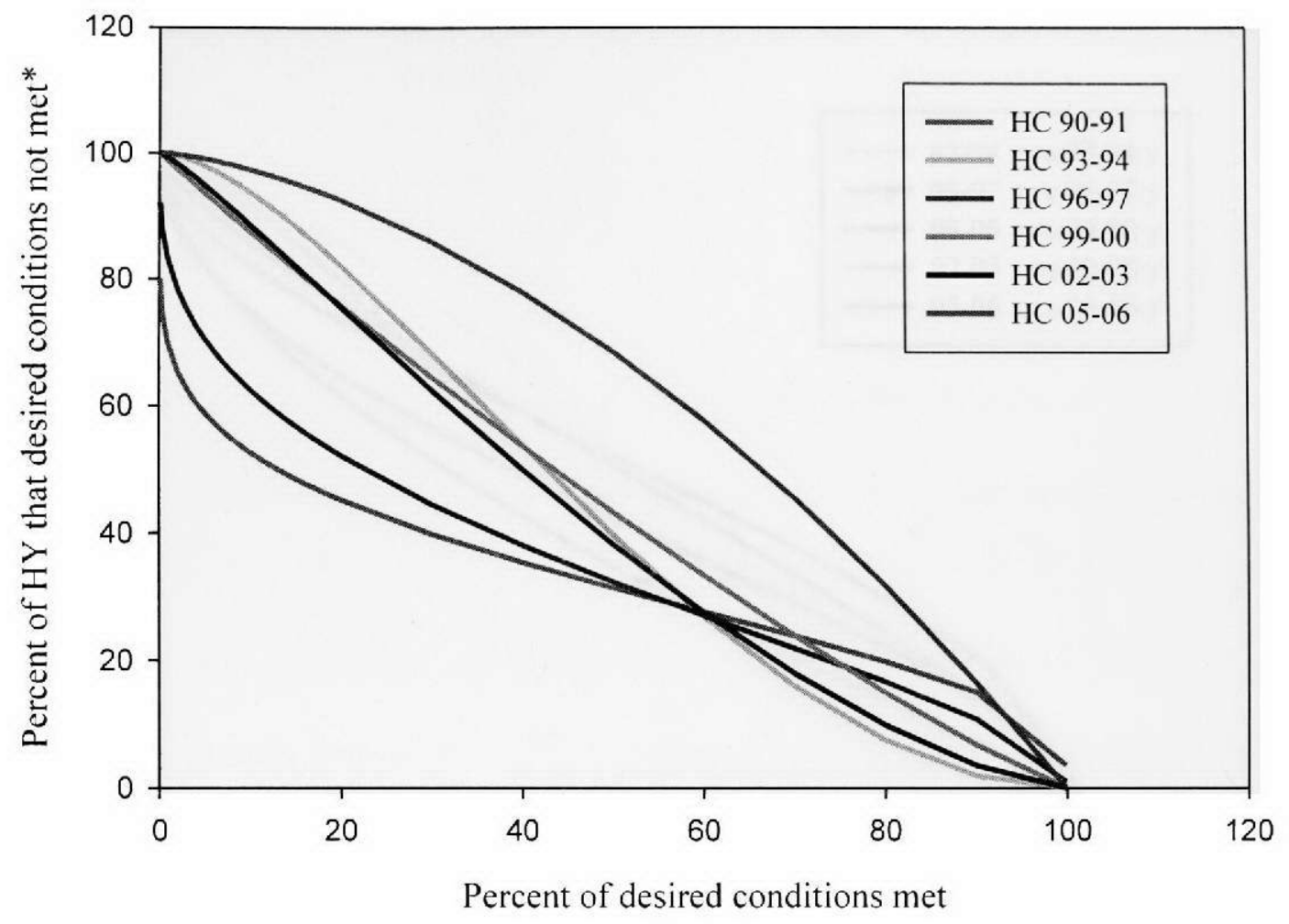

Figure 4.9. JPC for Highway Creek. 


\section{Barnes Sound}

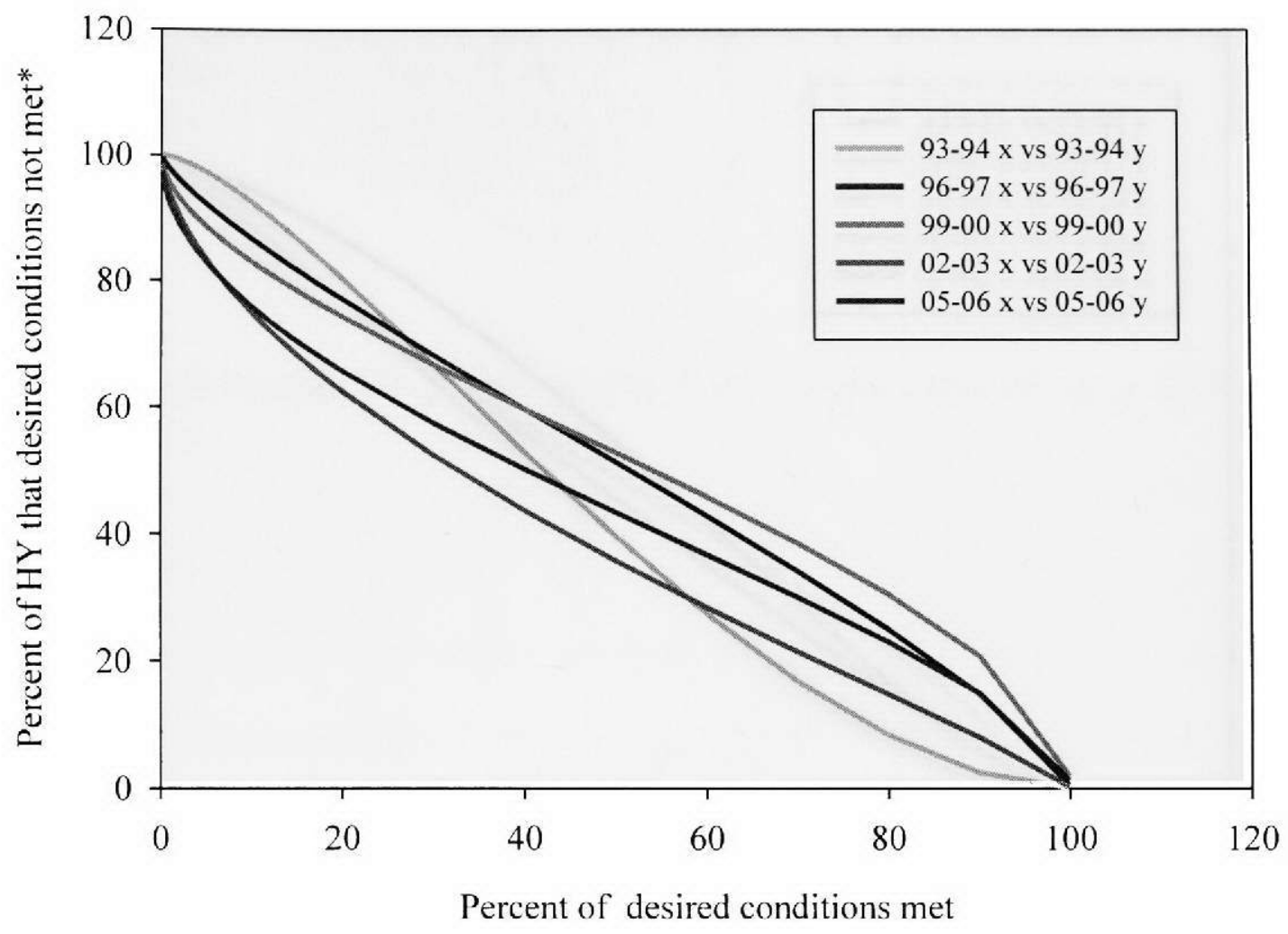

Figure 4.10. JPC for Barnes Sound. 


\section{Taylor River}

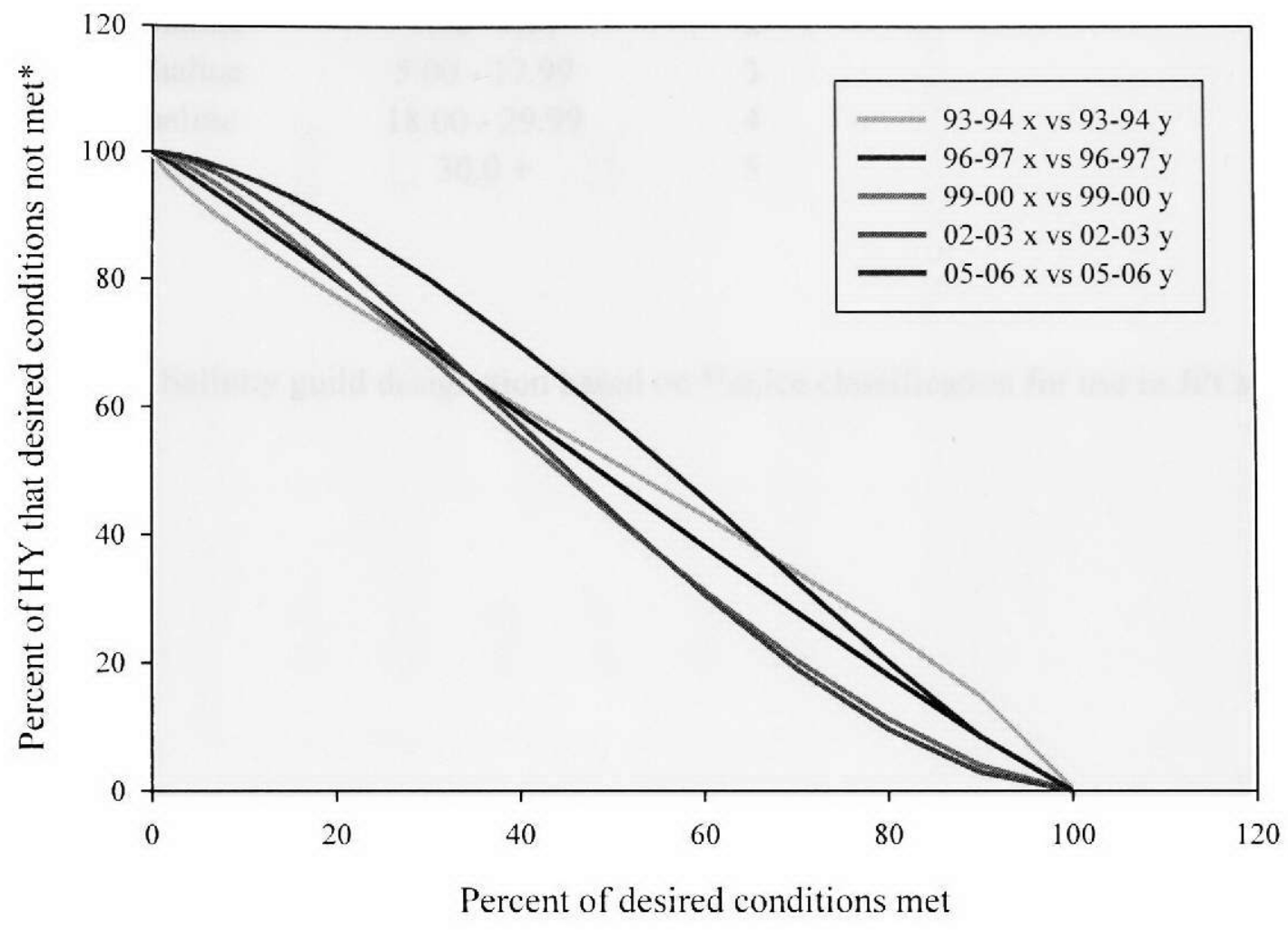

Figure 4.11. JPC for Taylor River. 


$\begin{array}{ccc}\begin{array}{c}\text { Venice } \\ \text { Classification }\end{array} & \begin{array}{c}\text { Salinity range } \\ (\mathrm{ppt})\end{array} & \begin{array}{c}\text { Salinity } \\ \text { Guild }\end{array} \\ \text { Freshwater } & 0.00-0.99 & 1 \\ \text { Oligohaline } & 1.00-4.99 & 2 \\ \text { Mesohaline } & 5.00-17.99 & 3 \\ \text { Polyhaline } & 18.00-29.99 & 4 \\ \text { Marine } & 30.0+ & 5\end{array}$

Table 4.1. Salinity guild designation based on Venice classification for use in JPCs. 


\begin{tabular}{|c|c|c|c|c|c|c|c|c|}
\hline JOE BAY & $\begin{array}{l}\text { Maximum } \\
\text { Salinity } \\
\text { (ppt) }\end{array}$ & $\begin{array}{l}\text { Minimum } \\
\text { Salinity } \\
\text { (ppt) }\end{array}$ & $\begin{array}{c}\text { Mean } \\
\text { Salinity } \\
\text { (ppt) }\end{array}$ & $\begin{array}{c}\text { Percent of HY } \\
\text { Salinity bet. } \\
\text { 0-13.4 ppt }\end{array}$ & $\begin{array}{l}\text { Percent of } \\
\text { HY } \\
\text { Salinity } \\
\text { bet. } \\
\text { 0.5-13.4 ppt }\end{array}$ & $\begin{array}{c}\text { Percent of } \\
\text { HY } \\
\text { Salinity } \\
\text { below } \\
0.5 \text { ppt }\end{array}$ & $\begin{array}{c}\text { Percent of } \\
\text { HY } \\
\text { Salinity } \\
\text { above } \\
13.4 \text { ppt }\end{array}$ & $\begin{array}{c}\text { Percent } \\
\text { of HY } \\
\text { Salinity } \\
\text { bet. } \\
\text { 5-15 ppt }\end{array}$ \\
\hline 1990-1991 & 56.62 & 1.18 & 28.51 & 12.63 & 12.33 & 3.61 & 84.06 & 11.20 \\
\hline 1993-1994 & 25.26 & 0.22 & 1.81 & 99.28 & 86.13 & 13.15 & 0.72 & 3.70 \\
\hline $1996-1997$ & 32.43 & 0.24 & 6.40 & 90.68 & 66.81 & 23.87 & 9.32 & 10.72 \\
\hline $1999-2000$ & 36.99 & 0.26 & 4.87 & 91.02 & 60.77 & 30.25 & 8.98 & 11.13 \\
\hline $2002-2003$ & 29.02 & 0.31 & 5.92 & 86.29 & 68.47 & 17.82 & 13.71 & 10.13 \\
\hline $2005-2006$ & 45.52 & 0.25 & 9.43 & 83.03 & 72.60 & 10.43 & 16.97 & 13.98 \\
\hline
\end{tabular}

TABLE 4.2. Salinity profile for Joe Bay. Highlights indicate hydro years in which comparatively lower risk was calculated based upon protection for increased diversity $(80 \%$ protection for $\mathrm{D}<0.5)$ and risk percentage less than $50 \%$. 


\begin{tabular}{|c|c|c|c|c|c|c|c|c|}
\hline & $\begin{array}{c}\text { Maximum } \\
\text { Salinity } \\
\text { ppt }\end{array}$ & $\begin{array}{c}\text { Salinity } \\
\text { ppt }\end{array}$ & $\begin{array}{c}\text { Salinity } \\
\text { ppt }\end{array}$ & $\begin{array}{c}\text { Percent of } \\
\text { HY } \\
\text { Salinity bet. } \\
0-13.4 \text { pp }\end{array}$ & $\begin{array}{l}\text { Percent of } \\
\text { HY } \\
\text { Salinity bet. } \\
0.5-13.4 \text { ppt }\end{array}$ & $\begin{array}{c}\text { Percent of } \\
\text { HY } \\
\text { Salinity } \\
\text { below } \\
0.5 \mathrm{ppt}\end{array}$ & $\begin{array}{c}\text { Percent of } \\
\text { HY } \\
\text { Salinity } \\
\text { above } \\
13.4 \mathrm{ppt}\end{array}$ & $\begin{array}{c}\text { Percent of } \\
\text { HY } \\
\text { Salinity } \\
\text { bet. } \\
\text { 5-15 ppt }\end{array}$ \\
\hline \multicolumn{9}{|c|}{ HIGHWAY CREEK } \\
\hline 1990-1991 & 57.78 & 0.19 & 17.15 & 53.78 & 46.27 & 7.51 & 46.22 & 24.86 \\
\hline 1993-1994 & 7.42 & 0.00 & 1.96 & 100.00 & 77.33 & 22.67 & 0.00 & 6.87 \\
\hline 1996-1997 & 24.71 & 0.16 & 5.76 & 86.02 & 66.56 & 19.46 & 13.98 & 16.62 \\
\hline $1999-2000$ & 26.02 & 0.11 & 5.14 & 90.31 & 72.88 & 17.75 & 9.37 & 16.94 \\
\hline $2002-2003$ & 31.37 & 0.23 & 6.40 & 85.53 & 73.02 & 12.51 & 14.47 & 18.65 \\
\hline $2005-2006$ & 46.35 & 0.10 & 10.34 & 79.59 & 64.47 & 15.12 & 20.41 & 19.61 \\
\hline
\end{tabular}

TABLE 4.3. Salinity profile for Highway Creek. Highlights indicate hydro years in which comparatively lower risk was calculated based upon protection for increased diversity $(80 \%$ protection for $\mathrm{D}<0.5)$ and risk percentage less than $50 \%$. 


\begin{tabular}{|c|c|c|c|c|c|c|c|}
\hline Maximum & Minimum & Mean & $\begin{array}{c}\text { Percent of } \\
\text { HY }\end{array}$ & $\begin{array}{l}\text { Percent of } \\
\text { HY }\end{array}$ & $\begin{array}{c}\text { Percent of } \\
\text { HY }\end{array}$ & $\begin{array}{c}\text { Percent of } \\
\text { HY }\end{array}$ & $\begin{array}{c}\text { Percent of } \\
\text { HY }\end{array}$ \\
\hline Salinity & Salinity & Salinity & Salinity bet. & Salinity bet. & $\begin{array}{l}\text { Salinity } \\
\text { below }\end{array}$ & $\begin{array}{l}\text { Salinity } \\
\text { above }\end{array}$ & $\begin{array}{l}\text { Salinity } \\
\text { bet. }\end{array}$ \\
\hline $\mathrm{ppt}$ & ppt & ppt & $0-13.4 \mathrm{pp}$ & $0.5-13.4 \mathrm{ppt}$ & $0.5 \mathrm{ppt}$ & $13.4 \mathrm{ppt}$ & $5-15 p p t$ \\
\hline
\end{tabular}

BARNES SOUND

1990-1991

1993-1994 29.58

1996-1997 38.1

$1999-2000 \quad 37.69$

2002-2003 42

2005-2006

42.60

0.78

19.95

18.50

34.95

16.58

46.84

33.31

36.96

TABLE 4.4. Salinity profile for Barnes Sound. Highlights indicate hydro years in which comparatively lower risk was calculated based upon protection for increased diversity $(80 \%$ protection for $\mathrm{D}<0.5)$ and risk percentage less than $50 \%$. 


\begin{tabular}{|c|c|c|c|c|c|c|c|}
\hline Maximum & Minimum & Mean & $\begin{array}{c}\text { Percent of } \\
\text { HY }\end{array}$ & $\begin{array}{c}\text { Percent of } \\
\text { HY }\end{array}$ & $\begin{array}{c}\text { Percent of } \\
\text { HY }\end{array}$ & $\begin{array}{c}\text { Percent of } \\
\text { HY }\end{array}$ & $\begin{array}{c}\text { Percent of } \\
\text { HY }\end{array}$ \\
\hline Salinity & Salinity & Salinity & Salinity bet. & Salinity bet. & $\begin{array}{l}\text { Salinity } \\
\text { below }\end{array}$ & $\begin{array}{l}\text { Salinity } \\
\text { above }\end{array}$ & $\begin{array}{c}\text { Salinity } \\
\text { bet. }\end{array}$ \\
\hline ppt & $\mathrm{ppt}$ & $\mathrm{ppt}$ & $0-13.4 \mathrm{pp}$ & $0.5-13.4 \mathrm{ppt}$ & $0.5 \mathrm{ppt}$ & $13.4 \mathrm{ppt}$ & $5-15 \mathrm{ppt}$ \\
\hline
\end{tabular}

TAYLOR RIVER

$\begin{array}{lllllllll}1990-1991 & 63.81 & 1.32 & 24.77 & 39.50 & 39.50 & 0.00 & 60.46 & 20.70 \\ 1993-1994 & 29.55 & 0.08 & 2.35 & 99.00 & 45.89 & 53.13 & 0.98 & 2.50 \\ 1996-1997 & 24.43 & 0.15 & 4.83 & 94.10 & 41.50 & 52.60 & 5.90 & 6.10 \\ 1999-2000 & 26.37 & 0.14 & 3.45 & 95.00 & 41.30 & 53.67 & 5.03 & 6.10 \\ 2002-2003 & 26.64 & 0.23 & 3.24 & 94.60 & 49.90 & 44.66 & 5.44 & 5.40 \\ 2005-2006 & 50.14 & 0.27 & 8.88 & 88.30 & 69.30 & 19.00 & 11.70 & 12.08\end{array}$

TABLE 4.5. Salinity profile for Taylor River. Highlights indicate hydro years in which comparatively lower risk was calculated based upon protection for increased diversity $(80 \%$ protection for $\mathrm{D}<0.5)$ and risk percentage less than $50 \%$. 


\section{Salinity Guild at which $80 \%$ of Desired \\ Criteria Met}

\section{Percent of HY salinities \\ that exceed or \\ fall below \\ protective \\ range* $\quad(\%$ Risk $)$}

$\begin{array}{cccccc}\text { Site } & \text { Hydro Year } & & & & \\ \text { Joe Bay } & 1990-1991 & 4.63 & 66.2 & 33.8 & 56.67 \\ & \mathbf{1 9 9 3 - 1 9 9 4} & \mathbf{2 . 7 9} & \mathbf{9 1 . 3 6} & \mathbf{8 . 6 4} & \mathbf{2 2 . 4 3} \\ & 1996-1997 & 2.91 & 77.66 & 22.34 & 53.93 \\ & 1999-2000 & 2 & 64.47 & 35.53 & 63.34 \\ & \mathbf{2 0 0 2 - 2 0 0 3} & \mathbf{2 . 9 9} & \mathbf{8 0 . 9 2} & \mathbf{1 9 . 0 8} & \mathbf{4 6 . 8 9} \\ & \mathbf{2 0 0 5 - 2 0 0 6} & \mathbf{3 . 7 7} & \mathbf{8 2 . 7 5} & \mathbf{1 7 . 2 5} & \mathbf{4 1 . 6 8}\end{array}$

*Protective range inclusive of $80 \%$ of salinities that meet desired criteria

TABLE 4.6. Risk profile for Joe Bay. Highlights indicate hydro years in which greater than $80 \%$ of the salinities were protective of increased diversity ( $\mathrm{D}<0.5$ ). Note that the percent risks in these years (as AUC) are less than $50 \%$ indicating comparatively lower risk. 


\section{Salinity Guild at \\ which \\ $80 \%$ of Desired \\ Criteria Met}

\author{
Percent of HY salinities \\ that fall within protective \\ range*
}

Percent of HY
salinities
that exceed or
$\begin{aligned} & \text { fall below } \\ & \text { protective } \\ & \text { range* }\end{aligned} \quad$ AUC

Site Hydro Year

Highway 1990-1991

Creek 1993-1994

1996-1997

1999-2000

2002-2003

2005-2006
4.62
2.85
3.13
3.16
3.99
2.92

80.12

92.51

83.34

85.03

90.13

68.22
19.88

7.49

16.66

14.97

9.87

31.78
30.80

44.01

34.11

45.24

42.32

62.28

* Protective range inclusive of $80 \%$ of salinities that meet desired criteria

TABLE 4.7. Risk profile for Highway Creek. Highlights indicate hydro years in which greater than $80 \%$ of the salinities were protective of increased diversity $(\mathrm{D}<0.5)$. Note that the percent risks in these years (as AUC) are less than $50 \%$ indicating comparatively lower risk. 


\section{Salinity Guild at which $80 \%$ of Desired \\ Criteria Met}

$\begin{array}{lcc}\begin{array}{r}\text { Site } \\ \text { Barnes }\end{array} & \text { Hydro Year } & \\ \text { Sound } & 1990-1991 & \text { N/A } \\ & \mathbf{1 9 9 3 - 1 9 9 4} & \mathbf{4 . 6 1} \\ & 1996-1997 & 4.19 \\ & 1999-2000 & 3.94 \\ & \mathbf{2 0 0 2 - 2 0 0 3} & \mathbf{5 . 1 3} \\ & 2005-2006 & 4.58\end{array}$

$\begin{array}{ccc} & \begin{array}{c}\text { Percent of } \mathrm{HY} \\ \text { salinities } \\ \text { that exceed or } \\ \text { fall below } \\ \text { protective } \\ \text { range* }\end{array} & \text { AUC } \\ \begin{array}{c}\text { Percent of HY salinities } \\ \text { that fall within protective } \\ \text { range* }\end{array} & \text { Nisk) } \\ \text { N/A } & \text { N/A } & \text { N/A } \\ \mathbf{9 1 . 6 6} & \mathbf{8 . 3 4} & \mathbf{4 3 . 6 9} \\ 75.03 & 24.97 & 50.54 \\ 69.51 & 30.49 & 51.00 \\ \mathbf{8 5 . 2 5} & \mathbf{1 4 . 7 5} & \mathbf{3 8 . 6 2} \\ 77 & 23 & 43.66\end{array}$

* Protective range inclusive of $80 \%$ of salinities that meet desired criteria

TABLE 4.8. Risk profile for Barnes Sound. Highlights indicate hydro years in which greater than $80 \%$ of the salinities were protective of increased diversity $(\mathrm{D}<0.5)$. Note that the percent risks in these years (as AUC) are less than $50 \%$ indicating comparatively lower risk. 


\section{Salinity Guild at which $80 \%$ of Desired \\ Criteria Met}

$\begin{array}{ccc}\text { Site } & \text { Hydro Year } & \\ \text { Taylor } & 1990-1991 & \text { N/A } \\ \text { River } & 1993-1994 & 1.77 \\ & \mathbf{1 9 9 6 - 1 9 9 7} & \mathbf{2 . 6 9} \\ & \mathbf{1 9 9 9 - 2 0 0 0} & \mathbf{2 . 8 7} \\ & \mathbf{2 0 0 2 - 2 0 0 3} & \mathbf{2 . 9 9} \\ & 2005-2006 & 3.36\end{array}$

\section{Percent of HY salinities} that fall within protective range*

$\begin{aligned} & \text { Percent of } H Y \\ & \text { salinities } \\ & \text { that exceed or } \\ & \text { fall below } \\ & \text { protective } \\ & \text { range* }\end{aligned} \quad$ AUC

N/A

75.05

82.03

88.84

$\mathbf{9 0 . 4 3}$

79.87

$\begin{array}{cc}\text { N/A } & \text { N/A } \\ 24.95 & 50.67 \\ \mathbf{1 7 . 9 7} & \mathbf{4 8 . 8 6} \\ \mathbf{1 1 . 1 6} & \mathbf{4 5 . 4 7} \\ \mathbf{9 . 5 7} & \mathbf{4 6 . 1 3} \\ 20.13 & 54.96\end{array}$

* Protective range inclusive of $80 \%$ of salinities that meet desired criteria

TABLE 4.9. Risk profile for Taylor River. Highlights indicate hydro years in which greater than $80 \%$ of the salinities were protective of increased diversity $(\mathrm{D}<0.5)$. Note that the percent risks in these years (as AUC) are less than $50 \%$ indicating comparatively lower risk. 
Appendix A: Species used in Species Sensitivity Distribution (from Lorenz and Serafy, 2006).

\begin{tabular}{|c|c|}
\hline Species & $\begin{array}{l}\text { Salınity } \\
\text { Affinity (ppt) }\end{array}$ \\
\hline Erimyzon sucetta & 0.5 \\
\hline Lepomis gulosus & 0.5 \\
\hline Lepomis microlophus & 0.5 \\
\hline Elassoma evergladei & 0.5 \\
\hline Notropis spp. & 0.5 \\
\hline Ameiurus sp. & 0.5 \\
\hline Micropterus salmoides & 0.5 \\
\hline Lucania goodei & 0.5 \\
\hline Fundulus chrysotus & 0.5 \\
\hline Fundulus seminolis & 0.5 \\
\hline Cichlasoma bimaculatum & 0.5 \\
\hline Lepomis marginatus & 0.5 \\
\hline Enneacanthus gloriosus & 0.5 \\
\hline Jordanella floridae & 0.5 \\
\hline Heterandria formosa & 0.5 \\
\hline Clarias batrachus & 0.5 \\
\hline Lepomis macrochirus & 0.5 \\
\hline Noturus gyrinus & 0.5 \\
\hline Lepomis punctatus & 0.5 \\
\hline Tilapia mariae & 0.5 \\
\hline Giosoma bosc & 1 \\
\hline Lophogobius cyprinoides & 1 \\
\hline Gobiosoma robustum & 1 \\
\hline Cichlasoma urophthalmus & 1 \\
\hline Lepomis spp. & 1 \\
\hline Belonesox belizanus & 1 \\
\hline Gambusia holbrooki & 2 \\
\hline Adinia xenica & 2 \\
\hline Fundulus confluentus & 3 \\
\hline Poecilia latipinna & 4 \\
\hline Lucania parva & 4 \\
\hline Cyprinodon variegatus & 5 \\
\hline
\end{tabular}

Menidia spp

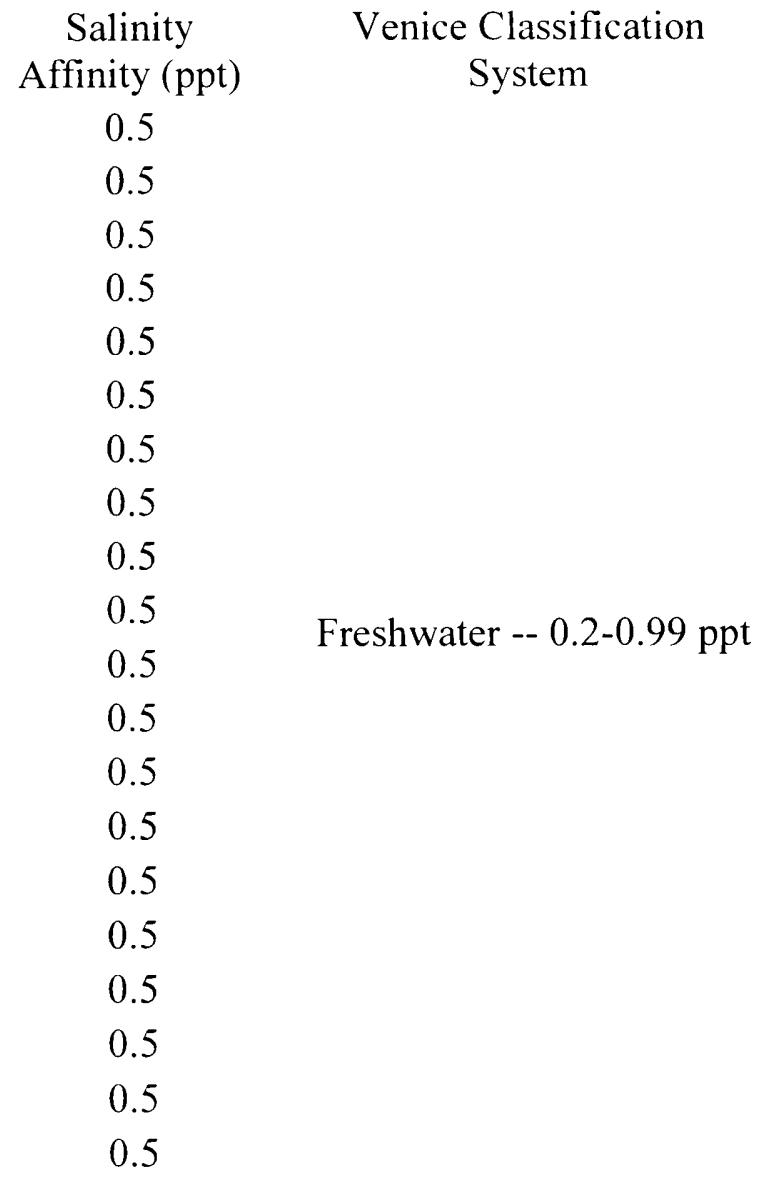


Trinectes maculatus

Microgobius gulosus

Fundulus grandis

Strongylura notata

Opsanus beta

Floridichthys carpio

Eucinostomus spp.

Syngnathus scovelli

Fundulus similis
14

14

15

16

19

21

22

22

23 
Appendix B. Diversity Calculations by HY and Sampling Site.

\begin{tabular}{|c|c|c|c|c|c|}
\hline Site & HY & $\begin{array}{c}\text { Sampling } \\
\text { Date }\end{array}$ & D & $\begin{array}{l}\text { 60d Salinity } \\
\text { Avg.(ppt) }\end{array}$ & $\begin{array}{c}\text { Salinity } \\
\text { Guild }\end{array}$ \\
\hline \multirow[t]{17}{*}{ Joe Bay } & 1990-1991 & 11/1/1990 & 0.34 & 5.54 & 3 \\
\hline & & $11 / 29 / 1990$ & 0.26 & 10.68 & 3 \\
\hline & & $12 / 21 / 1990$ & 0.39 & 12.13 & 3 \\
\hline & & $1 / 21 / 1991$ & 0.28 & 18.45 & 4 \\
\hline & & 2/26/1991 & 0.39 & 26.08 & 4 \\
\hline & & $3 / 21 / 1991$ & 0.29 & 30.13 & 5 \\
\hline & 1993-1994 & $6 / 21 / 1993$ & 0.49 & 12.14 & 3 \\
\hline & & 9/30/1993 & 0.34 & 1.94 & 2 \\
\hline & & $12 / 2 / 1993$ & 0.41 & 1.79 & 2 \\
\hline & & $1 / 25 / 1994$ & 0.25 & 2.36 & 2 \\
\hline & & $3 / 14 / 1994$ & 0.20 & 1.52 & 2 \\
\hline & & $4 / 20 / 1994$ & 0.15 & 1.51 & 2 \\
\hline & 1996-1997 & $6 / 25 / 1996$ & 0.28 & 12.74 & 3 \\
\hline & & $8 / 27 / 1996$ & 0.20 & 0.66 & 1 \\
\hline & & $10 / 28 / 1996$ & 0.26 & 0.35 & 1 \\
\hline & & $11 / 28 / 1996$ & 0.16 & 0.74 & 1 \\
\hline & & 1/9/1997 & 0.19 & 1.58 & 2 \\
\hline
\end{tabular}




\begin{tabular}{|c|c|c|c|c|c|}
\hline Site & HY & $\begin{array}{l}\text { Sampling } \\
\text { Date }\end{array}$ & $\mathrm{D}$ & $\begin{array}{c}\text { 60d Salinity } \\
\text { Avg.(ppt) }\end{array}$ & $\begin{array}{c}\text { Salinity } \\
\text { Guild }\end{array}$ \\
\hline \multirow[t]{19}{*}{ Joe Bay } & 1996-1997 & $2 / 24 / 1997$ & 0.31 & 1.58 & 2 \\
\hline & & $3 / 22 / 1997$ & 0.17 & 3.56 & 2 \\
\hline & & $4 / 21 / 1997$ & 0.22 & 11.36 & 3 \\
\hline & $1999-2000$ & $7 / 22 / 1999$ & 0.53 & 21.43 & 4 \\
\hline & & $9 / 18 / 1999$ & 0.56 & 0.51 & 1 \\
\hline & & $11 / 23 / 1999$ & $\mathrm{~N} / \mathrm{A}$ & 0.51 & 1 \\
\hline & & $12 / 15 / 1999$ & 0.42 & 0.76 & 1 \\
\hline & & $1 / 30 / 2000$ & 0.30 & 0.9 & 1 \\
\hline & & $2 / 24 / 2000$ & 0.19 & 0.89 & 1 \\
\hline & & $3 / 23 / 2000$ & 0.20 & 1.25 & 2 \\
\hline & $2002-2003$ & $6 / 18 / 2002$ & 0.52 & 25.14 & 4 \\
\hline & & $10 / 2 / 2002$ & 0.43 & 0.43 & 1 \\
\hline & & $11 / 16 / 2002$ & 0.18 & 1.87 & 2 \\
\hline & & $12 / 19 / 2002$ & 0.41 & 2.81 & 2 \\
\hline & & $1 / 16 / 2003$ & 0.19 & 1.91 & 2 \\
\hline & & $2 / 18 / 2003$ & 0.22 & 4.2 & 2 \\
\hline & & $3 / 21 / 2003$ & 0.53 & 13.02 & 3 \\
\hline & & $4 / 30 / 2003$ & 0.37 & 14.35 & 3 \\
\hline & $2005-2006$ & $6 / 1 / 2005$ & 0.44 & 38.73 & 5 \\
\hline
\end{tabular}




\begin{tabular}{|c|c|c|c|c|c|}
\hline Site & HY & $\begin{array}{l}\text { Sampling } \\
\text { Date }\end{array}$ & $\mathrm{D}$ & $\begin{array}{l}\text { 60d Salinity } \\
\text { Avg.(ppt) }\end{array}$ & $\begin{array}{l}\text { Salinity } \\
\text { Guild }\end{array}$ \\
\hline \multirow[t]{7}{*}{ Joe Bay } & $2005-2006$ & $10 / 18 / 2005$ & 0.49 & 1.37 & 2 \\
\hline & & $11 / 13 / 2005$ & 0.20 & 1.25 & 2 \\
\hline & & $12 / 20 / 2005$ & 0.25 & 1.76 & 2 \\
\hline & & $1 / 10 / 2006$ & 0.23 & 1.21 & 2 \\
\hline & & $2 / 7 / 2006$ & 0.16 & 3.2 & 2 \\
\hline & & $3 / 7 / 2006$ & 0.13 & 6.81 & 3 \\
\hline & & $4 / 4 / 2006$ & 0.23 & 15.42 & 3 \\
\hline
\end{tabular}




\begin{tabular}{|c|c|c|c|c|c|}
\hline Site & HY & $\begin{array}{l}\text { Sampling } \\
\text { Date }\end{array}$ & $\mathrm{D}$ & $\begin{array}{l}\text { 60d Salinity } \\
\text { Avg.(ppt) }\end{array}$ & $\begin{array}{l}\text { Salinity } \\
\text { Guild }\end{array}$ \\
\hline \multicolumn{6}{|l|}{ Highway } \\
\hline \multirow[t]{19}{*}{ Creek } & $1990-1991$ & $12 / 18 / 90$ & 0.42 & 6.13 & 3 \\
\hline & & 2/28/1991 & 0.27 & 19.95 & 4 \\
\hline & & $3 / 28 / 1991$ & 0.37 & 22.29 & 4 \\
\hline & & $4 / 29 / 1991$ & 0.17 & 29.88 & 4 \\
\hline & 1993-1994 & $6 / 8 / 1993$ & 0.37 & 12.26 & 3 \\
\hline & & $10 / 5 / 1993$ & 0.26 & 0.61 & 1 \\
\hline & & $11 / 8 / 1993$ & 0.23 & 0.4 & 1 \\
\hline & & $1 / 26 / 1994$ & 0.41 & 3.45 & 2 \\
\hline & & $3 / 22 / 1994$ & 0.23 & 3.23 & 2 \\
\hline & & $4 / 21 / 1994$ & 0.34 & 2.86 & 2 \\
\hline & 1996-1997 & 7/3/1996 & 0.31 & 7.43 & 3 \\
\hline & & 9/6/1996 & 0.48 & 1.14 & 2 \\
\hline & & $10 / 22 / 1996$ & 0.60 & 0.39 & 1 \\
\hline & & $10 / 22 / 1996$ & 0.42 & 1.11 & 2 \\
\hline & & 1/16/1997 & 0.39 & 3.66 & 2 \\
\hline & & $2 / 27 / 1997$ & 0.26 & 3.51 & 2 \\
\hline & & $3 / 26 / 1997$ & 0.30 & 6.48 & 3 \\
\hline & & $4 / 24 / 1997$ & 0.28 & 13.74 & 3 \\
\hline & $1999-2000$ & $7 / 15 / 1999$ & 0.42 & 15 & 3 \\
\hline
\end{tabular}




\begin{tabular}{|c|c|c|c|c|c|}
\hline Site & HY & $\begin{array}{l}\text { Sampling } \\
\text { Date }\end{array}$ & $\mathrm{D}$ & $\begin{array}{l}\text { 60d Salinity } \\
\text { Avg.(ppt) }\end{array}$ & $\begin{array}{c}\text { Salinity } \\
\text { Guild }\end{array}$ \\
\hline \multicolumn{6}{|c|}{ Highway } \\
\hline \multirow{19}{*}{ Creek } & $1999-2000$ & 9/30/1999 & 0.51 & 0.59 & 1 \\
\hline & & $11 / 16 / 1999$ & 0.33 & 0.56 & 1 \\
\hline & & $12 / 12 / 1999$ & 0.33 & 1.38 & 2 \\
\hline & & $1 / 20 / 2000$ & 0.36 & 1.74 & 2 \\
\hline & & $2 / 21 / 2000$ & 0.22 & 2.49 & 2 \\
\hline & & $3 / 20 / 2000$ & 0.29 & 4.81 & 2 \\
\hline & & $04 / 20 / 00$ & 0.46 & 8.4 & 3 \\
\hline & $2002-2003$ & $6 / 11 / 2002$ & 0.32 & 29.18 & 4 \\
\hline & & $11 / 4 / 2002$ & 0.30 & 1.51 & 2 \\
\hline & & $12 / 12 / 2002$ & 0.27 & 3.5 & 2 \\
\hline & & 1/9/2003 & 0.61 & 3.09 & 2 \\
\hline & & $2 / 11 / 2003$ & 0.75 & 4.44 & 2 \\
\hline & & $3 / 12 / 2003$ & 0.29 & 10.57 & 3 \\
\hline & & $4 / 8 / 2003$ & 0.25 & 14.51 & 3 \\
\hline & $2005-2006$ & $6 / 1 / 2005$ & 0.55 & 36.48 & 5 \\
\hline & & $10 / 18 / 2005$ & 0.27 & 0.64 & 1 \\
\hline & & $11 / 15 / 2005$ & 0.23 & 0.7 & 1 \\
\hline & & $12 / 16 / 2005$ & 0.26 & 1.2 & 2 \\
\hline & & $1 / 20 / 2006$ & 0.22 & 1.93 & 2 \\
\hline
\end{tabular}




$\begin{array}{cccccc}\text { Site } & \text { HY } & \begin{array}{c}\text { Sampling } \\ \text { Date }\end{array} & \text { D } & \begin{array}{c}\text { 60d Salinity } \\ \text { Avg.(ppt) }\end{array} & \begin{array}{c}\text { Salinity } \\ \text { Guild }\end{array} \\ \text { Highway } & & & & & \\ \text { Creek } & 2005-2006 & 2 / 18 / 2006 & 0.42 & 5.79 & 3 \\ & & 3 / 7 / 2006 & 0.58 & 9.12 & 3 \\ & & 4 / 3 / 2006 & 0.64 & 16.61 & 3\end{array}$




\begin{tabular}{|c|c|c|c|c|c|}
\hline Site & HY & $\begin{array}{l}\text { Sampling } \\
\text { Date }\end{array}$ & D & $\begin{array}{l}\text { 60d Salinity } \\
\text { Avg.(ppt) }\end{array}$ & $\begin{array}{c}\text { Salinity } \\
\text { Guild }\end{array}$ \\
\hline \multirow{21}{*}{ Barnes Sound } & $1990-1991$ & NO DATA & & & \\
\hline & 1993-1994 & 6/11/1993 & 0.32 & 24.86 & 4 \\
\hline & & $10 / 7 / 1993$ & 0.58 & 21.29 & 4 \\
\hline & & $11 / 23 / 1993$ & 0.38 & 21.76 & 4 \\
\hline & & 2/4/1994 & 0.27 & 21.69 & 4 \\
\hline & & $3 / 18 / 1994$ & 0.19 & 20.01 & 4 \\
\hline & & $4 / 26 / 1994$ & 0.24 & 16.68 & 3 \\
\hline & 1996-1997 & $7 / 11 / 1996$ & 0.21 & 17.99 & 3 \\
\hline & & $8 / 31 / 1996$ & 0.41 & 9.96 & 3 \\
\hline & & $10 / 31 / 1996$ & 0.29 & 11.14 & 3 \\
\hline & & $11 / 30 / 1996$ & 0.37 & 10.23 & 3 \\
\hline & & $1 / 24 / 1997$ & 0.18 & 18.2 & 4 \\
\hline & & $3 / 3 / 1997$ & 0.21 & 19.77 & 4 \\
\hline & & 4/1/1997 & 0.22 & 24.65 & 4 \\
\hline & & $4 / 30 / 1997$ & 0.27 & 29.24 & 4 \\
\hline & $1999-2000$ & 7/29/1999 & 0.29 & 23.2 & 4 \\
\hline & & $10 / 7 / 1999$ & 0.31 & 17.32 & 3 \\
\hline & & $11 / 6 / 1999$ & 0.29 & 9.21 & 3 \\
\hline & & 12/8/1999 & 0.59 & 5.23 & 3 \\
\hline & & $1 / 13 / 2000$ & 0.21 & 5.86 & 3 \\
\hline & & $2 / 15 / 2000$ & 0.20 & 8.49 & 3 \\
\hline
\end{tabular}




$\begin{array}{cccccc}\text { Site } & \text { HY } & \begin{array}{c}\text { Sampling } \\ \text { Date }\end{array} & \text { D } & \begin{array}{c}\text { 60d Salinity } \\ \text { Avg.(ppt) }\end{array} & \begin{array}{c}\text { Salinity } \\ \text { Guild }\end{array} \\ \text { Barnes Sound } & 1999-2000 & 3 / 13 / 2000 & 0.13 & 12.89 & 3 \\ & & 4 / 15 / 2000 & 0.37 & 20.16 & 4 \\ \text { Barnes Sound } & & & & \\ & & & & & \\ & & 6 / 6 / 2002 & 0.37 & 44.35 & 5 \\ & 9 / 17 / 2002 & 0.31 & 9.93 & 3 \\ & 11 / 1 / 2002 & 0.32 & 16.01 & 3 \\ & 12 / 4 / 2002 & 0.23 & 20.33 & 4 \\ & 2 / 6 / 2003 & 0.33 & 24.8 & 4 \\ & 3 / 6 / 2003 & 0.31 & 32.72 & 5 \\ & 4 / 3 / 2003 & 0.36 & 33.05 & 5 \\ & & & & \\ & & & & 36.74 & 5 \\ & & 6 / 7 / 2005 & 0.30 & 9.32 & 3 \\ & 10 / 11 / 2005 & 0.31 & 9.67 & 3 \\ & 11 / 8 / 2005 & 0.25 & 11.11 & 4 \\ & 12 / 2 / 2005 & 0.25 & 18.62 & 4 \\ & 1 / 10 / 2006 & 0.16 & 25.06 & 4 \\ & 2 / 3 / 2006 & 0.37 & 29.85 & 4\end{array}$




\begin{tabular}{|c|c|c|c|c|c|}
\hline \multirow{2}{*}{$\begin{array}{l}\text { Site } \\
\text { Taylor }\end{array}$} & & $\begin{array}{l}\text { Sampling } \\
\text { Date }\end{array}$ & D & \multirow[t]{2}{*}{$\begin{array}{l}\text { 60d Salinity } \\
\text { Avg.(ppt) }\end{array}$} & \multirow[t]{2}{*}{$\begin{array}{c}\text { Salinity } \\
\text { Guild }\end{array}$} \\
\hline & & & & & \\
\hline & $1990-1991$ & NO DATA & & & \\
\hline & 1993-1994 & $6 / 16 / 1993$ & 0.50 & 1 & 2 \\
\hline & & $9 / 28 / 1993$ & 0.32 & 0.4 & 1 \\
\hline & & $12 / 1 / 1993$ & 0.45 & 0.3 & 1 \\
\hline & & $1 / 21 / 1994$ & 0.38 & 0.4 & 1 \\
\hline & & $3 / 9 / 1994$ & 0.41 & 0.4 & 1 \\
\hline & & $4 / 19 / 1994$ & 0.44 & 0.5 & 1 \\
\hline & 1996-1997 & 6/30/1996 & 0.22 & 11.1 & 3 \\
\hline & & $8 / 22 / 1996$ & 0.00 & 0.3 & 1 \\
\hline & & $10 / 10 / 1996$ & 0.26 & 0.3 & 1 \\
\hline & & $11 / 10 / 1996$ & 0.22 & 0.2 & 1 \\
\hline & & 1/6/1997 & 0.18 & 0.3 & 1 \\
\hline & & $2 / 20 / 1997$ & 0.26 & 0.5 & 1 \\
\hline & & $3 / 19 / 1997$ & 0.39 & 1.4 & 2 \\
\hline & & $4 / 17 / 1997$ & 0.48 & 8 & 3 \\
\hline & $1999-2000$ & 7/7/1999 & 0.20 & 18.4 & 4 \\
\hline & & 9/9/1999 & 0.27 & 2.3 & 2 \\
\hline & & $11 / 9 / 1999$ & 0.30 & 2.8 & 2 \\
\hline & & $12 / 22 / 1999$ & 0.20 & 0.2 & 1 \\
\hline & & $2 / 3 / 2000$ & 0.24 & 0.26 & 1 \\
\hline
\end{tabular}




\begin{tabular}{|c|c|c|c|c|c|}
\hline Site & HY & $\begin{array}{l}\text { Sampling } \\
\text { Date }\end{array}$ & $\mathrm{D}$ & $\begin{array}{l}\text { 60d Salinity } \\
\text { Avg.(ppt) }\end{array}$ & $\begin{array}{c}\text { Salinity } \\
\text { Guild }\end{array}$ \\
\hline \multicolumn{6}{|l|}{ Taylor } \\
\hline \multirow[t]{18}{*}{ River } & $1999-2000$ & $2 / 29 / 2000$ & 0.18 & 0.27 & 1 \\
\hline & & $3 / 16 / 2000$ & 0.27 & 0.29 & 1 \\
\hline & $2002-2003$ & $6 / 27 / 2002$ & 0.30 & 20.51 & 4 \\
\hline & & $10 / 8 / 2002$ & 0.26 & 0.33 & 1 \\
\hline & & $11 / 21 / 2002$ & 0.20 & 0.44 & 1 \\
\hline & & $12 / 22 / 2002$ & 0.20 & 0.45 & 1 \\
\hline & & $1 / 22 / 2003$ & 0.25 & 0.35 & 1 \\
\hline & & $2 / 12 / 2003$ & 0.16 & 0.36 & 1 \\
\hline & & $3 / 21 / 2003$ & 0.23 & 4.12 & 2 \\
\hline & & $4 / 25 / 2003$ & 0.30 & 7.79 & 3 \\
\hline & 2005-2006 & $6 / 8 / 2005$ & 0.29 & 43.53 & 5 \\
\hline & & $10 / 11 / 2005$ & 0.28 & 1.57 & 2 \\
\hline & & $11 / 8 / 2005$ & 0.22 & 0.86 & 1 \\
\hline & & $12 / 3 / 2005$ & 0.37 & 0.94 & 1 \\
\hline & & $1 / 13 / 2006$ & 0.19 & 0.62 & 1 \\
\hline & & $2 / 9 / 2006$ & 0.15 & 0.93 & 1 \\
\hline & & $3 / 3 / 2006$ & 0.32 & 1.11 & 2 \\
\hline & & $4 / 11 / 2006$ & 0.26 & 6.79 & 3 \\
\hline
\end{tabular}


VITA

\section{PAMELA MARIE BACHMAN}

1991

1999-2002

2003-2008

2008-Pressent
B.A. Biology

University of Connecticut

Storrs, Connecticut

Laboratory Manager

Graduate Assistant Coordinator

Department of Environmental Studies

Florida International University

Miami, Florida

Laboratory Manager

Ecotoxicology \& Risk Assessment Laboratory

Florida International University

North Miami, Florida

Senior Ecotoxicologist

Monsanto Company

St. Louis, Missouri

\section{PUBLICATIONS AND PRESENTATIONS}

Bachman P.M., Rand, G.M. and W.B. Perry. 2004. Physiological Performance Measures for Estuarine Indicator Species in South Florida. Society of Environmental Toxicology and Chemistry Annual Meeting, Portland, Oregon.

Bachman P.M., Rand, G.M. and W.B. Perry. 2004. Physiological Performance Measures for Estuarine Indicator Species in Florida Bay. First National Conference on Ecosystems Restoration, Orlando, Florida

Bachman P.M., Rand, G.M. and W.B. Perry. 2005. Performance Measures and Tolerance Limits of Indicator Species in Florida Bay. Florida Bay Conference, Duck Key, Florida

Bachman P.M., Rand, G.M. and W.B. Perry. 2006. Physiological and Behavioral Responses of Estuarine Fish to Salinity Change: Implications towards the Comprehensive Everglades Restoration Plan (CERP). Society of Environmental Toxicology and Chemistry Annual Meeting, Montreal, Canada.

Rand G.M. and P.M. Bachman. 2006. Results of two experiments exposing Cyprinodon variegatus fish embryos and fry to St. Lucie sediments. Annual Status Report to NOAA Southeast Fisheries Science Center, Miami, FL. 
Bachman, P.M. and G.M. Rand. 2007. Florida Bay: A Risk Assessment for Salinity to Make Management Decisions. Society of Environmental Toxicology \& Chemistry Annual Meeting, Milwaukee, Wisconsin.

Rand G.M. and P.M. Bachman. 2007. Physiological Performance Measures and Tolerance limits of Estuarine Indicator Species in South Florida (DOI Cooperative Agreement Number H5284020094). Final Report to Everglades National Park, Homestead, FL.

Rand G.M. and P.M. Bachman. 2007. Salinity Relationships of Epifaunal Species in Near-Shore Biscayne Bay Cooperative Agreement CP060610--Final Report to South Florida Water Management District, West Palm Beach, FL.

Bachman, P.M and G.M. Rand. 2008. Physiological performance measures of estuarine indicator species in South Florida. Ecotoxicology. Special Issue: Ecotoxicology \& Risk Issues in South Florida. 17:7, 591-597.

Rand, G.M. and P.M. Bachman. 2008. South Florida ecosystems. Special Issue Ecotoxicology: Ecotoxicology \& Risk Issues in South Florida. 17:7, 565-568.

Rand, G.M., Bachman, P.M., and E.C. Rogevich (Eds.) 2008. Special Issue Ecotoxicology: Ecotoxicology \& Risk Issues in South Florida. 17:7, 565-696.

Bachman, P.M. and G.M. Rand. 2008. Behavioral Effects of Salinity Change on Estuarine Species. Society of Environmental Toxicology \& Chemistry Annual Meeting, - Tampa, Florida.

Hoang, T.C., Schuler, L.J., Rogevich, E.C., Bachman, P.M. Rand, G.M., and R.A. Frakes. 2009. Copper Release, Speciation, and Toxicity Following Multiple Floodings of Copper Enriched Agriculture Soils: Implications in Everglades Restoration Wat. Air Soil. Poll. 199: 1-4, 79-93. 